Prepared in cooperation with Bureau of Ocean Energy Management (OCS Study BOEM 2017-002)

\title{
Southern Sea Otter Range Expansion and Habitat Use in the Santa Barbara Channel, California
}

Open-File Report 2017-1001

U.S. Department of the Interior U.S. Geological Survey 
Cover: Photograph showing a male sea otter (Enhydra lutris) pausing from grooming to display its uniquely colored flipper tags, used for visual identification. Photograph by Nicole LaRoche, U.S. Geological Survey. 


\section{Southern Sea Otter Range Expansion and Habitat Use in the Santa Barbara Channel, California}

By M. Tim Tinker, Joseph Tomoleoni, Nicole LaRoche, Lizabeth Bowen, A. Keith Miles, Mike Murray, Michelle Staedler, and Zach Randell

Prepared in cooperation with Bureau of Ocean Energy Management (OCS Study BOEM 2017-002)

Open-File Report 2017-1001

U.S. Department of the Interior

U.S. Geological Survey 


\section{U.S. Department of the Interior \\ SALLY JEWELL, Secretary}

\section{U.S. Geological Survey \\ Suzette M. Kimball, Director}

U.S. Geological Survey, Reston, Virginia: 2017

For more information on the USGS-the Federal source for science about the Earth,

its natural and living resources, natural hazards, and the environment-visit

http://www.usgs.gov/ or call 1-888-ASK-USGS (1-888-275-8747).

For an overview of USGS information products, including maps, imagery, and publications, visit http://store.usgs.gov/.

This product has been technically reviewed and approved for publication by the Bureau of Ocean Energy Management.

Any use of trade, firm, or product names is for descriptive purposes only and does not imply endorsement by the U.S. Government.

Although this information product, for the most part, is in the public domain, it also may contain copyrighted materials as noted in the text. Permission to reproduce copyrighted items must be secured from the copyright owner.

Suggested citation:

Tinker, M.T., Tomoleoni, Joseph, LaRoche, Nicole, Bowen, Lizabeth, Miles, A. Keith, Murray, Mike, Staedler, Michelle, and Randell, Zach, 2017, Southern sea otter range expansion and habitat use in the Santa Barbara Channel, California: U.S. Geological Survey Open-File Report 2017-1001 (OCS Study BOEM 2017-002), 76 p., http://doi.org/10.3133/ofr20171001.

ISSN 2331-1258 (online) 


\section{Contents}

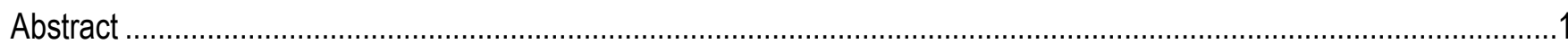

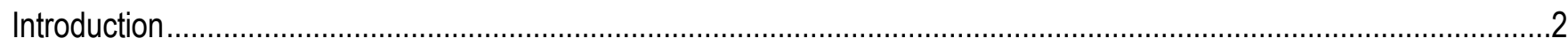

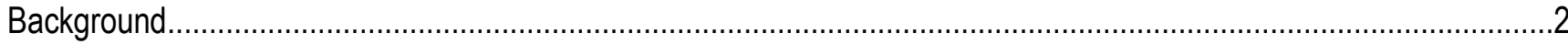

Primary Objectives

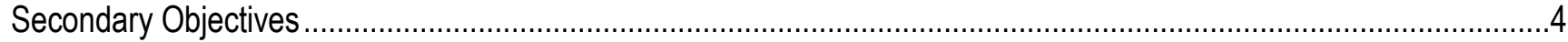

Methods

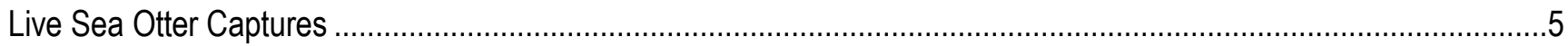

Processing, Sampling, Health Assessments, and Tagging ...............................................................................

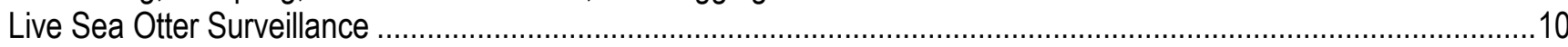

Dead Sea Otter Surveillance ……………………………………………………………………….....14

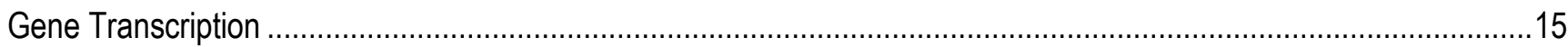

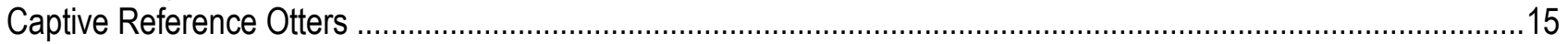

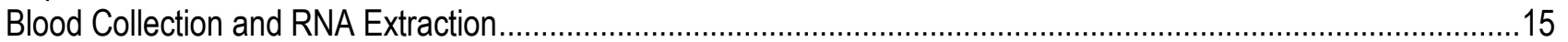

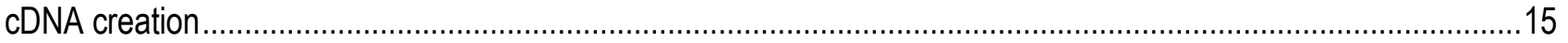

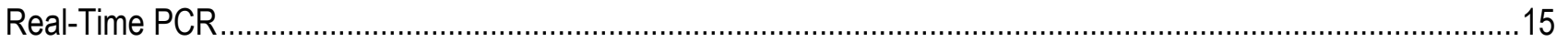

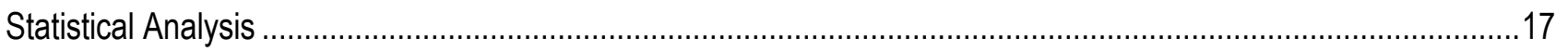

Movement, Behavior, Home Range, and Habitat Selection_A Synoptic Model.....................................................18

Synoptic Model Details ....................................................................................................................

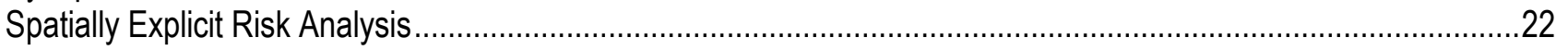

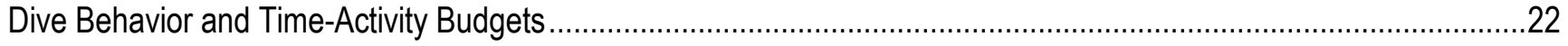

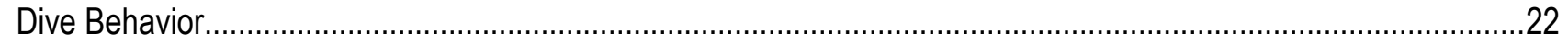

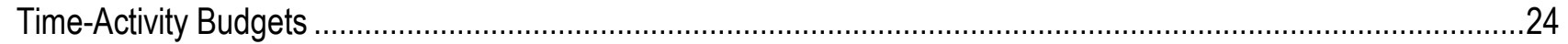

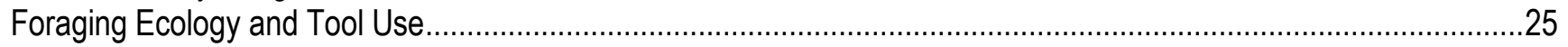

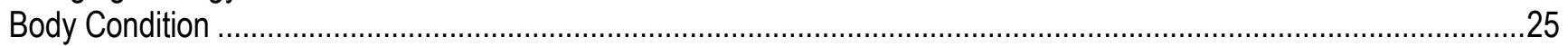

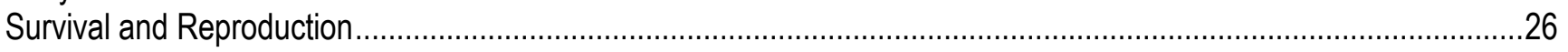

Cause of Death—Necropsy Analyses ...........................................................................................................2

Results

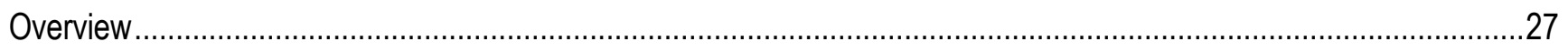

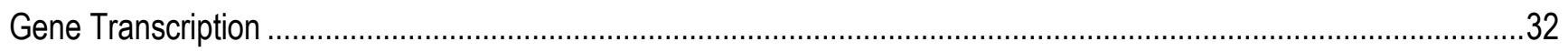

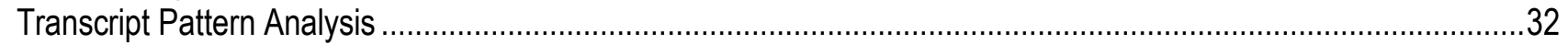

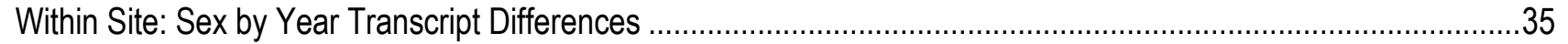

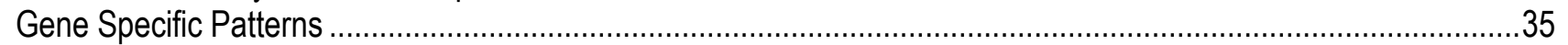

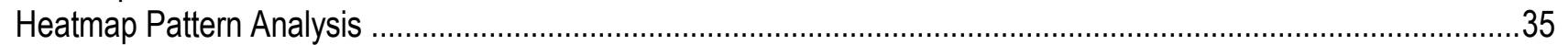

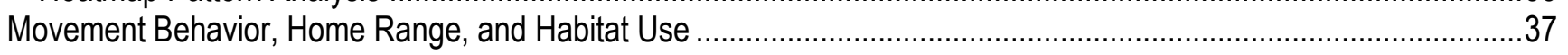

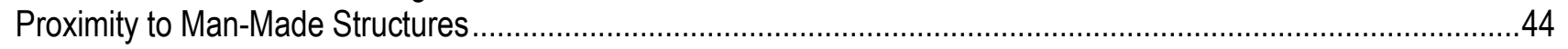

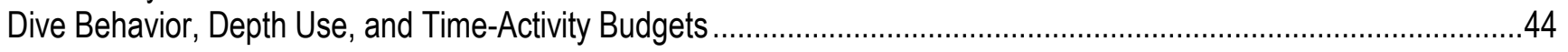

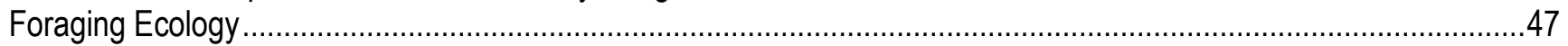

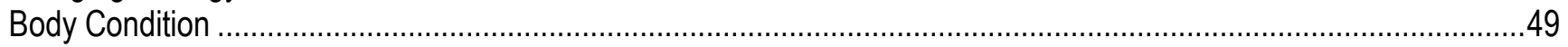

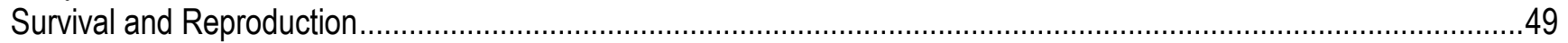

Preliminary Findings from Necropsy of Tagged Sea Otters ...........................................................................59

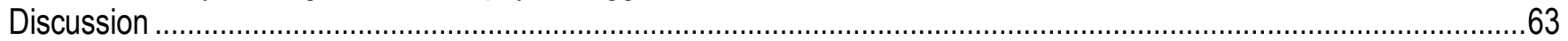

Primary Objectives: Space Use Patterns and Exposure to Oil and Gas Seeps ..........................................................63

Secondary Objectives: Population Status and Threats to Recovery ...................................................................64

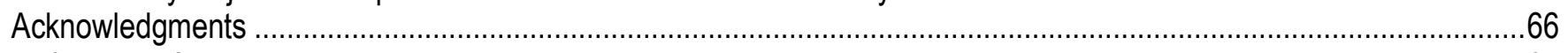

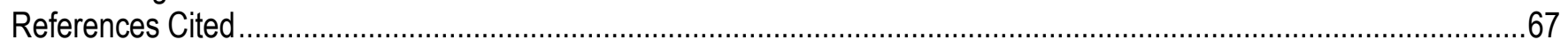

Appendix A. Analytical Methods for Dive Behavior and Time-Activity Budgets ........................................................... 


\section{Figures}

Figure 1. Map of the central California coast, illustrating the current distribution of the southern sea otter and spatial variation in relative population density..... 3

Figure 2. Photographs illustrating scuba-based methods used to capture sea otters... 6

Figure 3. Photographs illustrating health assessments and biosampling of anesthetized sea otters. 8

Figure 4. Photographs illustrating surgical procedure used to implant telemetry tracking devices in study animals.

Figure 5. Map of the Santa Barbara Channel Study Area.... 11

Figure 6. Photographs illustrating field monitoring of tagged study animals. 12

Figure 7. Photographs of (A) A male study animal pauses from grooming to display its uniquely-colored flipper tags, used for visual identification. (B) The view of a study animal from through a Questar spotting scope, demonstrating the potential for a trained observer to visually identify prey and record feeding behavior (in this case a clam of size " $1 \mathrm{c}$ " $(3.5-5 \mathrm{~cm})$ is being handled and consumed).

Figure 8. (A) Fitted kernel density function indicating the relative probability of an otter occurring at any point along the ATOS continuum from ATOS 1060 to 1160. (B) A map showing relevant ATOS points with connecting lines demonstrating where 3 index ATOS points match up in figure 7A.

Figure 9. A typical 24-hr period from a TDR record showing dive activity (left vertical axis = depth below surface, black "drop-lines" represent dives to the indicated depth) and behavior classifications (top horizontal axis) based on dive activity

Figure 10. One-dimensional Kernel density estimates and associated two-dimensional synoptic model-based estimates of the home ranges for a typical female (A), a territorial male with a single center of use (B), and a transient male with multiple centers of use (C).

Figure 11. Results of the MDS analysis of gene transcription $C_{T}$ values showing a tight clustering in the "Captives" group with the remaining otters from other study areas diffusely clustered into smaller groups or single animal outliers. 34

Figure 12. A hierarchical cluster analysis conducted using individual sea otter transcription data......................... 36

Figure 13. Histograms showing number of distinct centers of use (COU) for females $(A)$ and males (B)............. 39

Figure 14. Graphs showing range spans of female sea otter $(A)$ and male sea otter $(B)$ home ranges in the Santa Barbara Channel study area showing distinct bi-modality.

Figure 15. Graphs showing average probability of occurrence as a function of depth for females $(A)$ and males (B) as predicted by the synoptic model.

Figure 16. Posterior distributions of parameter estimates from Bayesian synoptic space-use model

Figure 17. A habitat utilization map (excluding home range tendencies) predicting the probably of female sea otter occurrence in the Santa Barbara Channel study area..

Figure 18. A habitat utilization map (excluding home range tendencies) predicting the probably of male sea otter occurrence in the Santa Barbara Channel study area.

Figure 19. Map of Santa Barbara Channel between Pt. Conception and Santa Barbara showing locations and probability of encounter by sea otters of 26 known oil or natural gas seeps.

Figure 20. Mean and maximum dive durations for males and females with no pup showing an overall similarity (A) and mean and maximum dive depths for males and females with no pup showing depths were deeper for males than for females (B).

Figure 21. Percent time spent feeding for female and male sea otters compared across four different locations in California.

Figure 22. Overall diet of sea otters in the Santa Barbara Channel (A) compared to San Nicolas Island (B), Monterey (C), and Big Sur (D). 
Figure 23. Growth curve fit to length vs age for females (A) and growth curve fit to body mass vs.

age for males (B)..

Figure 24. Boxplot comparison of sea otter structural size of females (A) and males (B) at seven and eight different locations in California (arranged north to south)

Figure 25. Boxplot comparison of sea otter body condition of females (A) and males (B) at seven and eight different locations in California (arranged from north to south)

Figure 26. Plot showing deviation of expected mass at a given age for females at seven locations

(A) and plot of female body condition indices compared across seven locations showing that SBC females clearly cluster with females from San Nicolas Island and Elkhorn Slough (B)......

Figure 27. Results of a proportional hazards survival analysis estimating the annual survival rate at a

given age for females (A) and males (B)

Figure 28. Posterior distributions of parameter estimates from the Bayesian survival model.

Figure 29. Plots of annual survival rate vs. body condition index for females $(A)$ and males (B) at six different sites.

Figure 30. Posterior distributions of the random effect differences in hazard rates across six different study areas in California

Figure 31. (A) Posterior distributions for adult female survival rates at four locations in California (as estimated from a full model including both fixed and random effects), and (B) Posterior distribution for a comparison of the difference in survival between females at Santa Barbara Channel and females at Cambria, showing significantly higher survival at SBC

Figure 32. A plot of female survival as a function of age when shark bites were taken into account and when shark bites were excluded from the analysis.

Figure 33. A hazards analysis for pup survival as a function of pup age in weeks

Figure 34. Pup survival rate (weaning success) plotted as a function of the mother's age $(A)$ and as a function of the mother's body condition (B)

\section{Tables}

Table 1. Biological samples collected from captured sea otters

Table 2. Documented function of 13 genes identified in free-ranging sea otters sampled in Monterey $(2009,2010)$, Big Sur $(2008,2009)$, San Luis Obispo (2012), Santa Barbara $(2012,2013)$, and in clinically normal captive reference animals sampled in 2008, 2009, or 2010.

Table 3. Dive attributes of southern sea otters in five classes determined for three different California study sites 23

Table 4. Summary information for sea otters captured, sampled, tagged, and monitored as part of this study...... 28

Table 5. Summary monitoring information for all tagged sea otters included in this study.

Table 6. Geometric mean, cycle threshold (Ct) of 13 genes identified in free-ranging sea otters sampled in Monterey $(2009,2010)$, Big Sur $(2008,2009)$, San Luis Obispo (2012), Santa Barbara $(2012,2013)$, and in clinically normal captive reference animals sampled in 2008, 2009, or 2010. 33

Table 7. Statistics on individual home ranges, including number of distinct. 


\section{Conversion Factors}

U.S. customary units to International System of Units

\begin{tabular}{llll}
\hline & Multiply & To obtain \\
\hline & Length & & \\
\hline foot $(\mathrm{ft})$ & 0.3048 & meter $(\mathrm{m})$ & \\
\hline
\end{tabular}

International System of Units to U.S. customary units

\begin{tabular}{lcll}
\hline & Multiply & By & To obtain \\
\hline meter $(\mathrm{m})$ & Length & & \\
millimeter $(\mathrm{mm})$ & 1.094 & yard (yd) & \\
kilometer $(\mathrm{km})$ & 0.0394 & inch (in.) & \\
\hline & 0.6214 & mile (mi) & \\
\hline \multirow{2}{*}{ kilogram $(\mathrm{kg})$} & Mass & & \\
\hline
\end{tabular}

Temperature in degrees Celsius $\left({ }^{\circ} \mathrm{C}\right)$ may be converted to degrees Fahrenheit $\left({ }^{\circ} \mathrm{F}\right)$ as:

$$
{ }^{\circ} \mathrm{F}=\left(1.8 \times{ }^{\circ} \mathrm{C}\right)+32 .
$$

\section{Abbreviations}

$\begin{array}{ll}\text { DOD } & \text { U.S. Department of Defense } \\ \text { EPA } & \text { U.S. Environmental Protection Agency } \\ \text { ppm } & \text { parts per million } \\ \text { USGS } & \text { U.S. Geological Survey }\end{array}$




\title{
Southern Sea Otter Range Expansion and Habitat Use in the Santa Barbara Channel, California
}

\author{
By M. Tim Tinker ${ }^{1}$, Joseph Tomoleoni¹, Nicole LaRoche¹, Lizabeth Bowen¹, A. Keith Miles ${ }^{1}$, Mike Murray², \\ Michelle Staedler ${ }^{2}$, and Zach Randell1,3
}

\begin{abstract}
The re-colonization of the Santa Barbara channel by sea otters brings these ESA-listed marine mammals closer to active oil and gas production facilities, shipping lanes and naturally occurring oil and gas seeps. However, the degree to which sea otters may actually be affected by human-caused oil spills or exposure to natural oil seeps is currently unknown. Between 2012 and 2014, the U.S. Geological Survey and collaborating agencies conducted a telemetry-based study of sea otters in Santa Barbara channel, in order to provide critical information for resource managers (specifically the Bureau of Ocean Energy Management, henceforth BOEM, and the U.S. Fish and Wildlife Service, henceforth USFWS) about the spatial ecology, population status, and potential population threats to sea otters in Santa Barbara Channel, with particular reference to exposure to manmade structures and sources of oil and natural gas. Analysis of spatial monitoring data using a Bayesian-based synoptic model allowed for description of sea otter home ranges, identification of hot-spots of use, and insights into habitat selection behavior by male and female sea otters. Important findings included the deeper modal depth preferred by males versus females, strong preferences by both sexes for areas with persistent kelp canopy, and greater use of soft-sediment areas by males. The synoptic model also provided the ability to predict population-level density distribution for each sex in new habitats: by calculating the value of these probability density distributions at the known locations of natural seeps, we were able to identify those seeps with higher potential for sea otter encounters. The relative probability of occurrence at locations near to some seeps was sufficiently high (about 1\% likelihood of occurrence for some of our study animals) that one would anticipate occasional encounters. Data on male and female survival, reproductive success, activity budgets, and body condition all indicated that sea otters in Santa Barbara Channel are not resource limited, and thus we would expect to see continued strong population growth in this area. However, the principal cause of death for study animals was lethal bites by white sharks, suggesting that shark bite mortality represents the single biggest threat to continued population growth in the Santa Barbara Channel.
\end{abstract}

\footnotetext{
${ }^{1}$ U.S. Geological Survey.

${ }^{2}$ Monterey Bay Aquarium, Monterey, California.

${ }^{3}$ Oregon State University, Department of Integrative Biology, Corvalis.
} 


\section{Introduction}

\section{Background}

Sea otters in California forage as an apex marine predator in nearshore habitat that occurs along a densely human-populated coastline. Sea otters are unusual among marine mammals in that they live outside of their zone of thermal neutrality and consequently have extremely high metabolic demands and rely on the integrity of their dense fur for insulation. These traits, in conjunction with their distribution and the preponderance of filter feeding benthic invertebrates in their diet (Riedman and Estes, 1990), make southern sea otters especially susceptible to human-induced stressors in their environment. Sea otters are particularly vulnerable to exposure to petroleum hydrocarbons, due both to the toxic effects via ingestion of contaminated prey (and/or grooming oiled fur) and to disruption of the insulating properties of their pelage (Lipscomb and others, 1993; Jessup and others, 2010). The southern sea otters status as "Threatened" under the ESA (Determination that the Southern Sea Otter is a Threatened Species; 42 FR 29652968 (Enhydra lutris nereis), U.S. Fish and Wildlife Service, 1977) is based largely on the risk posed to this small population by oil spills (Riedman and Estes, 1990). Thus a comprehensive understanding of the factors potentially limiting recovery of this population must include a description of the risks posed by exposure to oil and gas.

The current range of the sea otter extends from Pigeon Point in the north to Gaviota State Park in the south, and range expansion at the southern end of the range in the early 2000s occurred at a rate of approximately $5 \mathrm{~km} / \mathrm{yr}$ (Tinker, Bentall, and others, 2008). Since 1998, 15-110 sea otters per year have occupied areas south of Point Conception (fig. 1), including mainland areas of the Santa Barbara Channel (Jameson, 1989; Tinker, Doak, and others, 2006; Lafferty and Tinker, 2014). The recolonization of the Santa Barbara channel brings sea otters closer to active oil and gas production facilities, shipping lanes and naturally occurring oil and gas seeps. However, the degree to which sea otters may actually be affected by human-caused oil spills or exposure to natural oil seeps depends on the nature of sea otter movements, feeding activity, and spatial patterns of habitat use.

Unlike many marine mammals, sea otters have a relatively small home range, which typically includes no more than $20 \mathrm{~km}$ shoreline (Ralls and others, 1996). Adult females in particular exhibit high site fidelity, usually remaining within a small home range throughout their lives, although often moving between several focal centers of use (Tarjan and Tinker, 2016). Both males and females occasionally move longer distances, especially younger animals, and some males remain highly mobile throughout their lives (Jameson, 1989). Because of these age and sex-based differences in space use and movement behavior, various demographic groups may be differentially exposed to spatially explicit threats such as oil seeps. Understanding the risks to individuals and to the population as a whole therefore depends on a solid understanding of spatial ecology, including both large-scale and small-scale patterns. In the Santa Barbara Channel, there are a number of important outstanding questions: for example, are sea otters in Santa Barbara Channel resident in this area year round, or do they move to and from other parts of the range? How large is a typical home range for male and female otters in this area, and what habitat features are most heavily used or avoided by sea otters? The spatial ecology of sea otters has been explored in other areas (e.g., Laidre, Jameson and others, 2009; Tarjan and Tinker, 2016), but prior to this study, very little was known about individual space use patterns south of Point Conception. 


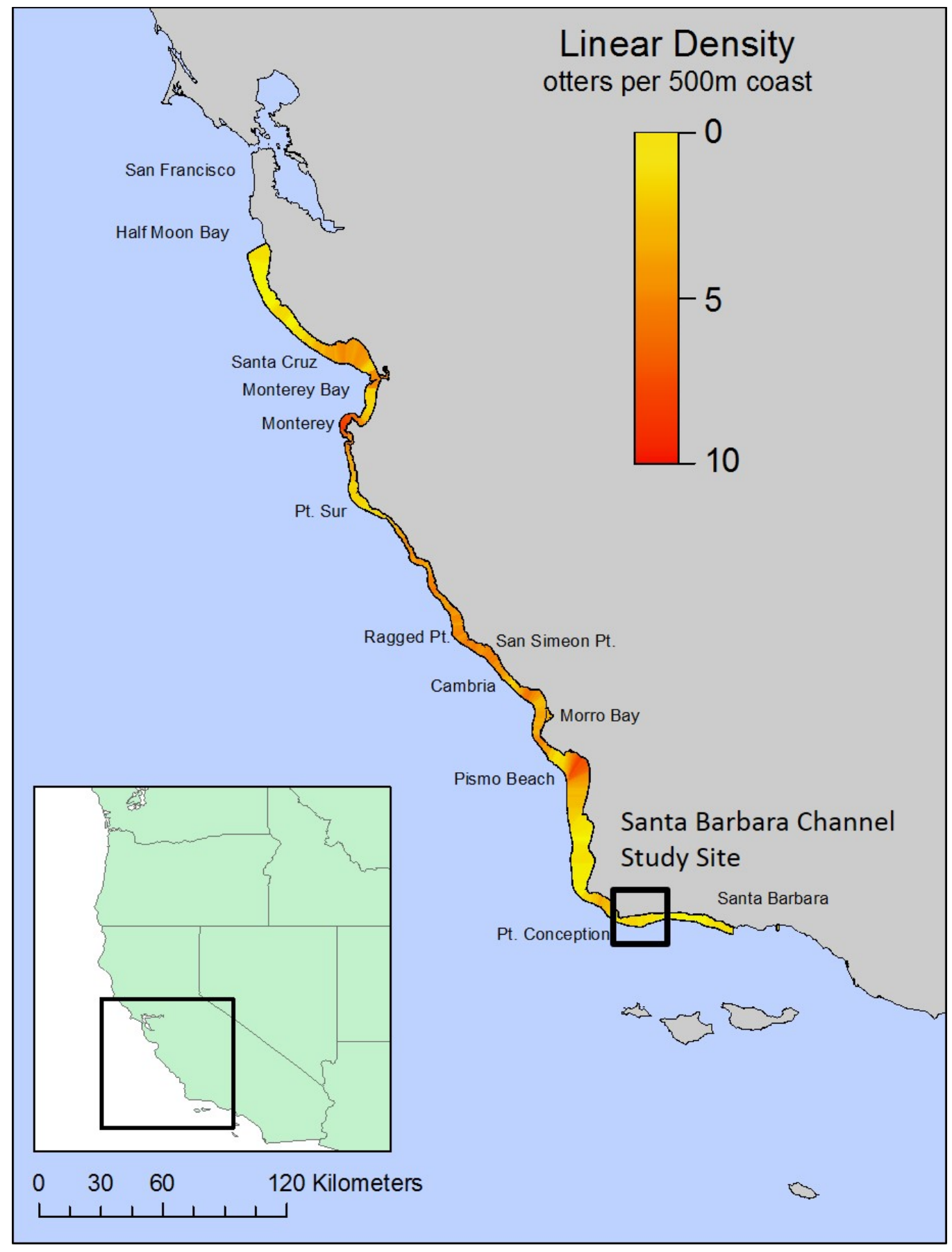

Figure 1. Map of the central California coast, illustrating the current distribution of the southern sea otter and spatial variation in relative population density. 


\section{Primary Objectives}

The current study was designed to provide critical information for resource managers (specifically the Bureau of Ocean Energy Management, henceforth BOEM, and the U.S. Fish and Wildlife Service, henceforth USFWS) about the spatial ecology, population status, and potential population threats to sea otters in Santa Barbara Channel, with particular reference to exposure to manmade structures and sources of oil and natural gas. Our four primary research objectives were:

1. Determine the extent of movements and spatial use patterns by sea otters along the southern California coast.

2. Identify important sea otter resting and foraging areas adjacent to manmade structures.

3. Assess sea otter distribution, behavior and habitat selection in the vicinity of natural oil and gas seep areas (e.g., Coal Oil Point, Santa Barbara County).

4. Combine data on tagged animal movements, habitat use patterns and population distribution (acquired during this study and from previous studies and USGS monitoring activities), to create population-level "risk of exposure" models for spatially explicit threats such as natural oil seeps or hypothetical oil spill scenarios.

\section{Secondary Objectives}

In addition to investigating the potential impacts of natural oil seeps and manmade structures on sea otters in the Santa Barbara Channel, conducting a long-term monitoring study at the extreme southern edge this species' range provided us the opportunity to examine a variety of biological and ecological parameters that are relevant to sea otters and nearshore ecosystems as a whole. In particular, by using a comparative approach (comparing various metrics between sea otters in Santa Barbara Channel and sea otters in other locations within the range), we can determine the status of the population in this region with respect to prey resources, and identify any natural and/or anthropogenic threats to population recovery.

Because sea otters have only recently recolonized the Santa Barbara Channel, we postulated that this area may be a resource-abundant environment for sea otters. That is to say, sea otters in the Santa Barbara Channel are at relatively low densities and have not persisted long enough in this area to have had a strong depleting effect on their invertebrate prey (Lafferty and Tinker, 2014). By contrast, most of the rest of the range of sea otters in central California has seen much longer otter occupation (50-100+ years) since their near extinction during the fur trade of the 18th and 19th centuries (Riedman and Estes, 1990). Sea otters currently exist in these more established areas at relatively high densities, which permits a greater exploitation of their prey resources over time, resulting in resource-limited communities (Tinker, Bentall, and others, 2008). Recently established areas at the peripheries of the range (north of Davenport and south of Pt. Conception, including Santa Barbara Channel) support lower densities of sea otters, and are expected to have more abundant food (Tinker, Doak, and others, 2008). The relative availability of sea otter prey resources in a particular habitat can be assessed by measuring a number of previously demonstrated indices, including the amount of time sea otters spend foraging (more time foraging in resource-limited areas, less time foraging in resource abundant areas), the rate of energy recovery during these foraging bouts, diet composition and diversity, and the relative health and body condition of sea otters in these areas. All three of these indices have been shown to be related to the survival rates of juvenile and adult sea otters (Tinker and others, 2013), and thus to the rate of population growth: when net mortality rates equal net birth rates then the annual growth rate $\lambda=0$, and the population is said to be at "carrying capacity," or $K$. 
We therefore set out to measure basic demographic parameters, as well as indices of population status in Santa Barbara Channel, in order to compare them to previously conducted studies in Monterey, Big Sur, San Luis Obispo, San Simeon, and San Nicolas Island. Our secondary objectives were:

1. Characterize basic vital rates (survival and reproduction) of sea otters in Santa Barbara Channel, and compare to other locations.

2. Characterize indices of population status for sea otters in Santa Barbara Channel, and compare to other locations in the range. Indices include body condition, diet diversity, foraging success, and percent time feeding.

3. Identify important causes of mortality for tagged sea otters, and compare to other locations.

Our overall goal was to identify to determine where the Santa Barbara Channel population falls on the spectrum of relative resource availability and sea otter health, and identify any potential threats that may be of relevance for resource managers.

\section{Methods}

\section{Live Sea Otter Captures}

All study animals were captured using standardized methods that utilize closed-circuit scuba techniques (Ames and others, 1983; Tomoleoni and others, 2012). Briefly, shore spotters with highpowered spotting scopes relayed information about resting sea otters to dive teams, which operated out of small 17-20 ft skiffs. After securing their boat near a group of otters, divers entered the water using closed-circuit oxygen rebreathers and electric propulsion vehicles to maneuver the traps directly under sea otters resting on the surface (fig. 2). The traps were then rapidly pushed upward to capture the unsuspecting otters in the trap's net bag, which was then closed by a purse line. Once the skiff arrived, the otters were transferred to a wooden capture box and transported to nearby veterinary facilities on shore for anesthetic immobilization, health assessments, biosampling, surgical implantation with VHF radio transmitters and time-depth recorders (TDRs), tagging, and eventual release to their initial capture site (detailed procedures described below). The entire procedure, from capture to release, generally took about 2-3 hours. All live animal procedures and fieldwork was conducted with authorization by the US Fish and Wildlife Service under a Federal research permit issued to MT Tinker (MA672624-18) and with oversight by the Institutional Animal Care and Use Committee at the University of California Santa Cruz (TINKT1510).

During the Santa Barbara Channel Study, three separate capture events were conducted. The initial capture of 22 sea otters (12 males, 10 females) took place from March 5-10, 2012. One of the sea otters captured was a previously tagged study animal that was captured in Estero Bay on October 30, 2005. The fortuitous capture of this male otter allowed us to add him to the current SBC study and provided us with additional information on this animal as far back as 2005. A second capture event was conducted 1 year later from March 10-18, 2013, and added an additional 23 sea otters (11 males, 12 females) to the study, while 1 sea otter (male) was recaptured from the 2012 capture event. This single recapture resulted in the recovery of that animal's TDR. From March 16-22, 2014, a third and final Santa Barbara Channel capture event took place in which no new sea otters were targeted for capture and all resources were put into recapture attempts to resample study animals and retrieve TDRs. The logistics of this final recapture event were made very difficult by a winter storm that destroyed a portion of the Gaviota pier and hoist just 2 weeks prior to our planned recapture event. This unforeseen obstacle required us to launch our boats at the Santa Barbara Harbor, resulting in several hours of additional 
daily transit time for the capture crews. Captured otters had to be brought ashore at Gaviota using an inflatable boat rather than the hoist on the pier. Despite these setbacks, we still managed to recapture three study animals (two males, one female) and successfully retrieved their TDRs. In addition, one new otter was incidentally caught and biosampled, tagged, and released.
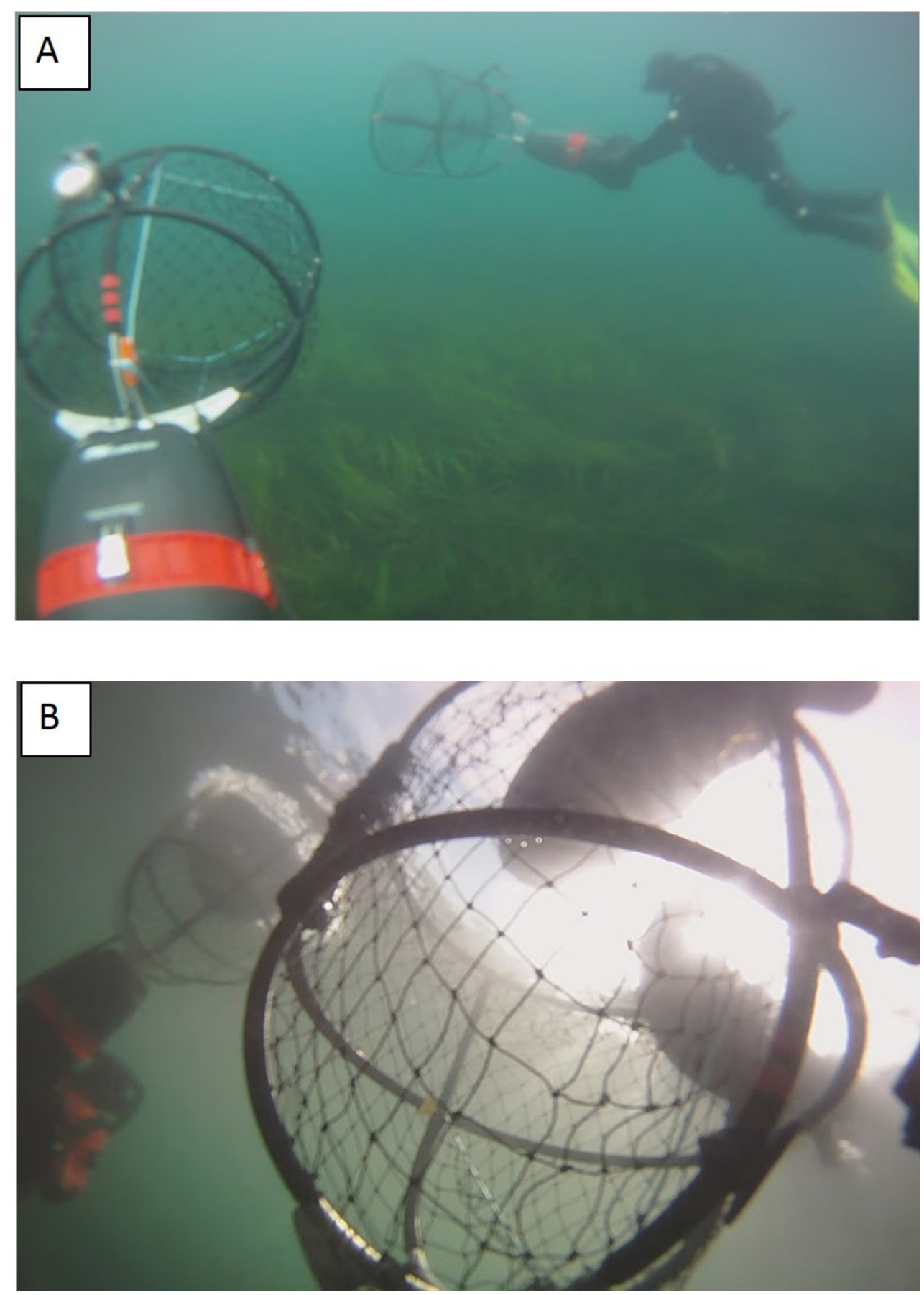

Figure 2. Photographs illustrating scuba-based methods used to capture sea otters. (A) A pair of divers travelling underwater with the Wilson traps propelled ahead of them using electric propulsion scooters.( B) Resting sea otters being captured within the Wilson traps (Photos: USGS) 


\section{Processing, Sampling, Health Assessments, and Tagging}

Upon arrival at the veterinary station (an onshore mobile veterinary facility stationed at Gaviota State Park), the capture box was floated in the ocean, alongside a boat, allowing the otter to rest and thermoregulate. Following this 10-20 minute soak time, the animals were moved to the veterinary laboratory for sedation, physical examination, collection of morphometric data, acquisition of biological samples, tagging, and implantation of instruments (detailed descriptions below) (fig. 3A). The sea otters were chemically immobilized using standard doses of the opiate, fentanyl citrate $(0.22-0.33 \mathrm{mg} / \mathrm{kg})$, and midazolam hydrochloride $(0.07-0.11 \mathrm{mg} / \mathrm{kg}$ ) administered intramuscularly (Monson and others, 2001). Once adequately sedated, typically after 6-10 minutes, the sea otter was removed from the capture box and processed. While anesthetized, vital signs (heart rate, respiratory rate, end-tidal $\mathrm{CO}_{2}$, blood pressure, blood oxygen saturation, and rectal body temperature) were monitored at 5-minute intervals. Anomalies were corrected as indicated. Following completion of the examinations, measurements, sample collections, and tagging procedures, the effects of sedative (fentanyl), were reversed with an intramuscular dose of naltrexone hydrochloride $(1.1-1.65 \mathrm{mg} / \mathrm{kg})$.

For all captured study animals, a suite of standardized health parameters were recorded, including: weight, length, girth, fur condition and degree of grizzle, tooth-wear (and tooth-based age estimates: fig. 3B), and general body condition. A set of biological samples were collected from each animal, as summarized in table 1, for use in analyses that are reported on in subsequent sections of this report, for example, blood samples were collected for clinical health assessments and gene expression analyses. The animals were then prepared for surgical implantation of the VHF radio transmitters $(80 \times$ $22 \times 50 \mathrm{~mm}$, about $160 \mathrm{~g}$, Advanced Telemetry Systems, Isanti, MN) and time depth recorders (TDRs, $67 \times 17 \times 17 \mathrm{~mm}$, about 27g, Wildlife Computers, Redmond, WA) using standardized surgical techniques (fig. 4; Williams and Siniff, 1983). The VHF transmitter was used for telemetric monitoring and relocation of the otter post-release, and emitted a radio signal at 1-second intervals on a unique frequency band that could be detected from up to $10 \mathrm{~km}$ away. The TDR was a biologging instrument that recorded depth (via scaled conversion of pressure transducer readings) and internal body temperature at 2-second intervals for a 2-3 year period, and allowed for detailed analysis of sea otter dive behavior and time-activity budgets. Each otter was also tagged with unique color/number coded polyethylene "Temple ${ }^{\circledR}$ Tags" (livestock ear tags, Temple, TX) on their hind flippers (2-3 tags per otter), to allow for visual identification by field observers, and received a coded, passive integrated transponder (PIT) tag, implanted subcutaneously in the inner thigh, for later identification should the Temple $^{\circledR}$ Tags be lost.

Sea otters that were recaptured were subjected to the same anesthesia procedure for a second surgery performed in order to retrieve the archival TDR for data collection. All health parameters were re-assessed, tissue samples taken, and any missing flipper tags were replaced before release. 

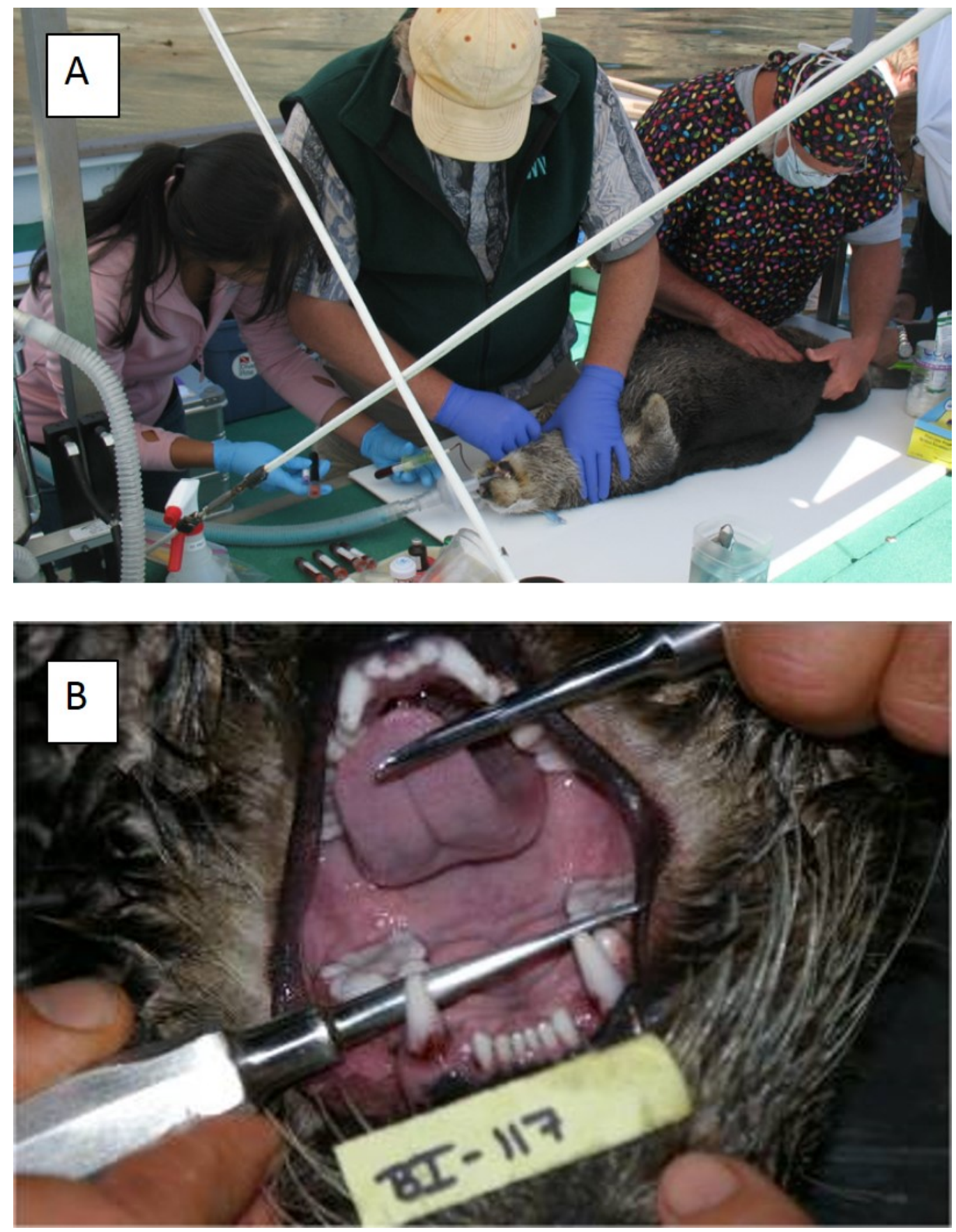

Figure 3. Photographs illustrating health assessments and biosampling of anesthetized sea otters. (A) Veterinarians conduct careful physical examinations and collect blood samples. (B) A veterinarian examines the dental and oral health of a sea otter, recording all incidences of tooth wear, breakage, and the presence of oral lesions (Photos: USGS). 

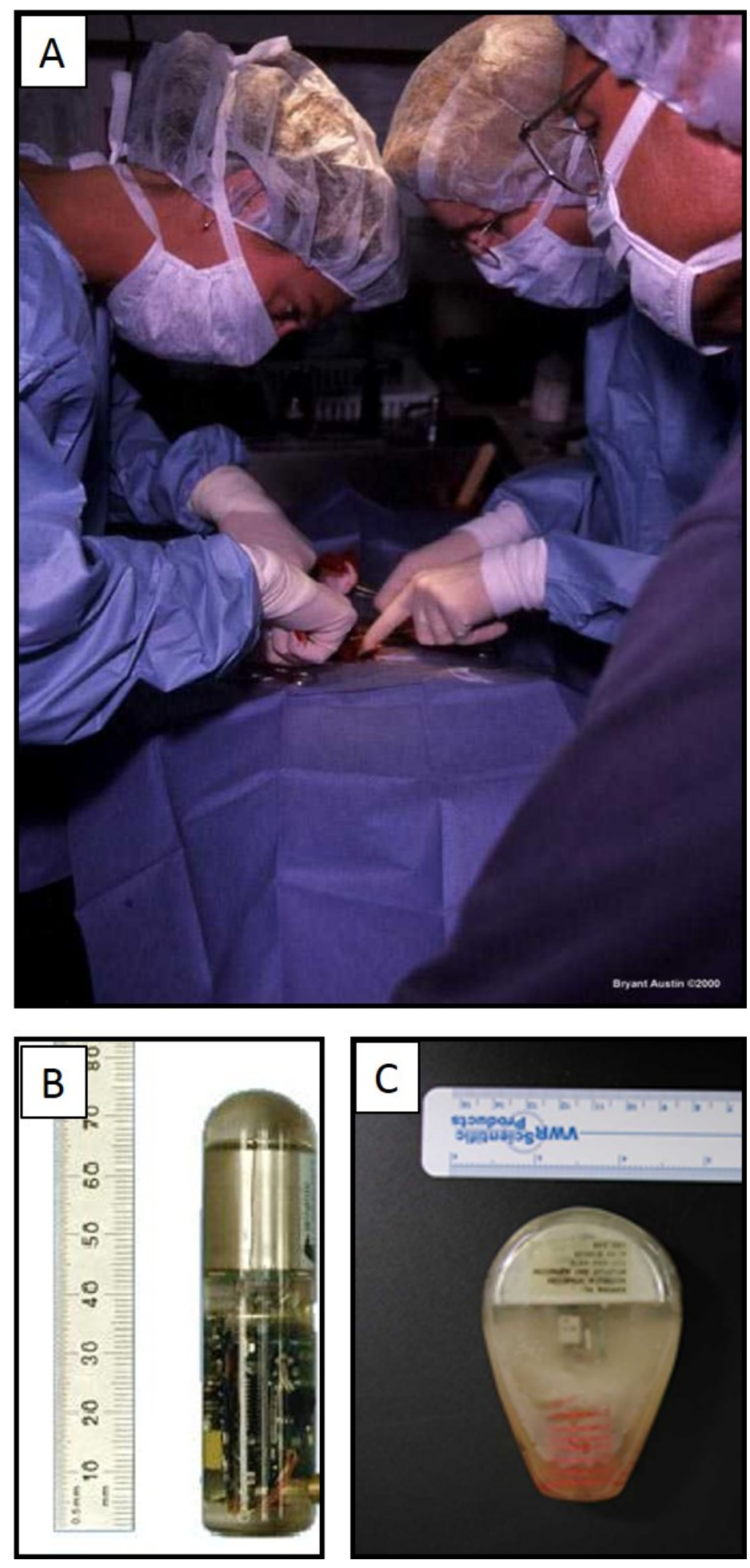

Figure 4. Photographs illustrating surgical procedure used to implant telemetry tracking devices in study animals. (A) A veterinary team performs abdominal surgery on an anaesthetized sea otter. (B) The Time Depth Recorder (TDR) used to record diving behavior and internal temperature. (C) The VHF transmitter used locate the study animals in the wild using standard wildlife telemetry techniques (Photos: USGS). 
Table 1. Biological samples collected from captured sea otters.

\begin{tabular}{ll}
\hline \multicolumn{1}{c}{ Sample type } & \multicolumn{1}{c}{ Use } \\
\hline Blood & $\begin{array}{l}\text { Hematology, clinical chemistry, infectious disease monitoring, biomarkers, } \\
\text { contaminants }\end{array}$ \\
$\begin{array}{ll}\text { External swabs (integument, oral } \\
\text { cavity, rectum, genital orifice) }\end{array}$ & Infectious disease (bacterial, fungal, parasitic, viral), contaminants, genetics \\
Saliva & Hormonal assays \\
Feces & $\begin{array}{l}\text { Diet assessment, infectious disease (bacterial, fungal, parasitic, viral), contaminants, } \\
\text { biotoxin, hormonal assay }\end{array}$ \\
Adipose tissue & Fatty acids, contaminants \\
Liver biopsies & Histopathology, toxicology, contaminants, genetics, chemical analysis (i.e., Vit A \\
analysis) & Genetics \\
Skin plugs & Stable isotope \\
Vibrissae & Cementum aging \\
Tooth & Hormonal assays, toxins, contaminants \\
Fur &
\end{tabular}

\section{Live Sea Otter Surveillance}

Tracking and observation of the study animals occurred on a semi-regular basis (approximately 2-5 days per week, consistent with previous telemetry-based studies in California) for the duration of the study, which commenced with the first day of captures on March 5, 2012, and continued with minimal interruption through June 30, 2014. Monitoring efforts were supplemented in August and September of 2014, when 5 separate boat tracking trips were conducted.

The SBC study area encompassed the coastal waters bounded by Vandenberg Air Force Base in the north and Gaviota State Park in the south (fig. 5). Nearly all of the study area was adjacent to private property (Hollister Ranch, Surfing Cowboy Ranch, Cojo-Jalama Ranch) with either prohibited or very restricted access. As a result, field personnel were unable to conduct regular shore-based surveys of the study area. As a result of the inaccessibility of most of the coastline, most sea otter resighting data were collected by boat-based tracking from a 17-foot Boston Whaler (Edgewater, FL) launched from the Gaviota hoist (and later, Santa Barbara Harbor), supplemented by shore-based surveys whenever possible. Aerial flights were conducted periodically to locate missing study animals. 


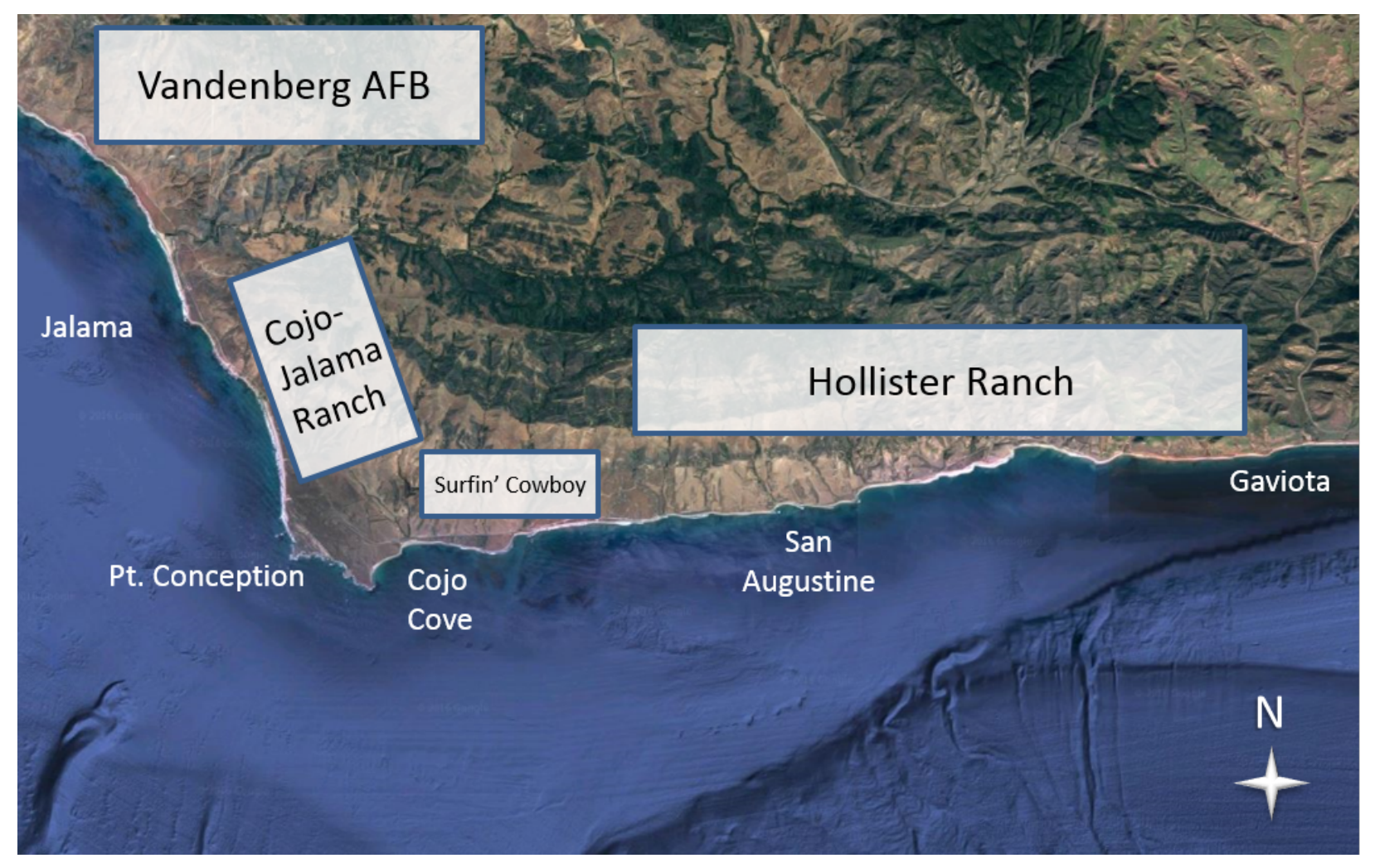

Figure 5. Map of the Santa Barbara Channel Study Area.

Both shore-based and boat-based tracking involved locating study animals using standard telemetric protocols (triangulation of radio signal and visual identification: fig. 6) identical to the methods used in previous sea otter tracking studies (Siniff and Ralls, 1991; Tinker, Doak, and others, 2006; Tinker and others, 2013). Initial locations were determined by driving (boat or car) and/or hiking throughout the study area while using a radio receiver and antenna to scan for telemetry signals. When a signal was obtained, trackers used a combination of binoculars and high-powered (80X) spotting scopes (Questar Inc., New Hope, PA) to positively identify individuals via their unique flipper tag color combination (fig. 7A). Once individual animals were located, observers recorded a variety of biogeographic, behavioral, and environmental data including GPS position, survival, reproductive status, and instantaneous behavior. Because most tracking occurred from boats, and because following otters around in boats is known to alter their behavior, observational time-activity budgets (detailed focal-animal observations, termed "activity budgets," on behavior, diet, distance-to-shore and fine-scale movements [habitat use]) were not conducted. However, detailed sea otter time-activity budgets were estimated using TDR data (Bodkin and others, 2007; Thometz and others, 2016). 

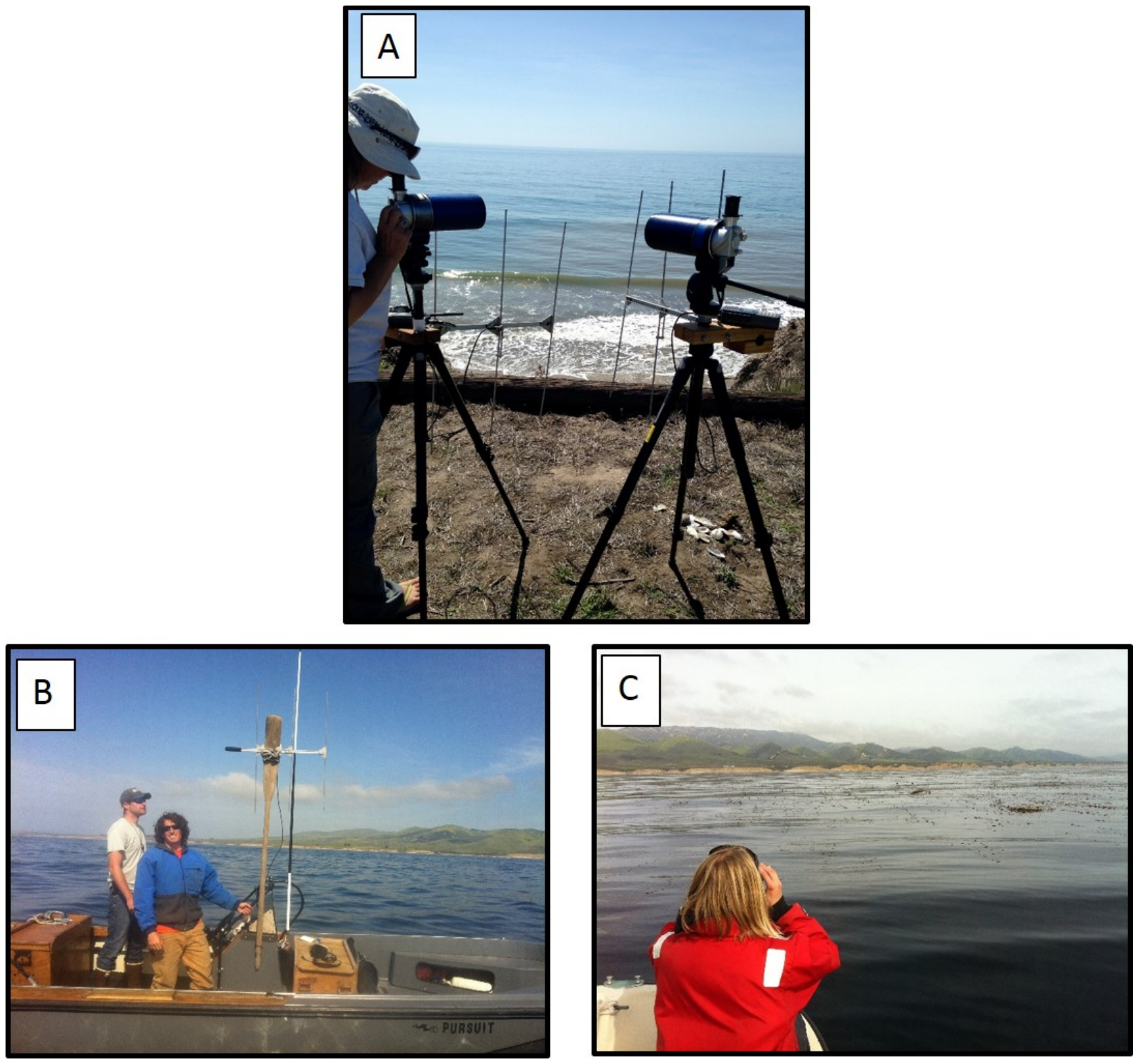

Figure 6. Photographs illustrating field monitoring of tagged study animals. (A) Field observers using a radio receiver/antenna to localize source of the VHF signal from a study animal, and a 50-80x telescope to visually monitor the study animal from shore.(B) A pair of researchers using a VHF receiver and Yagi antenna to locate study animals by boat-based tracking. (C) A researcher using binoculars from a boat to determine tag colors and combinations on a resting pair of sea otters (Photos: USGS). 

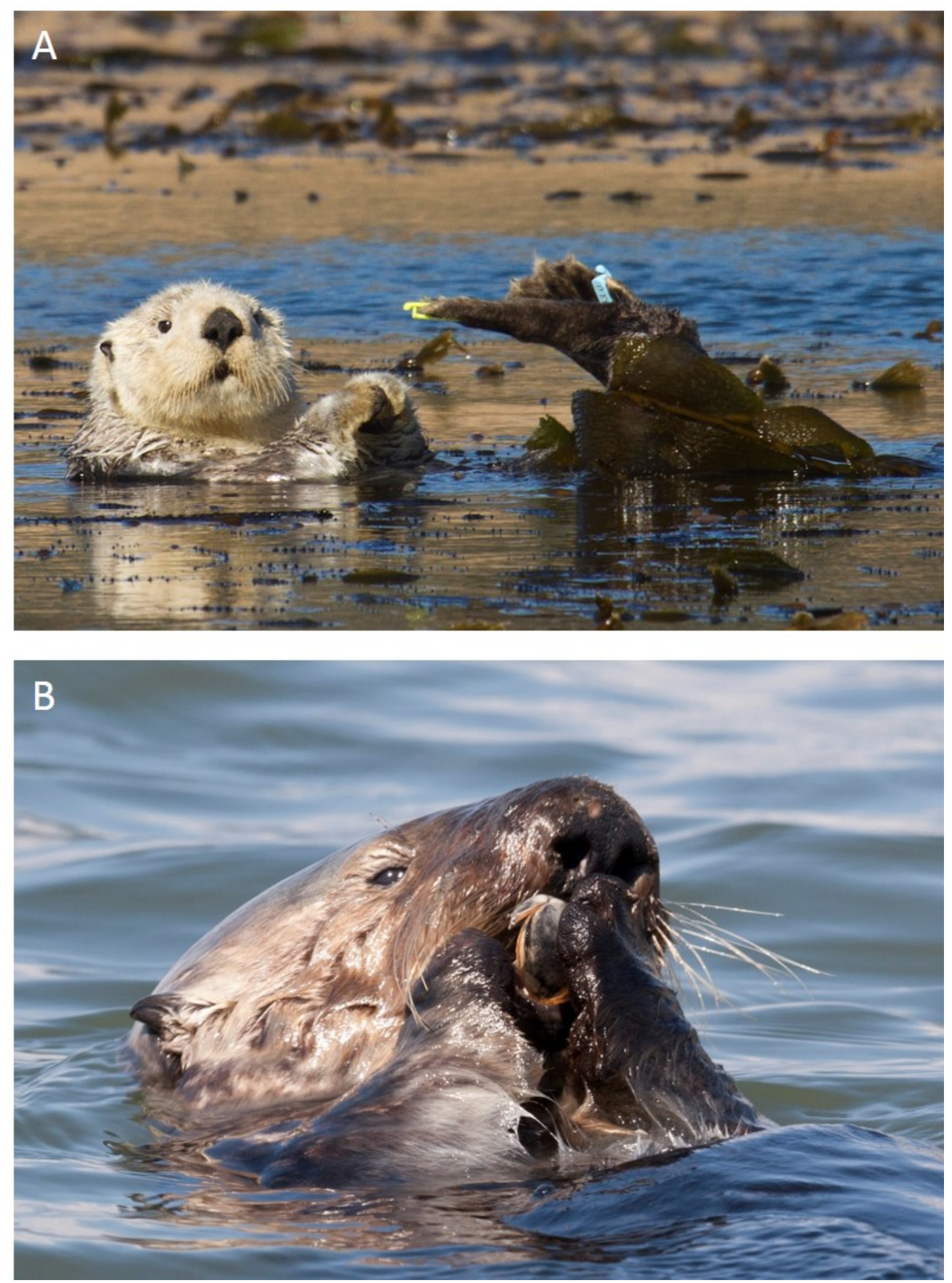

Figure 7. Photographs of (A) A male study animal pauses from grooming to display its uniquely-colored flipper tags, used for visual identification. (B) The view of a study animal from through a Questar spotting scope, demonstrating the potential for a trained observer to visually identify prey and record feeding behavior (in this case a clam of size " $1 \mathrm{c}$ " $(3.5-5 \mathrm{~cm})$ is being handled and consumed) (Photos: Nicole LaRoche/USGS). 
Observational foraging data were collected from radio-tagged sea otters (fig. 7B) following wellestablished protocols (Ralls and Siniff, 1990; Ralls and others, 1995; Ralls and others, 1996; Tinker, Doak, and others, 2006; Tinker, Estes, and others, 2006). However, observational foraging data are very difficult to collect by boat, which prevents field personnel from using high power spotting scopes, and also presents additional challenges in terms of distance, swell, wind, boat movement, etc. Because of the difficulty of collecting foraging data on focal study animals, we decided to include the opportunistic collection of foraging data on any sea otter in the study area, including non-tagged, non-study animals. Data from tagged study animals were prioritized, however, foraging data from non-study animals were still considered useful for characterizing the overall diet of sea otters in the Santa Barbara Channel. In addition to the data collected during regular boat surveys, shore-based foraging data were collected whenever possible. Field observations were collected as often as possible throughout the study period, with a team of one to three observers conducting systematic searches of the study areas and collecting foraging observations whenever the opportunity presented itself.

Later in the study (spring 2014) when shore access was granted for a 1-month period by the Surfing Cowboy Ranch, a concentrated effort to collect as much foraging data as possible was made. Study animals were initially located by radio signal using standard telemetric techniques, and then visually monitored from shore (using a 50-80X spotting scopes) or by boat (using binoculars). Foraging bouts (defined as contiguous sequences of feeding dives made by the focal otter) typically last 1-4 hours, and data were recorded throughout the entire bout or for as many dives as possible. The information recorded during these bouts includes date and time, precise location of each dive (determined by visual triangulation using GPS, compass and laser range-finder), duration of the subsurface dive interval ("DT") and the post-dive surface interval ("ST") for each feeding dive (in seconds), outcome of each dive (i.e., whether or not prey was captured), species of prey captured, number and size of prey items, per-item handling time (number of seconds required to handle and consume each item), whether or not tools were used to handle the prey, and ambient environmental conditions (including sea-state, wind, etc.). Prey size was recorded as the estimated diameter of the shell or maximum body dimension (excluding appendages), categorized into $5 \mathrm{~cm}$ size-classes. For observations where prey could not be reliably identified to species, the items in question were assigned to the lowest possible taxonomic unit. Any items that could not be reliably categorized to any taxonomic level were listed as "unidentified prey" (although size class and \# items would still be recorded for such items). Additional information recorded by observers included numbers of prey items that were stolen by or from the focal animal and, in the case of females with dependent pups, the number of items that were shared with the pups. All data were entered into GPS-enabled handheld computers in the field and later transferred to a central relational database.

\section{Dead Sea Otter Surveillance}

Field personnel made every effort possible to locate and collect any animals that died during the course of the study. A number of animals disappeared from the focal study areas, and in these cases aerial telemetry was used in an attempt to locate them. If a carcass was located by shore-based trackers or by plane, researchers were dispatched by foot, boat, or kayak to retrieve the carcass, which was placed on ice and transported immediately to the California Department of Fish and Wildlife's Marine Wildlife Veterinary Care and Research Center (CDFW-MWVCRC) for necropsy. Every sea otter carcass retrieved was subject to detailed necropsies by a veterinary pathologist and followed established. In addition to determining the primary and contributing cause(s) of death, the pathologist supervised the collection of tissue samples for a variety of otter and ecosystem health studies. 


\section{Gene Transcription}

\section{Captive Reference Otters}

Blood samples from 17 captive sea otters were obtained from the Monterey Bay Aquarium (Monterey, CA), Shedd Aquarium (Chicago, IL), Oregon Coast Aquarium (Newport, OR), and the Vancouver Aquarium (Vancouver, BC) in 2008, 2009, and 2010, and included both northern and southern subspecies (Bowen and others, 2012). These animals were identified as clinically normal by staff veterinarians at these aquaria during the time interval of blood collection.

\section{Blood Collection and RNA Extraction}

A $2.5 \mathrm{~mL}$ sample from each sea otter was drawn directly into a PAXgene ${ }^{\mathrm{TM}}$ blood RNA collection tube (PreAnalytiX, Switzerland) from either the jugular or popliteal veins and then frozen at $20{ }^{\circ} \mathrm{C}$ until extraction of RNA (Bowen and others, 2012a). Rapid RNA degradation and induced transcription of certain genes after blood draws has led to the development of methodologies for preserving the RNA transcription profile immediately after blood is drawn. The PAXgene ${ }^{\mathrm{TM}}$ tube contains a blend of RNA stabilizing reagents that protect RNA molecules from degradation by RNases and prevents further induction of gene transcription. Without this stabilization, copy numbers of individual mRNA species in whole blood can change more than 1,000-fold during storage and transport. The RNA from blood in PAXgene ${ }^{\mathrm{TM}}$ tubes was isolated according to manufacturer's standard protocols, which included an on-column DNase treatment to remove contaminating gDNA (silica-based microspin technology), and the extracted RNA stored at $-80^{\circ} \mathrm{C}$ until analysis. All RNA was checked for quality on a NanoDrop 2000 (Thermo Scientific, Wilmington, DE) and achieved A260/A280 ratios of approximately 2.0 and A260/A230 ratios of less than 1.0.

\section{cDNA creation}

A standard cDNA synthesis was performed on $2 \mu \mathrm{g}$ of RNA template from each animal. Reaction conditions included 4 units reverse transcriptase (Omniscript ${ }^{\circledR}$, Qiagen, Valencia, CA), $1 \mu \mathrm{M}$ random hexamers, $0.5 \mathrm{mM}$ each dNTP, and 10 units RNase inhibitor, in RT buffer (Qiagen, Valencia, CA). Reactions were incubated for 60 minutes at $37{ }^{\circ} \mathrm{C}$, followed by an enzyme inactivation step of 5 minutes at $93{ }^{\circ} \mathrm{C}$, and then stored at $-20{ }^{\circ} \mathrm{C}$ until further analysis.

\section{Real-Time PCR}

Real-time PCR systems for the individual, sea otter-specific reference or housekeeping gene (S9) and genes of interest were run in separate wells (Bowen and others, 2012a; Miles and others, 2012) (table 2). Briefly, $1 \mu \mathrm{L}$ of cDNA was added to a mix containing $12.5 \mu \mathrm{L}$ of QuantiTect SYBR Green ${ }^{\circledR}$ Master Mix [ $5 \mathrm{mM} \mathrm{Mg}^{2+}$ ] (Qiagen, Valencia, CA), $0.5 \mu \mathrm{L}$ each of forward and reverse sequence specific primers, $0.5 \mu \mathrm{L}$ of Uracil-N-Glycosylase (Invitrogen, Carlsbad, CA), and 10.0 $\mu \mathrm{L}$ of RNase-free water; total reaction mixture was $25 \mu \mathrm{L}$. The reaction mixture cDNA samples for each gene of interest and the S9 gene were loaded into 96 well plates in duplicate and sealed with optical sealing tape (Applied Biosystems, Foster City, CA). Reaction mixtures containing water, but no cDNA, were used as negative controls; thus approximately three to four individual sea otter samples were run per plate. 
Table 2. Documented function of 13 genes identified in free-ranging sea otters sampled in Monterey $(2009,2010)$, Big Sur (2008, 2009), San Luis Obispo (2012), Santa Barbara (2012, 2013), and in clinically normal captive reference animals sampled in 2008, 2009, or 2010.

\begin{tabular}{|c|c|}
\hline Gene & Gene function \\
\hline HDC & $\begin{array}{l}\text { The HDCMB21P gene codes for a translationally controlled tumor protein (TCTP) implicated in cell } \\
\text { growth, cell cycle progression, malignant transformation, tumor progression, and in the protection of cells } \\
\text { against various stress conditions and apoptosis (Bommer and Thiele, 2004; Tuynder and others, 2004; Ma } \\
\text { and others, 2010). Up-regulation of HDC is indicative of the development or existence of cancer. } \\
\text { Environmental triggers may be responsible for population-based, up-regulation of HDC. HDC transcription } \\
\text { is known to increase with exposure to carcinogenic compounds such as polycyclic aromatic hydrocarbons } \\
\text { (Bowen and others, 2007; Raisuddin and others, 2007; Zheng and others, 2008). }\end{array}$ \\
\hline COX2 & $\begin{array}{l}\text { Cyclooxygenase-2 catalyzes the production of prostaglandins that are responsible for promoting } \\
\text { inflammation (Goldsby and others, 2003). Cox } 2 \text { is responsible for the conversion of arachidonic acid to } \\
\text { prostaglandin H2, a lipoprotein critical to the promotion of inflammation (Harris and others, 2002). Up- } \\
\text { regulation of Cox } 2 \text { is indicative of cellular or tissue damage and an associated inflammatory response. }\end{array}$ \\
\hline CYT & $\begin{array}{l}\text { The complement cytolysis inhibitor protects against cell death (Jenne and Tschopp, 1989). Up-regulation of } \\
\text { CYT is indicative of cell or tissue death. }\end{array}$ \\
\hline AHR & $\begin{array}{l}\text { The arylhydrocarbon receptor responds to classes of environmental toxicants including polycyclic aromatic } \\
\text { hydrocarbons, polyhalogenated hydrocarbons, dibenzofurans, and dioxin (Oesch-Bartlomowicz and others, } \\
\text { 2005). Depending upon the ligand, AHR signaling can modulate T-regulatory }\left(\mathrm{T}_{\mathrm{REG}}\right) \text { (immune-suppressive) } \\
\left.\text { or T-helper type } 17 \text { ( } \mathrm{T}_{\mathrm{H}} 17\right) \text { (pro-inflammatory) immunologic activity (Quintana and others, 2008; Veldhoen } \\
\text { and others, 2008). }\end{array}$ \\
\hline THR & $\begin{array}{l}\text { The thyroid hormone receptor beta can be used as a mechanistically based means of characterizing the } \\
\text { thyroid-toxic potential of complex contaminant mixtures (Tabuchi and others, 2006). Thus, increases in } \\
\text { THR transcription may indicate exposure to organic compounds including PCBs and associated potential } \\
\text { health effects such as developmental abnormalities and neurotoxicity (Tabuchi and others, 2006). Hormone- } \\
\text { activated transcription factors bind DNA in the absence of hormone, usually leading to transcriptional } \\
\text { repression (Tsai and O'Malley, 1994). }\end{array}$ \\
\hline HSP 70 & $\begin{array}{l}\text { The heat shock protein } 70 \text { is produced in response to thermal or other stress (Iwama and others, 1999; Tsan } \\
\text { and Gao, 2004). In addition to being expressed in response to a wide array of stressors (including } \\
\text { hyperthermia, oxygen radicals, heavy metals, and ethanol) heat shock proteins act as molecular chaperones } \\
\text { (De Maio and others, 1999). For example, heat shock proteins aid the transport of the AHR/toxin complex } \\
\text { in the initiation of detoxification (Tanabe and others, 1994). }\end{array}$ \\
\hline IL-18 & $\begin{array}{l}\text { Interleukin-18 is a pro-inflammatory cytokine (Goldsby and others, 2003). Plays an important role in } \\
\text { inflammation and host defense against microbes (Krumm and others, 2008). }\end{array}$ \\
\hline IL-10 & $\begin{array}{l}\text { Interleukin-10 is an anti-inflammatory cytokine (Goldsby and others, 2003). Levels of IL-10 have been } \\
\text { correlated with relative health of free-ranging harbor porpoises, e.g., increased amounts of IL-10 correlated } \\
\text { with chronic disease whereas the cytokine was relatively reduced in apparently fit animals experiencing } \\
\text { acute disease (Beineke and others, 2007). Association of IL-10 transcription with chronic disease has also } \\
\text { been documented in humans (Rigopoulou and others, 2005). }\end{array}$ \\
\hline DRB & $\begin{array}{l}\text { A component of the major histocompatibility complex, the DRB class II gene, is responsible for the binding } \\
\text { and presentation of processed antigen to } \mathrm{T}_{\mathrm{H}} \text { lymphocytes, thereby facilitating the initiation of an immune } \\
\text { response (Goldsby and others, 2003; Bowen and others, 2006). Up-regulation of MHC genes has been } \\
\text { positively correlated with parasite load (Wegner and others, 2006), whereas down-regulation of MHC has } \\
\text { been associated with contaminant exposure (Dong and others, 1997). }\end{array}$ \\
\hline Mx1 & $\begin{array}{l}\text { The Mx1 gene responds to viral infection (Tumpey and others, 2007). Vertebrates have an early strong } \\
\text { innate immune response against viral infection, characterized by the induction and secretion of cytokines } \\
\text { that mediate an antiviral state, leading to the up-regulation of the MX-1 gene (Kibenge and others, 2005). }\end{array}$ \\
\hline CCR3 & $\begin{array}{l}\text { The chemokine receptor } 3 \text { binds at least seven different chemokines and is expressed on eosinophils, mast } \\
\text { cells (MC), and a subset of Th cells (Th2) that generate cytokines implicated in mucosal immune responses } \\
\text { (Gurish and others, 2002; Kringel and others, 2006). Up-regulation of CCR3 occurs in the presence of } \\
\text { parasites (Gurish and others, 2002; Kringel and others, 2006). }\end{array}$ \\
\hline
\end{tabular}




\begin{tabular}{|l|l|}
\hline \multicolumn{1}{|c|}{ Gene } & \multicolumn{1}{c|}{ Gene function } \\
\hline 5HTT & $\begin{array}{l}\text { The serotonin transport gene codes for an integral membrane protein that transports the neurotransmitter } \\
\text { serotonin from synaptic spaces into presynaptic neurons. This transport of serotonin by the SERT protein } \\
\text { terminates the action of serotonin and recycles it in a sodium-dependent manner (Jennings and others, 2006; } \\
\text { Squire and others, 2008). Increased transcription of 5HTT confers a low anxiety phenotype (Jennings and } \\
\text { others, 2006). }\end{array}$ \\
\hline CaM & $\begin{array}{l}\text { Calmodulin (CaM) is a small acidic Ca2+-binding protein, with a structure and function that is highly } \\
\text { conserved in all eukaryotes. CaM activates various Ca2+-dependent enzyme reactions, thereby modulating } \\
\text { a wide range of cellular events, including metabolism control, muscle contraction, exocytosis of hormones } \\
\text { and neurotransmitters, and cell division and differentiation (Chen and others, 2012). CaM has also been } \\
\text { reported to be a pivotal calcium metabolism regulator in the shell formation (Li and others, 2004). }\end{array}$ \\
\hline
\end{tabular}

Amplifications were conducted on a 7300 Real-time Thermal Cycler (Applied Biosystems, Foster City, CA). Reaction conditions were as follows: $50^{\circ} \mathrm{C}$ for 2 minutes, $95^{\circ} \mathrm{C}$ for 15 minutes, 40 cycles of $94^{\circ} \mathrm{C}$ for 30 seconds, $58^{\circ} \mathrm{C}$ for 30 seconds, $72^{\circ} \mathrm{C}$ for 31 seconds, an extended elongation phase at $72{ }^{\circ} \mathrm{C}$ for 10 minutes. Reaction specificity was monitored by melting curve analysis using a final data acquisition phase of 60 cycles of $65^{\circ} \mathrm{C}$ for 30 seconds and verified by direct sequencing of randomly selected amplicons (Bowen and others, 2007). Cycle threshold crossing values $\left(\mathrm{C}_{\mathrm{T}}\right)$ for the genes of interest were normalized to the S9 housekeeping gene.

\section{Statistical Analysis}

Analysis of qPCR data was conducted using normalized values, i.e., housekeeping gene threshold crossing (in qPCR, the point at which amplification is exponential) subtracted from the gene of interest threshold crossing for each animal (McLoughlin and others, 2006).

We used nonparametric statistical analyses because the cycle threshold $\left(\mathrm{C}_{\mathrm{T}}\right)$ measure of gene transcription provided by qPCR may have a highly skewed, non-normal distribution (McLoughlin and others, 2006). We conducted multivariate, multi-dimensional scaling (MDS) analysis in conjunction with cluster analysis for statistical and graphical representation of individual sea otters clustered by similarity in transcription and not by pre-defined groups such as location (Primer E, v6, Plymouth, UK). Statistical comparisons of individuals by clusters were made using SIMPROF, which is a similarity profile permutation test for significance among a priori, unstructured clusters of samples. We used ANOSIM (Primer E, Quest Research Limited, Auckland, New Zealand) one-way nonparametric, multivariate analysis to test for differences in gene transcription among locations, i.e., sea otters captured at or near the coastlines of Monterey Bay, Big Sur, San Luis Obispo County, and Santa Barbara County and the captive sea otters. We used two-way ANOSIM to examine within locations by sex and between or among capture years. Capture years varied by location (e.g., sea otters were captured only in 2012 at the San Luis Obispo region), thus analysis of all locations by years was not possible. Sea otters captured were biased towards adult animals (79\%), precluding any reliable characterization of juvenile gene transcription patterns, so age differences were not evaluated. Statistical significance was based on $p$ values $\leq 0.05$, and in the case of the ANOSIM tests, relative to the $R$ Statistic value. We further classified clusters into groups based on the number of genes markedly (i.e., three or more $\mathrm{C}_{\mathrm{T}}$ value) higher or lower than background values established for captive sea otters deemed clinically healthy (hereafter 'captives') (Bowen and others, 2012). Hereafter, 'high or low' followed by a gene identifier is used only to report those cases where gene transcription $\mathrm{C}_{\mathrm{T}}$ values were 'markedly' different. 
Additionally, we used gene transcript profiling based on per gene and per otter response correlation, using normalized qPCR data obtained from each individual otter, which were subjected to hierarchical clustering with complete linkage disequilibrium (Genesis, Graz, Switzerland); this was used to generate a heatmap profile of gene expression and physiologic health status.

\section{Movement, Behavior, Home Range, and Habitat Selection-A Synoptic Model}

To analyze habitat use and movement of sea otters at the southern end of their range, we utilized a synoptic model of space use to simultaneously describe individual home ranges and habitat selection behavior (Horne and others, 2008). The synoptic model results in a utilization probability surface for each individual study animal (a home range kernel, from which probabilistic isopleths can be calculated such as the $95 \%$ utilization polygon), but it achieves this by explicitly incorporating resource selection functions, allowing for insights into the role of various habitat features in determining the likelihood of use by sea otters (Horne and others, 2008; Slaght and others, 2013). The synoptic approach is based around a "null model" of utilization probability in the absence of any habitat-based covariates, but then builds on this null model by evaluating whether putative habitat covariates can improve the predictive ability of the model to describe space use by tagged animals. Previous examples of this approach have used maximum likelihood approaches to fit synoptic models, with a bivariate normal distribution as the "null model" (Horne and others, 2008; Slaght and others, 2013). We build on these previous case studies by developing a Bayesian hierarchal framework to estimate resource selection parameters for multiple animals simultaneously, and we relax assumptions of unimodal home ranges by using an adaptive kernel density function as the null model of space use, to accommodate multiple modes or "centers of use."

The use of bivariate normal probability functions for describing sea otter home ranges is problematic for two reasons: (1) many sea otters exhibit multi-modal patterns of space use, with resightings clustered around a number of distinct and geographically isolated centers of use (hereafter COU) (Ralls and others, 1996; Tinker, Doak, and others, 2006; Laidre, Jameson and others, 2009); and (2) the fact that sea otters utilize nearshore habitat along complex coastlines means that bivariate distributions fit to resighting locations tend to overlap large areas of land and/or very deep water (places where sea otters are not actually found). One approach that has been used to circumvent the first problem is to use non-parametric kernel density estimation techniques to fit a two-dimensional probability surface (Tinker, Doak, and others, 2006; Tinker, Doak, and others, 2008). Kernel density surfaces can easily accommodate multiple COU, however, they still often result in overlap of land. Laidre, Jameson and others (2009) presented a solution to this problem by fitting a univariate kernel density surface to sea otter resighting positions along a one-dimensional coastal axis. This approach is appropriate and effective for sea otter populations occurring along linear coastlines (such as Washington or California), although clearly it does not provide information about where an otter will be found along a second "inshore-offshore" dimension. However, because water depth is one of the habitat features that we expect will be predictive of sea otter use, and because depth varies strongly with distance to shore, we determined that a one-dimensional kernel density surface would provide a useful null model of home range behavior for tagged sea otters (Laidre, Jameson and others, 2009), and we then used the synoptic model to estimate selection gradients for water depth and other habitat features. The result of this combined approach is a two-dimensional home range utilization surface for each animal that does not overlap land, as well as individual and population-level estimates of habitat selection. 


\section{Synoptic Model Details}

Our first step was to utilize a locally adaptive kernel density algorithm (Shimazaki and Shinomoto, 2010) to fit probability surfaces to sea otter resighting positions along the one-dimensional coastal axis. The algorithm featured a variable the kernel bandwidth, optimized to avoid over-fitting in areas where resightings are sparse, resulting in a surface that is extremely faithful to the underlying dataset. We used the "As The Otter Swims" or "ATOS" line to describe coastal position, where ATOS units are defined as 500-m intervals along the 10-m bathymetry contour increasing from north to south, with ATOS $=0$ occurring at the southern end of the golden gate bridge and ATOS $=1111$ occurring at Pt. Conception (Tinker, Doak, and others, 2008). Each telemetry-based resighting location was assigned a decimal ATOS value by perpendicular interpolation to the ATOS line. The probability of occurrence of otter $i$ at any point $a$ on the ATOS line, $f_{0, i}(a)$, was derived from the fitted kernel density function for each individual (e.g., see fig. 8A). A critical value $f_{i}$, was defined for each animal to distinguish areas of utilization from non-use areas: specifically, numerical integration of $f_{0, i}(a)$ over all values of $a$ for which $f_{0, i}(a)>f_{i}$, described the $95 \%$ utilization region for each individual ( $f_{i}$, was solved for iteratively). We then calculated a number of statistics for each animal including (1) the 95\% utilization boundaries (the boundaries of all areas where $f_{0, i}(a)>f_{i}$, ), (2) the number of distinct centers of use (COU), defined as areas of utilization separated by distances of "non-utilization" of $>5 \mathrm{~km}$, (3) the distance between each COU, (4) the total length of coastline (measured along the ATOS line) contained within the $95 \%$ utilization region (over all $\mathrm{COU}$ ). We summarized these statistics for each individual and for males and females.

Having defined the null model of individual space utilization along the 1-dimensional ATOS axis, our next step was to develop a synoptic model of utilization that accounts for individual selection (preference or avoidance) of a suite of habitat variables, $H_{j}$. Following Horne and others (2008), for any point $x$ on the landscape we define $s_{i}(x)$ as the relative probability of occurrence for otter $i$, calculated as:

$$
s_{i}(x)=\frac{f_{0, i}(x) \prod_{j=1}^{J}\left(1+\beta_{i, j} \cdot H_{j}(x)\right)}{\int_{x}\left[f_{0, i}(x) \prod_{j=1}^{J}\left(1+\beta_{i, j} \cdot H_{j}(x)\right)\right]}
$$

where $f_{0, i}(x)$ is the null model probability of occurrence (one-dimensional kernel density function described above) and the fitted parameters $\beta_{i, j}$ determine the degree to which individual $i$ selects for or against each of $J$ habitat variables, $H_{j}$. If $\beta_{i, j}=0$ then habitat variable $H_{j}$ has no effect on the probability of occurrence of otter $i$, while if $\beta_{i, j}<0$ then increasing values of $H_{j}$ reduce the probability of occurrence, and if $\beta_{i, j}>0$ then increasing values of $H_{j}$ increase the probability of occurrence. Habitat variables can be either categorical $\left(H_{j}=0\right.$ or 1$)$ or continuous, in which case they are normalized to a $0-1$ scale. Note that the denominator for equation 1 acts as a normalizing factor, and for computational tractability it is estimated as a discreet summation over a large number of points distributed regularly over the landscape (Horne and others, 2008). In this case we created a grid of points at 100-m intervals within a band of habitat described by a $1.5 \mathrm{~km}$ wide buffer extending offshore from the low tide line. For each grid point $x$, we used ArcGIS to calculate the values of all habitat variables, $H_{j}(x)$, and we also calculated the corresponding ATOS value (by perpendicular interpolation), which was necessary in order to calculate $f_{0, i}(x)$. 


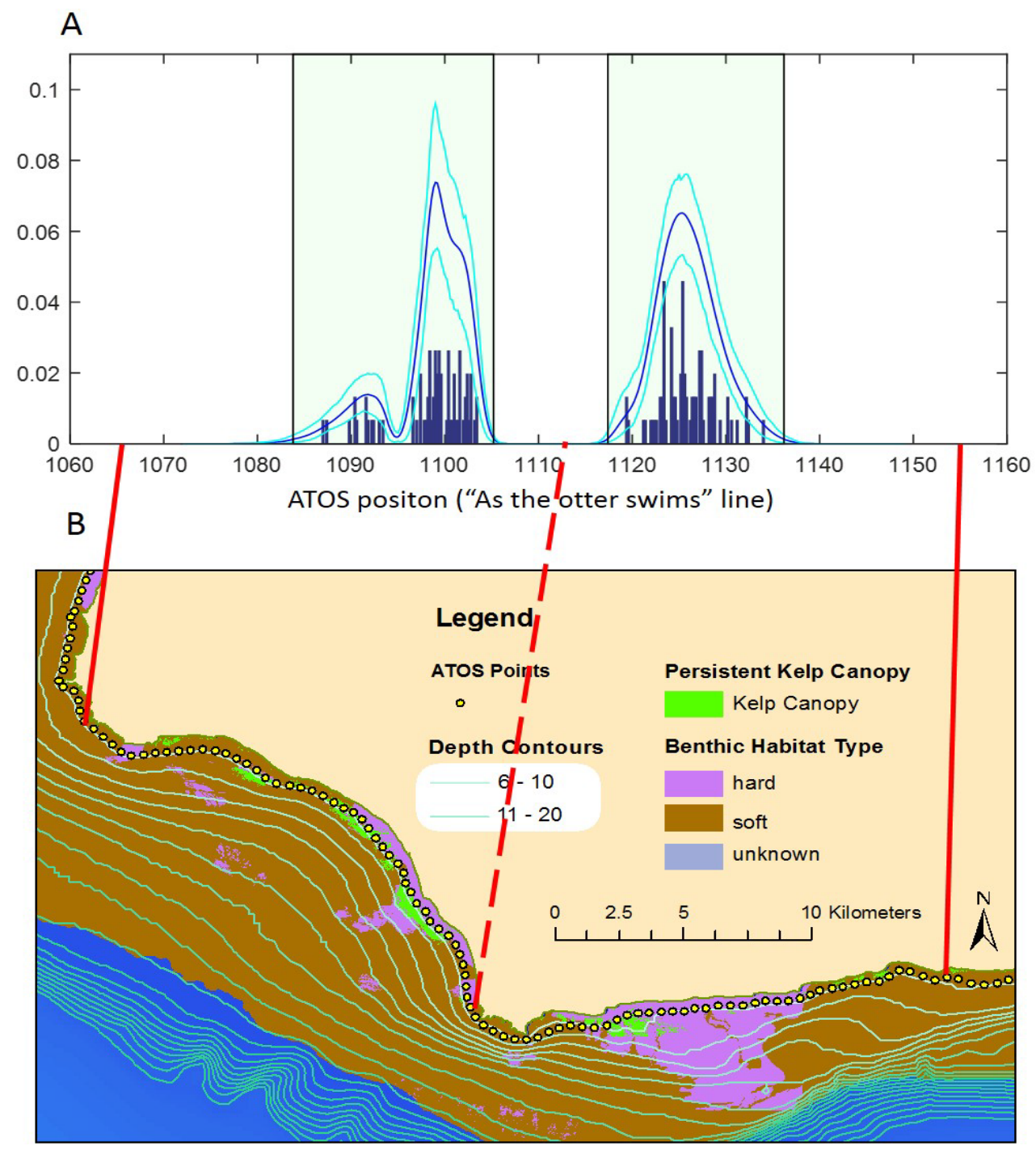

Figure 8. (A) Fitted kernel density function indicating the relative probability of an otter occurring at any point along the ATOS continuum from ATOS 1060 to 1160.(B) A map showing relevant ATOS points with connecting lines demonstrating where 3 index ATOS points match up in figure 7A. This map also shows the four key habitat variables (kelp canopy, proximity to kelp canopy, substrate type, and depth) used to predict sea otter probability of occurrence using the synoptic model of space use. 
We selected four habitat variables, which we believed could be important in determining sea otter utilization: the presence or absence of kelp canopy, proximity to kelp canopy, the type of benthic substrate (soft vs. hard sediment), and water depth (fig. 8B). Kelp canopy was determined for each coastal grid point in ArcGIS by a spatial join with the "persistent kelp canopy" GIS layers for central and southern California (California Department of Fish and Game, Marine Region), while water depth and substrate type were similarly derived using GIS layers provided by the California Seafloor Mapping Project (http://seafloor.otterlabs.org/csmp/csmp.html). We treated kelp canopy and substrate type as categorical variables: $H_{k}(x)=1$ if point $\mathrm{x}$ is in kelp canopy, 0 if not; $H_{p}(x)=1$ if point $\mathrm{x}$ is within $200 \mathrm{~m}$ of kelp canopy, 0 if not; $H_{s}(x)=1$ if point $\mathrm{x}$ has soft or unconsolidated benthic substrate, 0 if rocky or hard substrate. In the case of depth, $H_{D}(x)$, we knew from previous research (Thometz and others, 2016) that there is a continuous but nonlinear effect of depth on sea otter utilization, whereby sea otters tend to prefer intermediate depths and are less likely to occur in very shallow or very deep water (Lafferty and Tinker, 2014). We therefore used a modified selection function for depth, replacing the term $\left(1+\beta_{i, D^{\circ}}\right.$ $\left.H_{D}(x)\right)$ in equation 1 with the non-linear function $\delta_{i}(x)$, calculated as:

$$
\delta_{i}(x)=\left[\begin{array}{l}
{\left[1-\left(\frac{\beta_{i, D 1}-H_{d}(x)}{100}\right)^{2}\right]^{\beta_{i, D 2}} \text { if } H_{d}(x) \leq \beta_{i, D 1}} \\
{\left[1-\left(\frac{\beta_{i, D 1}-H_{d}(x)}{100}\right)^{2}\right]^{\beta_{i, D 3}} \text { if } H_{d}(x)>\beta_{i, D 1}}
\end{array} .\right.
$$

Equation 2 results in a hump-shaped probability function, the precise shape of which is determined by three parameters, $\beta_{i, D 1}, \beta_{i, D 2}$, and $\beta_{i, D 3}$. The first parameter, $\beta_{i, D 1}$, represents the "modal" (most likely) depth: the function will take on a maximum value of 1 when $H_{D}(x)=\beta_{i, D 1}$. The second parameter $\beta_{i, D 2}$ determines the rate at which the function decreases in value as depth drops below the modal depth, and the third second parameter $\beta_{i, D 3}$ determines the rate at which the function decreases in value as depth increases above the modal depth. Setting all three parameters to 0 results in $\delta_{i}(x)=1$ for all depths (i.e., the individual would be just as likely to be found at any depth).

We fit the $\beta$ parameters in equations 1 and 2 using Bayesian MCMC techniques, implemented using JAGS (“Just Another Gibbs Sampler") and MATLAB programming environments (Mathworks, Natick, MA). The "observed node" for the Bayesian analysis was $n_{i}(x)$, the number of resightings observed at grid point $x$ for individual $i$, which was represented in the MCMC simulations as a Poisson random variable:

$$
n_{i}(x) \sim \mathcal{P}(\lambda), \text { where } \lambda=N_{i} \cdot s_{i}(x)
$$

and where $N_{i}$ is the total number of resightings for individual $i$. We structured the model as a hierarchical model (Ponciano and others, 2009): population-level habitat selection parameters $\left(\beta_{j}\right)$ were estimated for the entire sample of animals, stratified by sex, and then individual-level parameters $\left(\beta_{i, j}\right)$ were estimated as normally distributed random effects with mean $\beta_{j}$ and standard deviation $\sigma_{j}$ (where $\sigma_{j}$ was also a fitted parameter). Population-level habitat selection parameters $\left(\beta_{j}\right)$ were initiated with uninformative normal priors, centered at 0 , except for the three depth parameters $\left(\beta_{D 1}, \beta_{D 2}\right.$, and $\left.\beta_{D 3}\right)$, which logically were constrained to $b e \geq 0$ and so were initiated with uninformative gamma priors. 
Precision parameters $\left(\tau_{j}=1 / \sigma_{j}^{2}\right)$ were also initiated with uninformative gamma priors. We summarized results by presenting $95 \%$ credible intervals $\left(\mathrm{CI}_{95}\right)$ for the posterior distributions of each $\beta_{j}$, and also express these in terms of odds ratios for habitat variables. We visually examined results using maps of individual home ranges (plotted as the density function $s_{i}(x)$, with associated $95 \%$ utilization isopleths), as well as "habitat preference maps" for males and females showing the expected degree of sea otter utilization by habitat type, independent of any single individual's home range behavior.

\section{Spatially Explicit Risk Analysis}

We used the results of the synoptic space use model to address primary objectives 3 and 4 of the study: to assess distribution, behavior and habitat use in proximity to natural seeps, and to develop a "risk of exposure" model for these seeps. For this analysis, we utilized a GIS-based dataset provided by BOEM, which showed the location of all known natural seeps, bubble vents, slicks and tar deposits in central and southern California. For the purposes of developing a risk of encounter model for sea otters, we filtered this dataset to focus on 26 natural gas and oil seeps (including bubble vents but excluding non-persistent slicks or tar deposits) in the coastal waters between Pt. Conception and Santa Barbara. For each of these locations, we determined the associated habitat variables (depth, distance from shore, benthic substrate type, presence/absence of kelp canopy), and based on these, we used the synoptic model results to estimate the probability of encounter by a male or female sea otter. Specifically, we used the posterior distributions of the population-level habitat selection parameters $\left(\beta_{j}\right)$, solved the synoptic model for each seep location, and then scaled the resulting estimates relative probability of occurrence of a sea otter, scaled relative to the maximum probability of occurrence at the modal depth and most preferred habitat types. Thus a seep occurring at the modal depth in the most preferred habitat type would have an expected encounter probability of 1, while seeps at all other depths and habitat types would have expected encounter probabilities of less than 1, with values approaching 0 for seeps that occurred in depths or habitat types with very low likelihoods of sea otter occurrence, based on the synoptic model results. We then created a GIS layer showing the relative likelihood off a sea otter encountering each seep, based on observed habitat selection behavior of our study animals.

\section{Dive Behavior and Time-Activity Budgets}

\section{Dive Behavior}

Archival data from TDRs were collected between March 2013 and March 2014. Archived data ranged from 40 days to more than 370 days, dependent on an individual otter's survival and battery life of the TDR, for a total of 40,182 hours of recorded data (table 3). Data from seven Santa Barbara study animals (three male, four female) were utilized for diving behavior analyses. To process the raw TDR datasets, we used established analytical procedures for sea otter TDR data (Thometz and others, 2016), details of which are provided in appendix A. The preprocessing steps resulted in a sample of 10,542 feeding bouts comprising 342,139 foraging dives. Because individual dives within a feeding bout tended to be auto-correlated with respect to some dive parameters, we used feeding bouts as the basic statistical unit in all further analyses, to insure independence. For each distinct feeding bout we calculated a series of 12 statistics: number of dives per bout, bout duration, mean dive depth, mean dive duration (DT), mean post-dive interval (PDI), variance in post-dive interval (Variance PDI), mean bottom time (BT), the mean ratio of bottom time to dive time (BT/DT), maximum dive depth, maximum dive duration, mean descent rate, and mean ascent rate. We summarize these statistics and compare them with the equivalent values for other populations in California from which TDR data have been collected (Big Sur $=\mathrm{BSR}$ and Monterey $=\mathrm{MBA})$. 
Table 3. Dive attributes of southern sea otters in five classes determined for three different California study sites.

[Values presented are means \pm standard error ( \pm SE) (in parentheses) with units as indicated in column headings. Site: BSR, Big Sur; MON, Monterey Bay; SBC, current study. Class: LP, female with large pup; MA, male; NP, female with no pup; SP, female with small pup; VP, female with very small pup. PDI: Post-dive interval. BT/DT: Ratio of bottom time to dive time]

\begin{tabular}{|c|c|c|c|c|c|c|c|c|c|c|c|c|c|c|}
\hline Site & Class & $\begin{array}{c}\text { Number } \\
\text { of } \\
\text { sea } \\
\text { otters }\end{array}$ & $\begin{array}{l}\text { Dives per } \\
\text { bout } \\
\text { (\#) }\end{array}$ & $\begin{array}{l}\text { Bout duration } \\
\text { (min) }\end{array}$ & $\begin{array}{c}\text { Dive depth } \\
\text { (meters) }\end{array}$ & $\begin{array}{c}\text { Dive } \\
\text { duration } \\
\text { (sec) }\end{array}$ & $\begin{array}{l}\text { PDI } \\
\text { (sec) }\end{array}$ & $\begin{array}{c}\text { Variance } \\
\text { PDI } \\
\text { (sec) }\end{array}$ & BT/DT & $\begin{array}{c}\text { Bottom } \\
\text { time } \\
(\mathrm{sec})\end{array}$ & $\begin{array}{c}\text { Maximum } \\
\text { depth } \\
\text { (meters) }\end{array}$ & $\begin{array}{l}\text { Maximum } \\
\text { duration } \\
\text { (min) }\end{array}$ & $\begin{array}{l}\text { Descent } \\
\text { rate }\end{array}$ & $\begin{array}{l}\text { Ascent } \\
\text { rate }\end{array}$ \\
\hline BSR & NP & 8 & $65.1(6.6)$ & $155.6(11.9)$ & $8.7(2.0)$ & $66.6(7.3)$ & $77.6(10.8)$ & $78.4(6.9)$ & $0.57(0.02)$ & $40.1(5.3)$ & $36.8(4.3)$ & $240.3(20.7)$ & $0.72(0.06)$ & $0.75(0.10)$ \\
\hline BSR & VP & 5 & $25.2(8.34)$ & $81.2(15.0)$ & $9.8(2.5)$ & $64.9(9.2)$ & $121.2(13.6)$ & $121.1(8.7)$ & $0.59(0.03)$ & $40.4(6.7)$ & $27.4(5.4)$ & $180.4(26.2)$ & $0.82(0.07)$ & $1.04(0.12)$ \\
\hline BSR & SP & 5 & $49.5(8.4)$ & $131.0(15.0)$ & $8.8(2.5)$ & $67.6(9.2)$ & $92.2(13.6)$ & $94.4(8.7)$ & $0.60(0.03)$ & $42.7(6.7)$ & $30.4(5.4)$ & $187.2(26.2)$ & $0.78(0.07)$ & $0.90(0.12)$ \\
\hline BSR & LP & 5 & $67.7(8.4)$ & $159.4(15.0)$ & $8.2(2.5)$ & $64.3(9.2)$ & 71.6(13.6) & $72.2(8.7)$ & $0.59(0.03)$ & $39.7(6.7)$ & $38.6(5.4)$ & $189.2(26.2)$ & $0.75(0.07$ & $0.80(0.12)$ \\
\hline BSR & MA & 2 & $44.9(13.2)$ & $143.7(23.7)$ & $13.0(3.9)$ & $79.2(14.6)$ & $121.9(21.5)$ & $96.3(13.7)$ & $0.59(0.05)$ & $50.2(10.5)$ & $80.5(8.5)$ & $270.0(41.4)$ & $0.85(0.11)$ & $0.92(0.19)$ \\
\hline MON & NP & 17 & $44.0(4.5)$ & $103.0(8.1)$ & 7.1(1.3) & $56.1(5.0)$ & $96.1(7.4)$ & $86.0(4.5)$ & $0.59(0.02)$ & $34.3(3.6)$ & $43.9(2.9)$ & $277.6(14.2)$ & $0.66(0.04)$ & $0.64(0.07)$ \\
\hline MON & VP & 12 & $24.6(5.4)$ & $68.4(9.7)$ & $9.7(1.6)$ & $58.2(6.0)$ & $123.9(8.8)$ & $115.2(5.6)$ & $0.61(0.02)$ & $36.7(4.3)$ & $26.0(3.5)$ & $177.3(16.9)$ & $0.76(0.05)$ & $0.97(0.08)$ \\
\hline MON & SP & 10 & $37.0(5.9)$ & $97.8(10.6)$ & $11.2(1.7)$ & $67.7(6.5)$ & $105.9(9.6)$ & $93.4(6.1)$ & $0.63(0.02)$ & $44.3(4.7)$ & $29.2(3.8)$ & $167.6(18.5)$ & $0.82(0.05)$ & $0.99(0.09)$ \\
\hline MON & LP & 10 & $54.6(5.9)$ & $129.0(10.6)$ & $9.9(1.7)$ & $67.5(6.5)$ & $80.8(9.6)$ & $72.6(6.1)$ & $0.64(0.02)$ & $44.8(4.7)$ & $40.2(3.8)$ & $210.6(18.5)$ & $0.72(0.05)$ & $0.81(0.09)$ \\
\hline MON & MA & 8 & $31.2(7.6)$ & $88.0(13.7)$ & $9.5(2.3)$ & $62.8(8.4)$ & $106.9(12.4)$ & $97.9(7.9)$ & $0.57(0.03)$ & $38.9(6.1)$ & $64.3(4.9)$ & $284.0(23.9)$ & $0.78(0.07)$ & $0.80(0.11)$ \\
\hline SBC & $\mathrm{NP}$ & 4 & $33.9(2.3)$ & $88.7(4.1)$ & $5.7(0.2)$ & $61.2(0.8)$ & $115.4(6.7)$ & $108.7(6.8)$ & $0.52(0.04)$ & $35.6(2.2)$ & $27.8(1.1)$ & $256.0(3.9)$ & $0.65(0.02)$ & $0.58(0.03)$ \\
\hline SBC & VP & 0 & $\mathrm{n} / \mathrm{a}$ & $\mathrm{n} / \mathrm{a}$ & $\mathrm{n} / \mathrm{a}$ & $\mathrm{n} / \mathrm{a}$ & $\mathrm{n} / \mathrm{a}$ & $\mathrm{n} / \mathrm{a}$ & $\mathrm{n} / \mathrm{a}$ & $\mathrm{n} / \mathrm{a}$ & $\mathrm{n} / \mathrm{a}$ & $\mathrm{n} / \mathrm{a}$ & $\mathrm{n} / \mathrm{a}$ & $\mathrm{n} / \mathrm{a}$ \\
\hline SBC & SP & 1 & 65.3 & 128.0 & 4.3 & 49.0 & 45.7 & 48.3 & 0.48 & 25.1 & 23.0 & 174.0 & 0.59 & 0.61 \\
\hline $\mathrm{SBC}$ & LP & 1 & 53.5 & 131.2 & 7.8 & 68.6 & 86.2 & 76.1 & 0.53 & 40.8 & 41.0 & 234.0 & 0.78 & 0.85 \\
\hline SBC & MA & 3 & $27.3(2.9)$ & 92.3(5.1) & $7.8(0.4)$ & $62.2(2.0)$ & $114.3(7.0)$ & $103.1(4.8)$ & $0.54(0.03)$ & $39.1(2.1)$ & $45.7(4.2)$ & $260(7.2)$ & $0.71(0.04)$ & $0.70(0.05)$ \\
\hline
\end{tabular}




\section{Time-Activity Budgets}

For each 24-hour period of each TDR record, we calculated a time-activity budget by summing the cumulative time spent in each of three activity states (see above for methods of classifying TDR records by activity state): $\mathrm{F}=$ feeding, $\mathrm{AO}=$ active-other, and $\mathrm{R}=$ inactive/resting (refer to Bodkin and others, 2007, for details). Figure 9 illustrates a typical 24-hour period from a TDR record, showing dive behavior and activity classifications. Time-activity budgets were then summarized for all otters, with each otter classified by sex, and for females, we also calculated activity budgets for each of four reproductive states: $\mathrm{NP}=$ no dependent pup, $\mathrm{VP}=$ very small dependent pup $(<3$ weeks $), \mathrm{SP}=$ small pup (3-10 weeks) and LP = large pup ( $>10$ weeks of age). We used two-way ANOVA to test for variation in percent time feeding due to sex and study site $(\mathrm{SBC}=$ current study, $\mathrm{BSR}=\mathrm{Big}$ Sur, MBA $=$ Monterey Bay, SNI = San Nicolas Island), as well as interactions between these main effects.

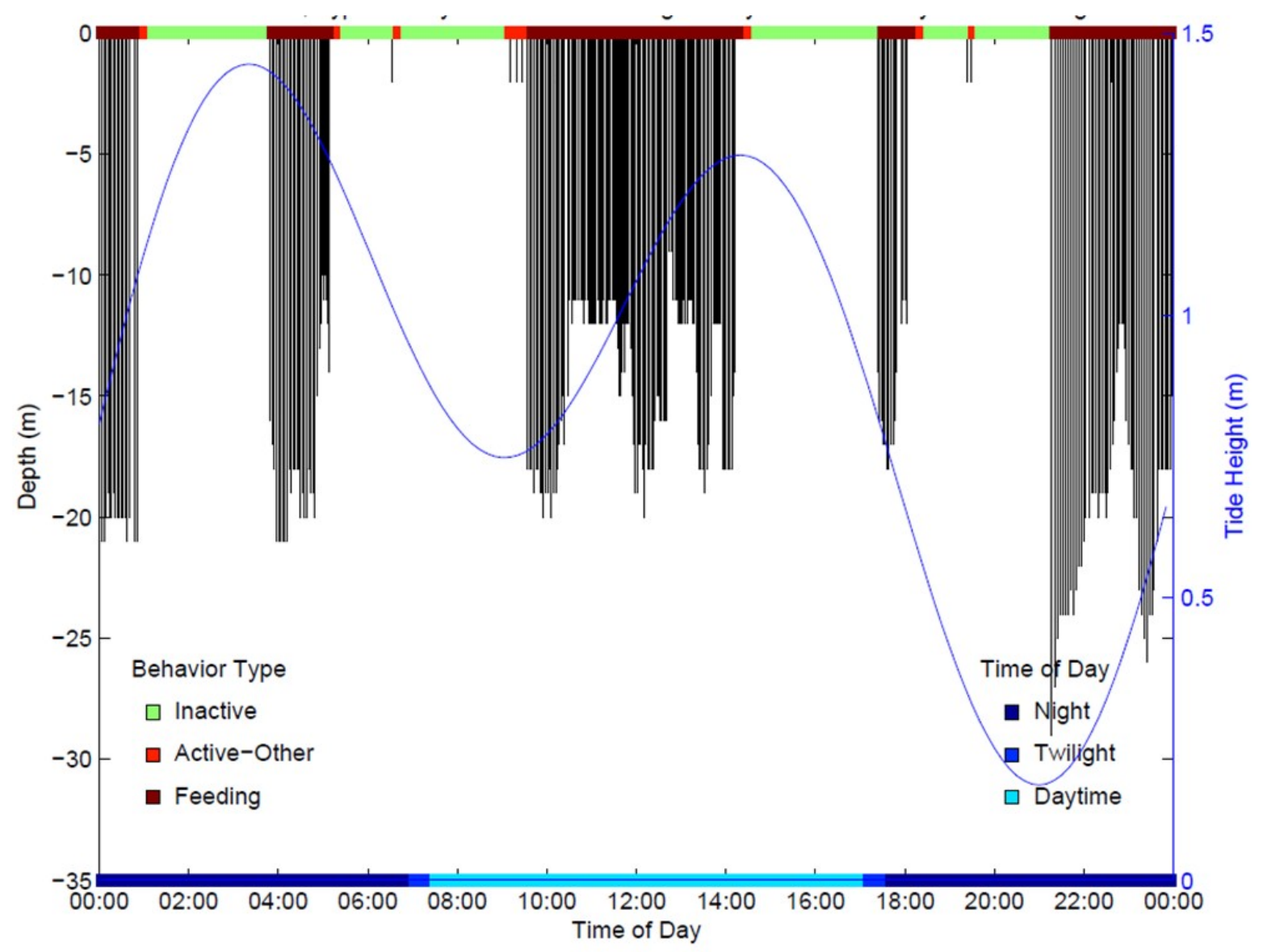

Figure 9. A typical 24-hr period from a TDR record showing dive activity (left vertical axis = depth below surface, black "drop-lines" represent dives to the indicated depth) and behavior classifications (top horizontal axis) based on dive activity. Time of day (bottom horizontal axis) and tide cycle (right vertical axis) have also been superimposed on this TDR trace. 


\section{Foraging Ecology and Tool Use}

We measured sea otter diet and foraging behavior following standardized field methods used in dozens of previous observational studies, as described previously in this report and documented in various publications (Watt and others, 2000; Tinker, Bentall, and others, 2008; Tinker and others, 2012). Due to the challenges of collecting foraging data from a boat on specific tagged sea otters, our protocols were modified to include the collection of foraging data on any feeding sea otters encountered in the study area and were not limited to tagged study animals. This modification was designed to acquire enough overall feeding data to statistically quantify the major prey items being consumed by sea otters in the Santa Barbara Channel. To obtain quantitative measures of the prevalence of various prey species in each individual's diet, field counts of prey capture frequency and prey shell diameter were converted to estimates of consumed biomass and caloric content using species-specific power functions for converting prey diameter to wet edible biomass and kcal per gram (Oftedal and others, 2007). These data were then analyzed using a Monte-Carlo procedure to estimate each individual's diet composition (in terms of the proportion of consumed biomass contributed by each prey taxa) and rate of energy gain, or kcal consumed per minute of feeding (Tinker, Bentall, and others, 2008). The Monte-Carlo procedure explicitly incorporates sampling uncertainty and adjusts for a number of recognized biases associated with direct observations of sea otter foraging (Tinker and others, 2012).

To account for inconsistencies in the taxonomic resolution of prey capture observations, all prey items were subsequently classified into 24 distinct functional groups of taxonomically and/or morphologically similar species, henceforth referred to as "prey types." We compared diet composition (proportional composition of diet for each prey type in terms of consumed biomass) and diet diversity (estimated as Shannon Weiner index, H') of sea otters in Santa Barbara Channel with that recorded for sea otters at four other study areas: CAM = Cambria/San Simeon (2001-2004), PTC = Point Conception (2001-2004), SNI = San Nicolas Island (2003-2005), MBA = Monterey Bay Area (2000-2014), and BSR $=$ Big Sur (2008-2011).

\section{Body Condition}

We measured the body mass, total length and tail length of each otter captured at the SBC study site (as described above). We estimated the age of each animal at time of capture based on patterns of tooth wear and on degree of fur "grizzle" around the head and neck. These "field age estimates" were validated for a subsample of animals for which "tooth age estimates" (estimates based on cementum analysis of extracted pre-molars) were also available, and age estimates using the two techniques have been found to be strongly correlated ( $\mathrm{R}>0.7$; Tinker and others, 2013), so we used field age estimates for all subsequent analyses (because tooth age estimates were not available for all study animals). We combined data from the current study (SBC 2012-2014, N = 44 otters having weight/length measurements) with data collected previously at six other study sites: CAM = Cambria/San Simeon (2001-2004), PTC = Point Conception (2001-2004), SNI = San Nicolas Island (2003-2005), MBA = Monterey Bay Area (2000-2014), and BSR = Big Sur (2008-2011). Our total sample size for analysis of body condition was 533 sea otters, ranging in estimated age from 6 months to 18 years. We assessed relative body condition for individual animals based on their residual values from average mass-at-age and length-at-age growth curves, following methods presented in previous studies (Laidre, Estes and others, 2009; Tinker and others, 2013) - detailed descriptions of the statistical methodology are provided in appendix A. We used two-way ANOVA to test for variation in body condition due to sex and study site $(\mathrm{SBC}=$ current study, $\mathrm{BSR}=\mathrm{Big}$ Sur, $\mathrm{MBA}=$ Monterey Bay, SNI = San Nicolas Island), as well as interactions between these main effects. 


\section{Survival and Reproduction}

We used the telemetry-based resighting data to estimate age- and sex-specific rates of survival and reproduction. We combined data from the 39 radio-tagged animals from this study with similar data collected in previous studies, for a total of 245 radio-tagged sea otters representing seven study sites: $\mathrm{SBC}=$ Santa Barbara Channel (current study), BSR = Big Sur (2008-2011), MON = Monterey Peninsula (2008-2011), CAM = Cambria/San Simeon (2001-2004), PTC = Point Conception (20012004), SNI = San Nicolas Island (2003-2005), and MB1 = Monterey Bay Area (2000-2004: note that MON and MB1 samples were spatially similar but temporally distinct, and so were treated as independent study sites). These seven sites varied both geographically and in terms of relative density, with SBC, SNI, and PTC representing recently established, low-density populations where prey resources were believed to be abundant during the period of study (Tinker, Bentall, and others, 2008; Tinker, and others, 2013), while the remaining four sites represent high-density, long-established sea otter populations. We estimated annual survival rates using a Bayesian instantaneous hazards model (Banerjee and others, 2003; Halstead and others, 2012), and incorporated potential effects for age, sex, body condition, reproductive status and study area. We evaluated models having different combinations of these fixed effectsm and used information theory (comparison of DIC values) to select the best supported model. The analytical methods have been reported elewhere (Tinker and others, 2013) and a detailed description of the statistical procedures can be found in appendix A. We estimated birth rates for females following established methods (Siniff and Ralls, 1991), and pup survival rates (also known as weaning success rated) using an instantaneous hazards model similar to that used for estimating survival of adults (see appendix A for details).

\section{Cause of Death-Necropsy Analyses}

All VHF transmitter-implanted otters from the Santa Barbara Channel Study that stranded, died, and where the carcass was recovered, plus any VHF transmitter-implanted animals that were euthanized during the course of the study (March 2012-2014), were submitted to the Marine Wildlife Veterinary Care and Research Center (MWVCRC) for postmortem examination. For animals that were recovered in an advanced state of postmortem decomposition, necropsy typically consisted of gross examination with photographs of any potential lesions. In some cases, tissues were collected for microscopic examination, and postmortem radiographs were performed to rule out gunshot as a cause of death, or to confirm and characterize bone lesions. For animals that were received in fresh or moderate postmortem condition, the examination process was more extensive, consisting of gross necropsy, microscopic examination of all major tissues, bacterial and/or fungal culture and biochemical analysis of feces, urine, liver or other samples for the presence of marine and freshwater biotoxins as funding permitted. Subsamples of many tissues, urine, serum, bile, pericardial fluid and cerebrospinal fluid were also cryoarchived at $-80^{\circ} \mathrm{C}$ to facilitate future diagnostic testing. Postmortem radiographs were performed for some cases, as directed by case history and presentation. Tissues examined on the microscope included: multiple lymph nodes, spleen, liver, pancreas, kidney, adrenal gland, bladder, reproductive tract, ovary, testis, epididymis, heart, aorta, peripheral nerves and ganglia, multiple skeletal muscles, diaphragm, tongue, tonsil, soft palate, esophagus, thyroid and parathyroid glands, thymus, omentum, pituitary gland, trigeminal nerve and ganglion, cerebrum, cerebellum, and brainstem. Microscopic examination of hematoxylin and eosin-stained tissues was completed by veterinary pathologists, and final reports were prepared that took into consideration information from gross and microscopic examination, bacterial culture, biochemical analysis and any available antemortem tests. 


\section{Results}

\section{Overview}

A total of 46 individual sea otters were captured in during the Santa Barbara Channel Study. Of those 46 otters, 39 were implanted with VHF radio transmitters and 34 also received TDRs. The 7 otters that did not receive any instruments were determined not to be good candidates for surgery due to a variety of reasons (palpably pregnant females, young pups, or extremely poor health). Summary information for all 46 animals captured for this study is provided in table 4.

During the initial capture and tagging of the study animals, it was noted that 3 individuals had tar on their fur. The veterinarian determined the fur was minimally compromised and not representative of a significant or hazardous oiling. At the time of capture, the overall impression was that these otters were in very good health. Subjective body condition appeared to be good and was confirmed with morphometric data collected during animal processing (see section, "Body Condition", for more details).

We collected 3,927 resightings of tagged study animals between March 2012 and June 2014 (table 5). Of the 23 tagged male sea otters, six remained within the study area, traveling frequently between the San Augustine/Cojo Cove areas south of Pt. Conception and the Jalama/Vandenberg areas north of Pt. Conception. Eight males were permanent residents in the San Augustine/Cojo Cove areas, never traveling north of Pt. Conception. Nine males made permanent (three) or periodic (six) moves north to other sites near Cambria or Estero Bay, with one male traveling to Big Sur. Of the 23 tagged female sea otters, all remained within the study area, and 16 made frequent moves between Cojo Cove (immediately southeast of Pt. Conception) and Jalama Beach or Vandenberg. Three females never left the Cojo Cove area, and one female never left the Jalama area. Figure 10 depicts typical home ranges for SBC study females, males with one center of use, and males with more than one center of use.

Of the 46 total sea otters that were captured and tagged, survival seemed relatively high compared to other locations in California. Throughout the 3-year duration of this study, a total of five study animals were confirmed deceased. Four of the five were likely victims of shark attack. An additional six otters went missing during the course of the study. These otters may have died, but no carcasses were recovered and no mortality signals were ever heard from their VHF radio transmitters. With the frequency of animals that regularly left the study area and made long travels north as far as Big Sur, it is possible that some or all of these otters may have simply moved to a different part of the California coast where they were not detected. For more detailed information, see section, "Survival and Reproduction."

Sixteen of the 23 tagged females had at least 1 pup during this study. Nine females gave birth to at least two pups, and one female had three pups during the 3-year study period. For more information on reproductive success, see section, "Survival and Reproduction." 
Table 4. Summary information for sea otters captured, sampled, tagged, and monitored as part of this study.

[Sex: f, female; m, male. Age class: a, adult; j, juvenile; p, pup, s, sub-adult. Age: estimate of age at time of capture. cm, centimeter; kg, kilogram]

\begin{tabular}{|c|c|c|c|c|c|c|c|c|c|}
\hline $\begin{array}{c}\text { Otter } \\
\text { identification } \\
\text { No. }\end{array}$ & $\begin{array}{c}\text { Capture } \\
\text { date }\end{array}$ & $\begin{array}{l}\text { General capture } \\
\text { location }\end{array}$ & $\begin{array}{l}\text { Capture site } \\
\text { latitude }\end{array}$ & $\begin{array}{l}\text { Capture site } \\
\text { longitude }\end{array}$ & Sex & $\begin{array}{l}\text { Age } \\
\text { class }\end{array}$ & $\begin{array}{l}\text { Weight } \\
\text { (kg) }\end{array}$ & $\begin{array}{l}\text { Total } \\
\text { length } \\
(\mathrm{cm})\end{array}$ & $\begin{array}{l}\text { Age in } \\
\text { years }\end{array}$ \\
\hline N-1460-12-S & 05-Mar-12 & Hollister Ranch & $34^{\circ} 26.971$ & $120^{\circ} 21.847$ & $\mathrm{~m}$ & $\mathrm{a}$ & 23.00 & 128.1 & 9.5 \\
\hline N-1461-12-S & 05-Mar-12 & Cojo Cove & $34^{\circ} 26.626$ & $120^{\circ} 24.173$ & $\mathrm{f}$ & $\mathrm{a}$ & 23.00 & 110.5 & 3.5 \\
\hline N-1462-12-S & 05-Mar-12 & Cojo Cove & $34^{\circ} 26.575$ & $120^{\circ} 24.757$ & $\mathrm{f}$ & $\mathrm{a}$ & 23.30 & 121.4 & 3 \\
\hline N-1463-12-S & 05-Mar-12 & Cojo Cove & $34^{\circ} 26.575$ & $120^{\circ} 24.757$ & $\mathrm{f}$ & a & 22.70 & 115.4 & 4.5 \\
\hline N-1464-12-S & 05-Mar-12 & Cojo Cove & $34^{\circ} 26.988$ & $120^{\circ} 21.629$ & $\mathrm{~m}$ & $\mathrm{a}$ & 29.00 & 124.0 & 6 \\
\hline N-1465-12-S & 05-Mar-12 & Cojo Cove & $34^{\circ} 26.988$ & $120^{\circ} 21.629$ & $\mathrm{~m}$ & a & 37.90 & 131.0 & 11 \\
\hline N-1466-12-S & 05-Mar-12 & Cojo Cove & $34^{\circ} 26.576$ & $120^{\circ} 24.200$ & $\mathrm{~m}$ & $\mathrm{a}$ & 27.10 & 122.8 & 8 \\
\hline N-1466-12-S & 15-Mar-13 & San Augustine & $34^{\circ} 27.033$ & $120^{\circ} 21.695$ & $\mathrm{~m}$ & $\mathrm{a}$ & 29.10 & 124.4 & 7 \\
\hline N-1466-12-S & 21-Mar-14 & Cojo Cove & $34^{\circ} 27.028$ & $120^{\circ} 24.578$ & $\mathrm{~m}$ & $\mathrm{a}$ & 28.10 & 125.0 & 8 \\
\hline N-1468-12-S & 07-Mar-12 & San Augustine & $34^{\circ} 27.125$ & $120^{\circ} 21.510$ & $\mathrm{~m}$ & a & 30.30 & 131.0 & 9 \\
\hline N-1469-12-S & 07-Mar-12 & San Augustine & $34^{\circ} 27.125$ & $120^{\circ} 21.510$ & $\mathrm{~m}$ & $\mathrm{a}$ & 27.40 & 126.0 & 5.5 \\
\hline N-1470-12-S & 07-Mar-12 & Cojo Cove & $34^{\circ} 26.640$ & $120^{\circ} 24.756$ & $\mathrm{f}$ & $\mathrm{a}$ & 21.10 & 120.4 & 9 \\
\hline N-1471-12-S & 05-Mar-12 & Cojo Cove & $34^{\circ} 26.575$ & $120^{\circ} 24.208$ & $\mathrm{f}$ & $\mathrm{a}$ & 22.90 & 124.0 & 9 \\
\hline N-1472-12-S & 07-Mar-12 & Cojo Cove & $34^{\circ} 26.640$ & $120^{\circ} 24.756$ & $\mathrm{f}$ & $\mathrm{a}$ & 21.20 & 116.5 & 4 \\
\hline N-1473-12-S & 08-Mar-12 & Cojo Cove & $34^{\circ} 26.601$ & $120^{\circ} 27.772$ & $\mathrm{~m}$ & $\mathrm{p}$ & 9.40 & 92.1 & \\
\hline N-1474-12-S & 08-Mar-12 & Cojo Cove & $34^{\circ} 26.601$ & $120^{\circ} 24.772$ & $\mathrm{f}$ & $\mathrm{a}$ & 20.50 & 117.0 & 5.5 \\
\hline N-1475-12-S & 08-Mar-12 & San Augustine & $34^{\circ} 26.995$ & $120^{\circ} 21.665$ & $\mathrm{~m}$ & $\mathrm{a}$ & 27.50 & 129.3 & 7 \\
\hline N-1476-12-S & 08-Mar-12 & San Augustine & $34^{\circ} 26.995$ & $120^{\circ} 21.665$ & $\mathrm{~m}$ & $\mathrm{a}$ & 25.90 & 122.8 & 6 \\
\hline N-1477-12-S & 08-Mar-12 & Cojo Cove & $34^{\circ} 26.400$ & $120^{\circ} 23.976$ & $\mathrm{f}$ & $\mathrm{a}$ & 21.60 & 118.5 & 8 \\
\hline N-1478-12-S & 08-Mar-12 & Cojo Cove & $34^{\circ} 26.632$ & $120^{\circ} 23.976$ & $\mathrm{f}$ & $\mathrm{p}$ & 13.10 & 100.4 & \\
\hline N-1479-12-S & 09-Mar-12 & Cojo Cove & $34^{\circ} 26.632$ & $120^{\circ} 23.976$ & $\mathrm{f}$ & $\mathrm{a}$ & 19.50 & 117.4 & 5 \\
\hline N-1480-12-S & 10-Mar-12 & San Augustine & $34^{\circ} 27.007$ & $120^{\circ} 21.919$ & $\mathrm{~m}$ & $\mathrm{a}$ & 33.30 & 126.9 & 11 \\
\hline N-1481-12-S & 10-Mar-12 & San Augustine & $34^{\circ} 27.053$ & $120^{\circ} 21.529$ & $\mathrm{~m}$ & $\mathrm{a}$ & 30.50 & 127.7 & 9 \\
\hline N-1482-12-S & 10-Mar-12 & San Augustine & $34^{\circ} 27.053$ & $120^{\circ} 21.529$ & $\mathrm{~m}$ & $\mathrm{a}$ & 23.00 & 119.0 & 5 \\
\hline N-1542-13-S & 11-Mar-13 & San Augustine & $34^{\circ} 27.666$ & $120^{\circ} 19.092$ & $\mathrm{f}$ & $\mathrm{a}$ & 31.10 & 124.5 & 6 \\
\hline N-1543-13-S & 11-Mar-13 & Cojo Cove & $34^{\circ} 26.879$ & $120^{\circ} 26.100$ & $\mathrm{f}$ & $\mathrm{a}$ & 19.80 & 118.5 & 5.5 \\
\hline N-1544-13-S & 11-Mar-13 & Cojo Cove & $34^{\circ} 26.879$ & $120^{\circ} 26.100$ & $\mathrm{f}$ & $\mathrm{p}$ & 6.50 & 80.0 & \\
\hline N-1545-13-S & 11-Mar-13 & Cojo Cove & $34^{\circ} 26.768$ & $120^{\circ} 25.518$ & $\mathrm{f}$ & $\mathrm{a}$ & 17.30 & 116.9 & 8 \\
\hline N-1546-13-S & 11-Mar-13 & San Augustine & $34^{\circ} 27.056$ & $120^{\circ} 21.529$ & $\mathrm{~m}$ & $\mathrm{a}$ & 32.90 & 132.0 & 7 \\
\hline N-1547-13-S & 12-Mar-13 & Cojo Cove & $34^{\circ} 26.875$ & $120^{\circ} 26.169$ & $\mathrm{f}$ & $\mathrm{a}$ & 18.30 & 113.6 & 6 \\
\hline N-1548-13-S & 12-Mar-13 & Cojo Cove & $34^{\circ} 26.825$ & $120^{\circ} 26.169$ & $\mathrm{~m}$ & $\mathrm{a}$ & 25.80 & 126.0 & 6 \\
\hline N-1548-13-S & 19-Mar-14 & Cojo Cove & $34^{\circ} 26.890$ & $120^{\circ} 26.198$ & $\mathrm{~m}$ & $\mathrm{a}$ & 27.00 & 124.5 & 9 \\
\hline N-1549-13-S & 12-Mar-13 & San Augustine & $34^{\circ} 27.103$ & $120^{\circ} 21.571$ & $\mathrm{~m}$ & $\mathrm{j}$ & 15.30 & 102.9 & \\
\hline N-1550-13-S & 12-Mar-13 & Cojo Cove & $34^{\circ} 26.759$ & $120^{\circ} 25.510$ & $\mathrm{f}$ & $\mathrm{a}$ & 26.10 & 117.5 & 6 \\
\hline N-1551-13-S & 12-Mar-13 & Cojo Cove & $34^{\circ} 26.825$ & $120^{\circ} 25.576$ & $\mathrm{f}$ & $\mathrm{a}$ & 23.40 & 123.0 & 7 \\
\hline N-1552-13-S & 12-Mar-13 & Cojo Cove & $34^{\circ} 26.825$ & $120^{\circ} 25.578$ & $\mathrm{~m}$ & $\mathrm{a}$ & 30.90 & 129.0 & 6 \\
\hline N-1552-13-S & 16-Mar-14 & Cojo Cove & $34^{\circ} 26.679$ & $120^{\circ} 25.335$ & $\mathrm{~m}$ & $\mathrm{a}$ & 34.00 & 130.1 & 7 \\
\hline
\end{tabular}




\begin{tabular}{|c|c|c|c|c|c|c|c|c|c|}
\hline $\begin{array}{c}\text { Otter } \\
\text { identification } \\
\text { No. }\end{array}$ & $\begin{array}{c}\text { Capture } \\
\text { date }\end{array}$ & $\begin{array}{c}\text { General capture } \\
\text { location }\end{array}$ & $\begin{array}{l}\text { Capture site } \\
\text { latitude }\end{array}$ & $\begin{array}{c}\text { Capture site } \\
\text { longitude }\end{array}$ & Sex & $\begin{array}{l}\text { Age } \\
\text { class }\end{array}$ & $\begin{array}{l}\text { Weight } \\
\text { (kg) }\end{array}$ & $\begin{array}{l}\text { Total } \\
\text { length } \\
(\mathrm{cm}) \\
\end{array}$ & $\begin{array}{l}\text { Age in } \\
\text { years }\end{array}$ \\
\hline N-1553-13-S & 13-Mar-13 & Cojo Cove & $34^{\circ} 26.928$ & $120^{\circ} 24.431$ & $f$ & $\mathrm{a}$ & 19.80 & 119.8 & 3 \\
\hline N-1554-13-S & 13-Mar-13 & Cojo Cove & $34^{\circ} 27.030$ & $120^{\circ} 21.726$ & $\mathrm{~m}$ & $\mathrm{a}$ & 29.20 & 128.0 & 8 \\
\hline N-1555-13-S & 13-Mar-13 & Cojo Cove & $34^{\circ} 26.520$ & $120^{\circ} 21.706$ & $\mathrm{f}$ & $\mathrm{a}$ & 23.90 & 118.0 & 9 \\
\hline N-1556-13-S & 13-Mar-13 & San Augustine & $34^{\circ} 27.074$ & $120^{\circ} 21.614$ & $\mathrm{~m}$ & $\mathrm{~s}$ & 17.50 & 110.1 & 2 \\
\hline N-1557-13-S & 13-Mar-13 & San Augustine & $34^{\circ} 27.074$ & $120^{\circ} 21.614$ & $\mathrm{~m}$ & $\mathrm{~s}$ & 21.80 & 115.4 & 2 \\
\hline N-1558-13-S & 14-Mar-13 & Cojo Cove & $34^{\circ} 27.126$ & $120^{\circ} 23.352$ & $\mathrm{~m}$ & $\mathrm{j}$ & 9.10 & 88.0 & 0.5 \\
\hline N-1559-13-S & 14-Mar-13 & Cojo Cove & $34^{\circ} 26.987$ & $120^{\circ} 24.637$ & f & $\mathrm{a}$ & 18.90 & 118.9 & 8 \\
\hline N-1560-13-S & 13-Mar-13 & San Augustine & $34^{\circ} 27.090$ & $120^{\circ} 21.897$ & $\mathrm{~m}$ & $\mathrm{a}$ & 32.10 & 128.3 & 9 \\
\hline N-1561-13-S & 13-Mar-13 & Cojo Cove & $34^{\circ} 26.776$ & $120^{\circ} 24.604$ & $\mathrm{f}$ & $\mathrm{a}$ & 20.90 & 118.5 & 10 \\
\hline N-1561-13-S & 19-Mar-14 & Cojo Cove & $34^{\circ} 26.517$ & $120^{\circ} 24.726$ & f & $\mathrm{s}$ & 20.00 & 117.0 & 9 \\
\hline N-1562-13-S & 15-Mar-13 & Cojo Cove & $34^{\circ} 26.775$ & $120^{\circ} 24.604$ & $\mathrm{f}$ & $\mathrm{a}$ & 25.30 & 115.4 & 8 \\
\hline N-1563-13-S & 18-Mar-13 & San Augustine & $34^{\circ} 25.277$ & $120^{\circ} 21.478$ & $\mathrm{~m}$ & $\mathrm{a}$ & 30.60 & 125.0 & 5 \\
\hline N-1564-13-S & 18-Mar-13 & San Augustine & $34^{\circ} 27.077$ & $120^{\circ} 21.478$ & $\mathrm{~m}$ & $\mathrm{a}$ & 31.00 & 128.5 & 7 \\
\hline N-1600-14-S & 19-Mar-14 & Cojo Cove & $34^{\circ} 26.517$ & $120^{\circ} 24.726$ & $\mathrm{f}$ & $\mathrm{p}$ & 4.60 & & \\
\hline
\end{tabular}

Table 5. Summary monitoring information for all tagged sea otters included in this study.

[Sex: f, female; m, male. Age class: a, adult; j, juvenile; $p$, pup, s, sub-adult. Number of resights: Total number of resights during the study. Status: Last known status (alive, dead, or unknown/missing) of each animal by the end of the study]

\begin{tabular}{llccrl}
\hline $\begin{array}{c}\text { Otter } \\
\text { Identification } \\
\text { No. }\end{array}$ & $\begin{array}{c}\text { General capture } \\
\text { location }\end{array}$ & Sex & $\begin{array}{c}\text { Age } \\
\text { class }\end{array}$ & $\begin{array}{c}\text { Number of } \\
\text { resights }\end{array}$ & Status \\
\hline N-1460-12-S & Hollister Ranch & m & a & 217 & Alive \\
N-1461-12-S & Cojo Cove & f & a & 18 & Unknown \\
N-1462-12-S & Cojo Cove & f & a & 158 & Unknown \\
N-1463-12-S & Cojo Cove & f & a & 139 & Alive \\
N-1464-12-S & Cojo Cove & m & a & 43 & Alive \\
N-1465-12-S & Cojo Cove & m & a & 121 & Dead \\
N-1466-12-S & Cojo Cove & m & a & 79 & Alive \\
N-1468-12-S & San Augustine & m & a & 261 & Alive \\
N-1469-12-S & San Augustine & m & a & 63 & Alive \\
N-1470-12-S & Cojo Cove & f & a & 180 & Unknown \\
N-1471-12-S & Cojo Cove & f & a & 39 & Dead \\
N-1472-12-S & Cojo Cove & f & a & 73 & Unknown \\
N-1473-12-S & Cojo Cove & m & p & 95 & Unknown \\
N-1474-12-S & Cojo Cove & f & a & 151 & Alive \\
N-1475-12-S & San Augustine & m & a & 9 & Dead \\
N-1476-12-S & San Augustine & m & a & 74 & Dead \\
N-1477-12-S & Cojo Cove & f & a & 146 & Unknown \\
N-1478-12-S & Cojo Cove & f & p & 165 & Unknown \\
N-1479-12-S & Cojo Cove & f & a & 156 & Unknown \\
& & & & &
\end{tabular}




\begin{tabular}{|c|c|c|c|c|c|}
\hline $\begin{array}{c}\text { Otter } \\
\text { Identification } \\
\text { No. }\end{array}$ & $\begin{array}{l}\text { General capture } \\
\text { location }\end{array}$ & Sex & $\begin{array}{l}\text { Age } \\
\text { class }\end{array}$ & $\begin{array}{c}\text { Number of } \\
\text { resights }\end{array}$ & Status \\
\hline N-1480-12-S & San Augustine & $\mathrm{m}$ & $\mathrm{a}$ & 19 & Dead \\
\hline N-1481-12-S & San Augustine & $\mathrm{m}$ & $\mathrm{a}$ & 139 & Alive \\
\hline N-1482-12-S & San Augustine & $\mathrm{m}$ & $\mathrm{a}$ & 41 & Dead \\
\hline N-1542-13-S & San Augustine & $\mathrm{f}$ & $\mathrm{a}$ & 18 & Unknown \\
\hline N-1543-13-S & Cojo Cove & $\mathrm{f}$ & $\mathrm{a}$ & 40 & Dead \\
\hline N-1544-13-S & Cojo Cove & $\mathrm{f}$ & $\mathrm{p}$ & 15 & Unknown \\
\hline N-1545-13-S & Cojo Cove & $\mathrm{f}$ & $\mathrm{a}$ & 52 & Unknown \\
\hline N-1546-13-S & San Augustine & $\mathrm{m}$ & $\mathrm{a}$ & 81 & Alive \\
\hline N-1547-13-S & Cojo Cove & $\mathrm{f}$ & $\mathrm{a}$ & 109 & Alive \\
\hline N-1548-13-S & Cojo Cove & $\mathrm{m}$ & $\mathrm{a}$ & 97 & Alive \\
\hline N-1549-13-S & San Augustine & $\mathrm{m}$ & $\mathrm{j}$ & 93 & Alive \\
\hline N-1550-13-S & Cojo Cove & $\mathrm{f}$ & $\mathrm{a}$ & 0 & Unknown \\
\hline N-1551-13-S & Cojo Cove & $\mathrm{f}$ & $\mathrm{a}$ & 27 & Unknown \\
\hline N-1552-13-S & Cojo Cove & $\mathrm{m}$ & $\mathrm{a}$ & 100 & Alive \\
\hline N-1553-13-S & Cojo Cove & $\mathrm{f}$ & $\mathrm{a}$ & 102 & Alive \\
\hline N-1554-13-S & Cojo Cove & $\mathrm{m}$ & $\mathrm{a}$ & 174 & Alive \\
\hline N-1555-13-S & Cojo Cove & $\mathrm{f}$ & $\mathrm{a}$ & 91 & Unknown \\
\hline N-1556-13-S & San Augustine & $\mathrm{m}$ & $\mathrm{s}$ & 43 & Alive \\
\hline N-1557-13-S & San Augustine & $\mathrm{m}$ & $\mathrm{s}$ & 72 & Alive \\
\hline N-1558-13-S & Cojo Cove & $\mathrm{m}$ & $\mathrm{j}$ & 81 & Alive \\
\hline N-1559-13-S & Cojo Cove & $\mathrm{f}$ & $\mathrm{a}$ & 89 & Alive \\
\hline N-1560-13-S & San Augustine & $\mathrm{m}$ & $\mathrm{a}$ & 29 & Unknown \\
\hline N-1561-13-S & Cojo Cove & $\mathrm{f}$ & $\mathrm{a}$ & 65 & Unknown \\
\hline N-1562-13-S & Cojo Cove & $\mathrm{f}$ & $\mathrm{a}$ & 0 & Unknown \\
\hline N-1563-13-S & San Augustine & $\mathrm{m}$ & $\mathrm{a}$ & 138 & Unknown \\
\hline N-1564-13-S & San Augustine & $\mathrm{m}$ & $\mathrm{a}$ & 25 & Unknown \\
\hline N-1600-14-S & Cojo Cove & $\mathrm{f}$ & $\mathrm{p}$ & 0 & Unknown \\
\hline
\end{tabular}




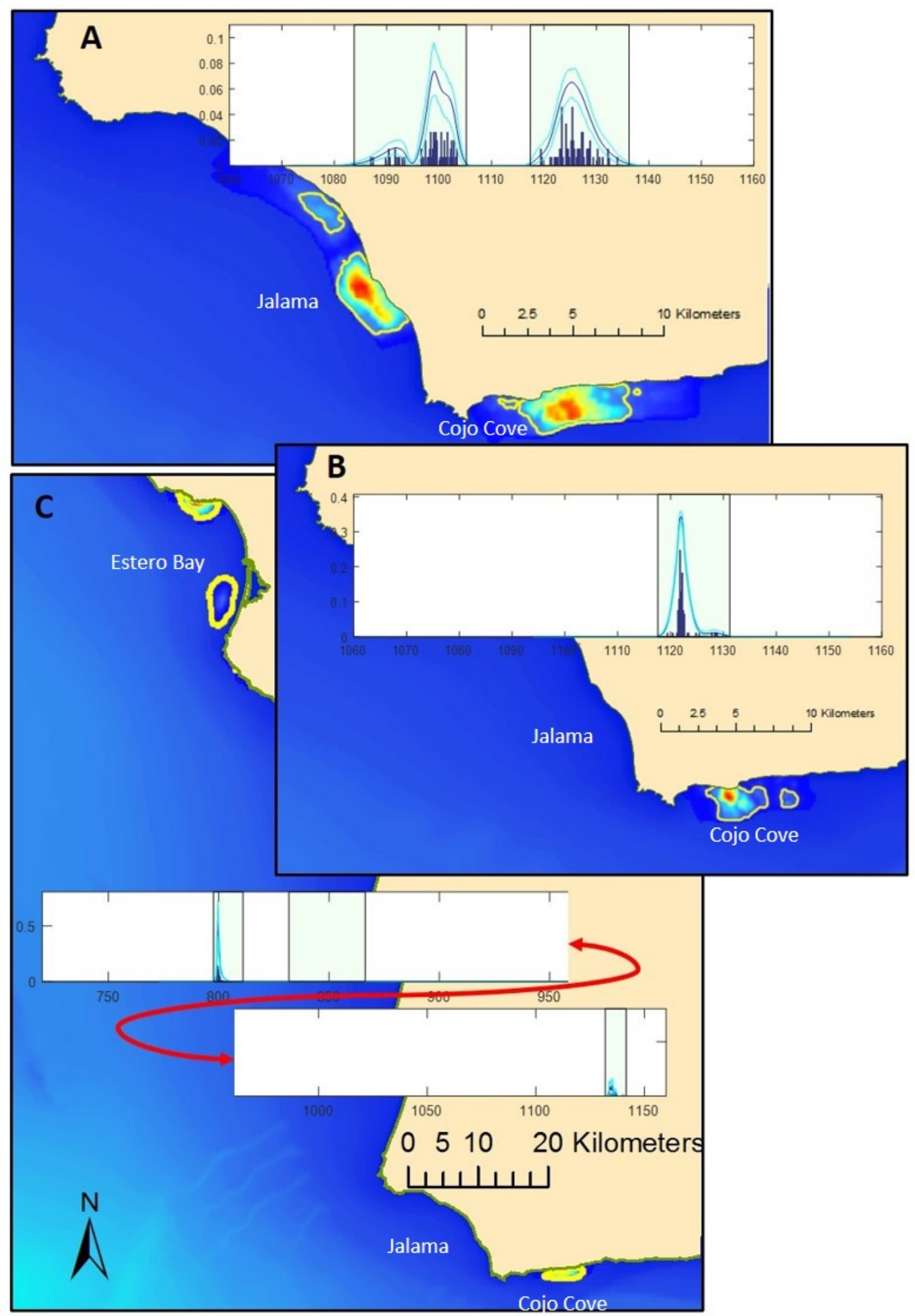

Figure 10. One-dimensional Kernel density estimates and associated two-dimensional synoptic model-based estimates of the home ranges for a typical female (A), a territorial male with a single center of use (B), and a transient male with multiple centers of use (C). Yellow lines indicate $95 \%$ isopleths, and warmer colors indicate higher probability of occurrence. 


\section{Gene Transcription}

\section{Transcript Pattern Analysis}

Transcription patterns were established for 180 sea otters from the central California coast. Sea otter gene transcription patterns differed among locations (ANOSIM, $p<0.001$, Global $R=0.21$, with 0 permuted statistics $>$ Global $R$ ). Pairwise tests indicated sea otters from the San Luis Obispo area differed significantly $(p<0.001)$ from the background captive values as well as all other areas; these differences were mainly influenced by San Luis Obispo area sea otters that had markedly lower transcription of HDC, THRB, IL10, and MX-1 than those from the other locations (table 6).

Sea otters from areas of Monterey Bay, Big Sur, or Santa Barbara did not differ from the captives $(p>0.14)$. However, transcription patterns of sea otters from Santa Barbara differed from those from Big Sur and Monterey $(p<0.001)$, which also differed significantly from one another $(p<0.002)$.

Santa Barbara area sea otters had markedly higher 5HTT and also low HDC and IL10 relative to sea otters from the other locations, and Monterey and Big Sur sea otters differed mainly in transcription of COX2 and CYT. The MDS analysis of gene transcription $\mathrm{C}_{\mathrm{T}}$ values depicts separations of which the denser mass of clusters included the captives, with the remaining otters diffusely clustered into smaller groups or single animal outliers (fig. 11). The captives were the only defined group that clustered tightly. The 3-D MDS depiction indicated a better fit (i.e., Stress $=0.10$ versus 0.14 for $2-\mathrm{D}$ ), and visual separation within the densest mass. SIMPROF analysis indicated highly significant $(p=0.001-0.007$; $79 \%$ of the clusters) or significant ( $p=0.01-0.05)$ separations among 33 clusters that included outliers.

Forty-one (23\% of total) sea otters comprising four clusters had transcription patterns similar to captives; differences among these clusters comprised mean or outlier $\mathrm{C}_{\mathrm{T}}$ values of targeted genes within three $\mathrm{C}_{\mathrm{T}}$ of clinically normal captives. The majority (27) of these animals were from the area near Big Sur, and the remainder from areas at Monterey Bay (11) or Santa Barbara Channel (3).

Qualifying the clusters into groups based on number of genes with markedly different $\mathrm{C}_{\mathrm{T}}$ than the captives, 6 clusters comprising 19 (11\% of total) sea otters separated into two subgroups, one with both elevated and low gene $C_{T}$ values and the other with elevated $C_{T}$ values relative to the captives. These were the only sea otters sampled that had transcription patterns that indicated reactive immune or defensive responses. A cluster including five sea otters from Santa Barbara had high 5HTT but low HDC and IL18, whereas one from Big Sur had high IL18 and low CYT and AHR. The remaining Monterey Bay area sea otter (ID 1117) in this group had the most concerning transcription pattern of any sea otter sampled in this study: high COX2, THR, IL10, DRB, MX1, and low HDC. The other subgroup had one sea otter with high IL18 and MX1, 7 Monterey Bay area sea otters with high CYT, and 1 Big Sur and 3 Santa Barbara sea otters with high MX1 and 5HTT.

All remaining clusters comprised average $\mathrm{C}_{\mathrm{T}}$ values that were markedly lower than those established for captives. Most of the sea otters that comprised this low transcription set were from the southern half of the sea otter range in California, i.e., San Luis Obispo area (63\%) and Santa Barbara (25\%, mostly animals that were captured in 2013), with $6 \%$ each from the northern sites of Big Sur and Monterey. 
Table 6. Geometric mean, cycle threshold (Ct) of 13 genes identified in free-ranging sea otters sampled in Monterey $(2009,2010)$, Big Sur (2008, 2009), San Luis Obispo (2012), Santa Barbara (2012, 2013), and in clinically normal captive reference animals sampled in 2008, 2009, or 2010.

[MON, Monterey Bay; SB, Santa Barbara; SLO, San Luis Obispo]

\begin{tabular}{|c|c|c|c|c|c|c|c|c|c|c|c|c|c|c|c|}
\hline & & $\mathrm{n}$ & HDC & COX2 & CYT & AHR & THRB & HSP70 & IL18 & IL10 & DRB & MX1 & CCR3 & $5 \mathrm{HTT}$ & CaM \\
\hline \multirow[t]{3}{*}{ CAPTIVES } & ALL & 17 & 5.90 & 6.78 & 2.41 & 11.01 & 13.30 & 9.62 & -1.11 & 13.71 & -0.78 & 10.99 & 4.59 & 10.97 & -1.06 \\
\hline & $\mathrm{M}$ & 7 & 6.92 & 7.81 & 2.77 & 11.00 & 13.94 & 9.35 & -1.90 & 13.90 & 1.20 & 11.25 & 4.44 & 10.70 & -1.43 \\
\hline & $\mathrm{F}$ & 10 & 5.28 & 6.14 & 2.19 & 11.01 & 12.87 & 9.82 & -1.10 & 13.57 & -0.58 & 10.81 & 4.69 & 11.17 & -0.97 \\
\hline $\mathrm{MON}$ & ALL & 30 & 6.62 & 5.72 & 1.92 & 10.07 & 13.59 & 10.99 & 1.33 & 13.77 & 0.70 & 12.31 & 4.83 & 11.56 & 0.29 \\
\hline \multirow[t]{4}{*}{ BIG SUR } & ALL & 51 & 6.64 & 8.18 & 3.60 & 10.73 & 13.48 & 10.57 & 1.84 & 13.69 & 0.61 & 11.90 & 4.81 & 12.00 & -0.21 \\
\hline & 2008 & 27 & 5.93 & 8.54 & 3.09 & 10.01 & 12.93 & 10.87 & 2.35 & 14.16 & 0.43 & 11.13 & 5.38 & 12.05 & -0.22 \\
\hline & 2009 & 12 & 6.56 & 7.96 & 3.16 & 11.56 & 13.04 & 10.73 & 1.13 & 12.20 & -0.72 & 12.91 & 4.78 & 11.74 & -0.18 \\
\hline & 2010 & 12 & 8.68 & 7.62 & 5.82 & 11.62 & 15.29 & 9.77 & 1.75 & 14.24 & 1.14 & 12.74 & 3.75 & 12.15 & -0.21 \\
\hline \multirow[t]{3}{*}{ SLO } & ALL & & 9.23 & 8.75 & 2.34 & 11.04 & 16.65 & 12.82 & 1.53 & 18.44 & 0.29 & 14.95 & 5.38 & 11.98 & 0.34 \\
\hline & $\mathrm{M}$ & 11 & 9.35 & 8.44 & 2.34 & 10.96 & 16.20 & 11.05 & 1.79 & 18.02 & -0.47 & 14.58 & 5.73 & 11.23 & -0.27 \\
\hline & $\mathrm{F}$ & 45 & 9.19 & 8.83 & 2.41 & 11.06 & 16.76 & 13.29 & 1.44 & 18.55 & 0.31 & 15.04 & 5.29 & 12.17 & 0.37 \\
\hline \multirow[t]{5}{*}{ SB } & ALL & 43 & 8.46 & 8.38 & 1.98 & 10.48 & 12.69 & 11.49 & 1.41 & 15.07 & 0.39 & 12.06 & 4.06 & 9.63 & 0.27 \\
\hline & $\mathrm{M}$ & 22 & 8.64 & 8.88 & 1.91 & 10.74 & 12.18 & 11.76 & 1.30 & 14.56 & 0.35 & 12.18 & 4.35 & 9.52 & 0.29 \\
\hline & $\mathrm{F}$ & 21 & 8.25 & 7.81 & 2.05 & 10.13 & 12.82 & 11.06 & 1.52 & 15.45 & -0.44 & 11.79 & 3.70 & 9.60 & 0.25 \\
\hline & 2012 & 20 & 8.70 & 7.89 & 2.49 & 10.01 & 10.73 & 10.32 & 1.16 & 12.59 & 0.36 & 10.54 & 3.39 & 8.16 & 0.24 \\
\hline & 2013 & 23 & 8.27 & 8.84 & 1.62 & 10.92 & 14.67 & 12.61 & 1.66 & 17.61 & 0.42 & 13.56 & 4.75 & 11.11 & -0.30 \\
\hline
\end{tabular}




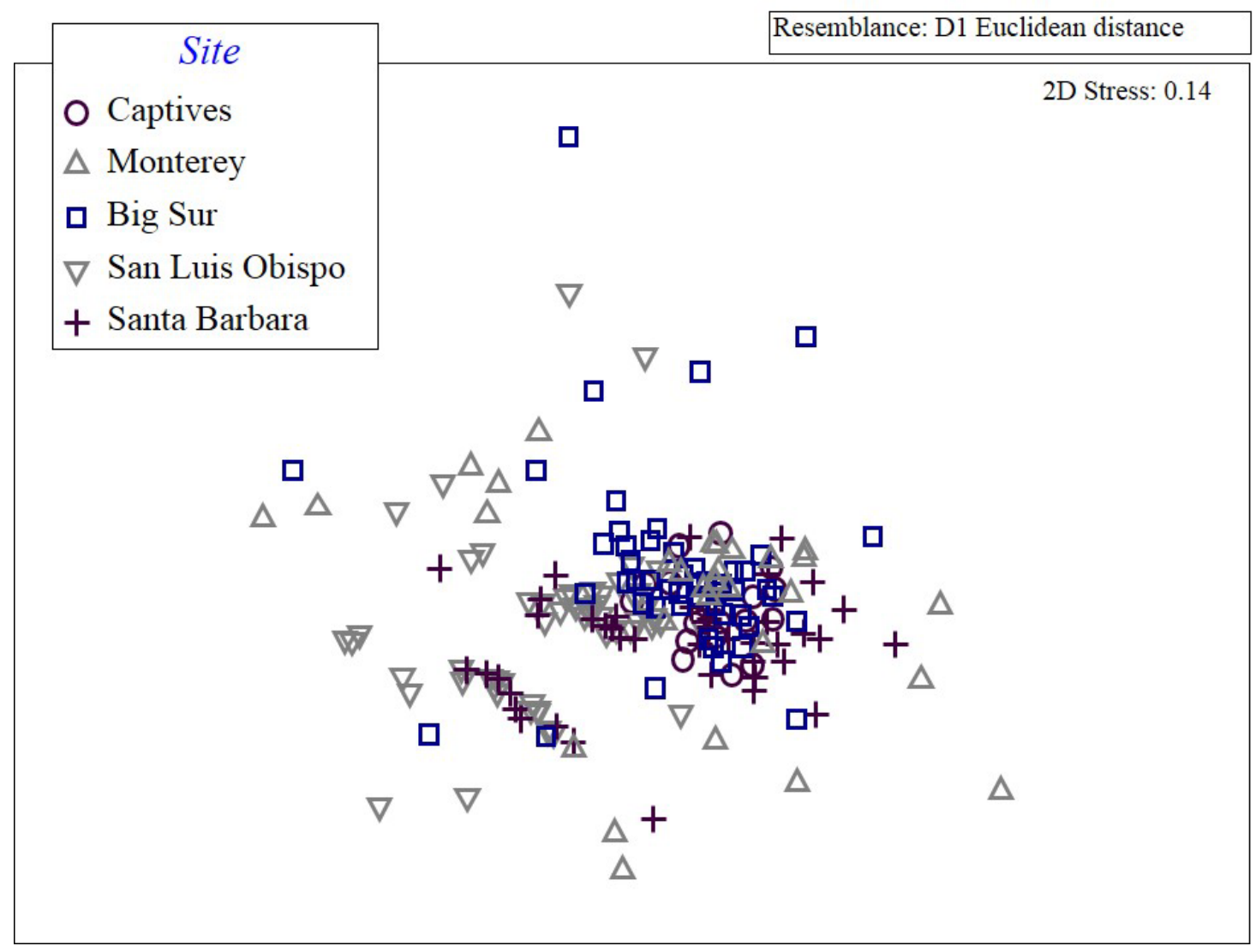

Figure 11. Results of the MDS analysis of gene transcription $C_{T}$ values showing a tight clustering in the "Captives" group with the remaining otters from other study areas diffusely clustered into smaller groups or single animal outliers.

In the 4-6 gene groups, 18 sea otters had 6 genes, 13 otters had 5 genes, and 20 otters had 4 genes of markedly lower transcription than those patterns determined for captives. Within these groupings, which 6,5 , or 4 genes were markedly lower varied among the 51 (28\% of total) sea otters. Within the 6-gene group, HSP 70, IL10, MX1, HDC, and COX2 were most evident, and then THR, AHR, IL18, or CCR3 comprised the 6th gene. Transcription of CYT, 5HTT, and CaM were similar to $\mathrm{C}_{\mathrm{T}}$ values of the captives. Within the 5-gene group low transcription of HSP70, IL18, and MX1 were prominent, followed by HDC, COX2, and IL10, and then CYT, CCR3, and 5HTT. In this group, only AHR and CaM were similar to the captives. Within the 4-gene group, low transcription of HDC, HSP70, IL10, and MX1 was evident for most (18 of 20) of these otters, whereas 2 otters had an altogether different set of 4 genes of low transcription. Transcriptions of THR, DRB, CCR3, 5HTT, and $\mathrm{CaM}$ were similar to those of the captives.

The next grouping of 69 sea otters (38\% of total) comprised 12 sea otters with 3 genes, 39 sea otters with 2 genes, or 18 otters with 1 gene markedly lower in transcription compare to captives. Sea otters from this set were more evenly spread across the range comprising 24 from San Luis Obispo, 19 from Santa Barbara, 16 from Big Sur, and 9 from Monterey Bay areas. Within the 3-gene group, most had low transcription of COX2, MX1, and either HDC or HSP70. In the 2-gene group, $72 \%$ of the sea otters had low transcription of IL18 but the 2nd gene was HDC, COX2, HSP70, IL10, or MX1. Within the 1-gene group, 15 sea otters had low transcription of HDC and the remaining 3 low transcription of IL10. 


\section{Within Site: Sex by Year Transcript Differences}

Multivariate analysis of transcription patterns of sex by years indicated no difference at Monterey Bay between 2009 and 2010 ( $p>0.53$; table 6). At Big Sur, transcription patterns among years differed $(2008,2009,2010 ; p<0.04)$ attributed to the difference between 2008 and $2010(\mathrm{p}<0.001)$, but did not differ by sex $(p>0.38)$. Although sexes were skewed toward more females captured, no marked or notable differences in transcription were apparent among the suite of genes. Transcription of HDC, CYT, AHR, and THRB decreased from 2008 to 2010 at Big Sur, while HSP70, IL18, and CCR3 increased but values were not markedly different from captive background levels.

Variation in transcription pattern at the Santa Barbara area were most evident where both sex $(p<0.04)$ and years $(p<0.001)$ differed (table 6$)$. Transcription of COX2 in female sea otters in 2012 was similar to captive levels but low in males in 2012 and in females in 2013. The genes THRB and 5HTT were markedly higher than captive values in both sexes in 2012, as well as CCR3 in females, but in 2013 these values were similar to background values. We found markedly (relative to background) low transcription of IL10 and MX-1 in 2013 than in 2012. Transcription of HDC in females captured in 2012 was similar to background but low to markedly lower by all other comparisons of sex or year.

\section{Gene Specific Patterns}

Cluster analyses did not reveal apparent transcription patterns in individual genes. Because of natural oil seeps near Santa Barbara, we examined elevated (relative to background captive levels) transcription of AHR and THRB among the sampled sea otters. Twenty-six sea otters had high $\left(\geq 2 \mathrm{C}_{\mathrm{T}}\right.$ value difference) to markedly higher AHR transcription. These animals were from areas of Monterey Bay (7), Big Sur (8), and Santa Barbara (8), with a few (3) from San Luis Obispo. Similarly, 26 sea otters had elevated transcription of THRB, and in this instance, 17 of these animals were from Santa Barbara, 6 from Big Sur, and 3 from Monterey Bay. Also, we found that IL10 was elevated in 26 sea otters (10 Big Sur, 8 Santa Barbara, 7 Monterey Bay, 1 San Luis Obispo). Only 19\% (5) of these sea otters had elevated transcription of all three genes, and 1 additional animal had 2 of these genes with elevated transcription.

\section{Heatmap Pattern Analysis}

Hierarchical cluster analysis was conducted using individual sea otter transcription data (fig. 12). Profile responses were successful in identifying transcriptional differences between capture locations and years, and yielded varying sized clusters of sea otters consisting of up to $100 \%$ of otters from single populations and time points. The largest clusters comprised San Luis Obispo and Santa Barbara 2013 otters. Otters from Monterey Bay (2009), Big Sur (both years), Santa Barbara 2012, and captive also dominated clusters. 


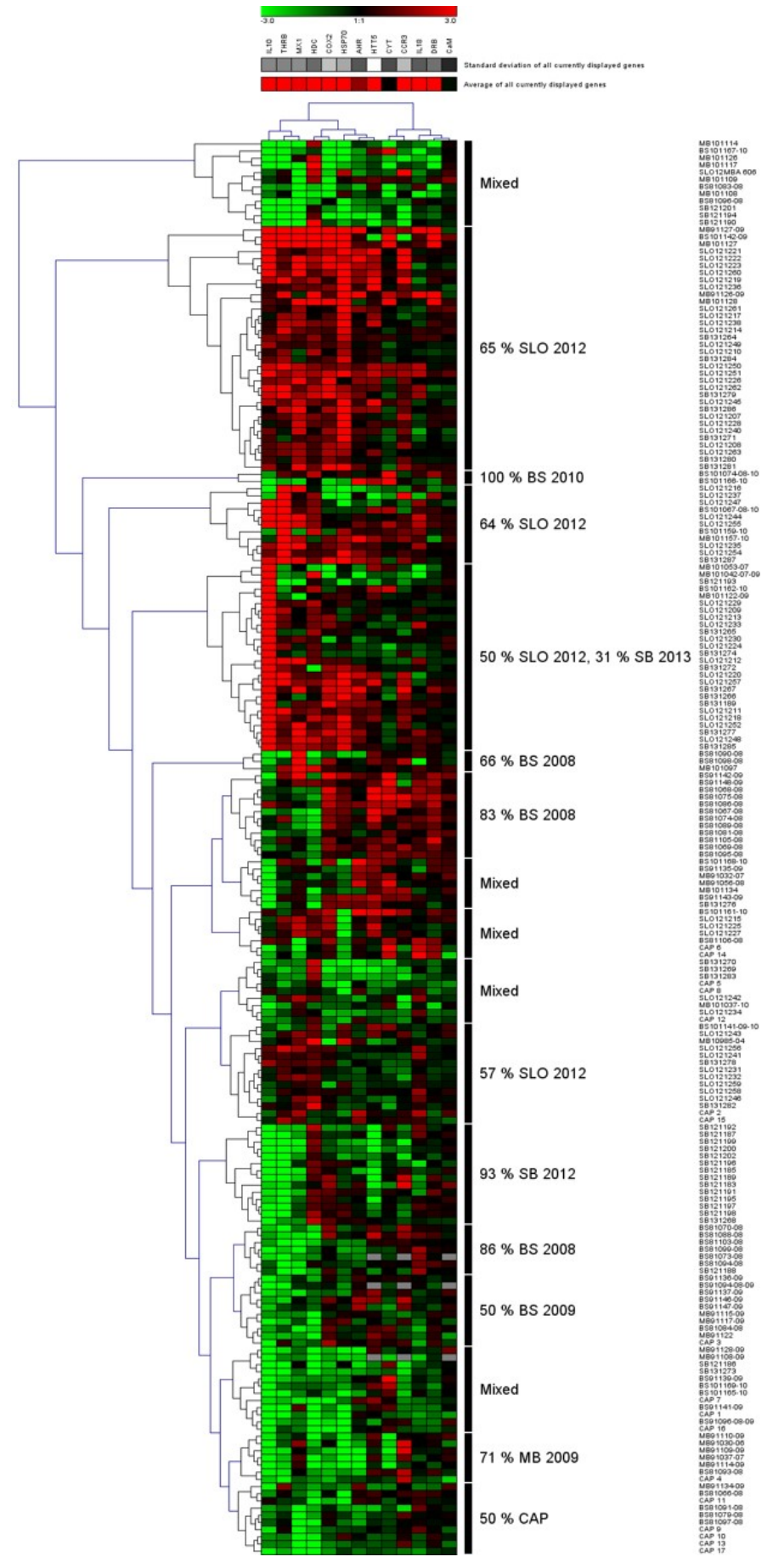

Figure 12. A hierarchical cluster analysis conducted using individual sea otter transcription data. 


\section{Movement Behavior, Home Range, and Habitat Use}

Sea otters showed considerable variation in range use patterns (table 7), although some general trends were evident. Almost all females (88\%) had two centers of use (fig. 13A), one just to the south of Pt. Conception in the Cojo Cove area, and one just to the north of Pt. Conception in the Jalama Beach area (e.g., see fig. 8A). The average number of COU for males was $1.8( \pm 0.79)$, but this value was more variable than for females, with almost equal numbers of individuals having 1, 2, or 3 centers of use (fig. 13B). The average distance between COU for females was $6.5 \mathrm{~km}( \pm 1.76)$, while for males with multiple centers of use the average distance between COU was $120.1 \mathrm{~km}( \pm 77.06)$, and this distance was far more variable than for females (fig. 13C-D). On average, females $95 \%$ home range polygons incorporated $19.3 \mathrm{~km}$ of coastline $( \pm 4.83)$ and spanned $25.4 \mathrm{~km}( \pm 6.09)$ from the northernmost to southernmost point of use (fig. 14A). In contrast, males 95\% home range polygons incorporated 28.4 $\mathrm{km}$ of coastline $( \pm 28.96)$ and spanned an average of $97.9 \mathrm{~km}( \pm 100.31)$ from the northernmost to southernmost point of use, although the distribution of range span lengths among males was distinctly bi-modal (fig. 14B).

The synoptic model produced estimated home range distributions for each animal that effectively captured the spatial extent of resightings and at the same time reflected individual habitat selection behavior. Figure 10 illustrates the typical home range density surfaces and 95\% isopleths for a typical female (fig. 10A), a male with one center of use (fig. 10B), and a male with multiple centers of use (fig. 10C).

The synoptic model fitting also produced habitat selection parameters for females and males. Females had a modal depth of $12.7 \mathrm{~m}\left(\mathrm{CI}_{95}=10.4-14.9\right)$, with gradually declining probability of use inshore and offshore of this modal depth (fig. 15A). At $50 \mathrm{~m}$ of depth the probability of occurrence was approximately $40 \%$ that of the modal depth and this probability dropped to approximately $0 \%$ by $80 \mathrm{~m}$. Females showed significant habitat preferences based on kelp canopy and bottom type (fig. 16): they were on average $3.1 \mathrm{X}$ more likely to be found inside kelp canopy as opposed to outside $\left(\mathrm{CI}_{95}=2.7-\right.$ 3.6X). When outside kelp canopy they were $2 \mathrm{X}$ more likely to be in close proximity to kelp than they were to be distant from kelp $\left(\mathrm{CI}_{95}=1.7-2.3 \mathrm{X}\right)$, and they were $1.8 \mathrm{X}$ more likely to be over rocky substrate than over soft substrate $\left(\mathrm{CI}_{95}=1.3-5.5 \mathrm{X}\right)$. These parameter values were combined with GIS layers of the associated habitat variables to produce a habitat utilization map (fig. 17), representing spatial variation in the expected probability of utilization by female sea otters after removing the home range centralizing tendency of any one individual.

Habitat selection by males was generally similar to that of females, although there were some important differences. Males had a deeper modal depth than females of $16.1 \mathrm{~m}\left(\mathrm{CI}_{95}=13.1-18.8\right)$, with gradually declining probability of use inshore and offshore of this modal depth (fig. 15B). At $50 \mathrm{~m}$ of depth the probability of occurrence was approximately $52 \%$ that of the modal depth, and this probability decreased to approximately $5 \%$ at $80 \mathrm{~m}$. As with females, males showed significant preferences based on kelp canopy, but unlike females they did not show differences in use based on bottom type $(p>0.05)$. Males were on average $6.8 \mathrm{X}$ more likely to be found inside kelp canopy as opposed to outside $\left(\mathrm{CI}_{95}=\right.$ 1.8-10.2X), and when outside kelp canopy they were 4.9X more likely to be in close proximity to kelp than they were to be distant from kelp $\left(\mathrm{CI}_{95}=4.2-5.7 \mathrm{X}\right)$. These parameter values were combined with GIS layers of the associated habitat variables to produce a habitat utilization map (fig. 18), representing spatial variation in the expected probability of utilization by male sea otters after removing the home range centralizing tendency of any one individual. 
Table 7. Statistics on individual home ranges, including number of distinct.

["Centers of Use" (COU), number of km of coastline (measured along the $10 \mathrm{~m}$ depth contour) included within the $95 \%$ utilization distribution for each animal, cumulative distance in between all COUs, and the total distance of coastline spanned by all COUs]

\begin{tabular}{|c|c|c|c|c|}
\hline SEX/OTTER ID & \# COU & $\begin{array}{l}\text { LINEAR RANGE } \\
\text { SIZE (KM) }\end{array}$ & $\begin{array}{l}\text { TOTAL INTER-COU } \\
\text { DISTANCE (KM) }\end{array}$ & RANGE SPAN (KM) \\
\hline \multicolumn{5}{|l|}{ FEMALES } \\
\hline F7-593_1193 & 2 & 13.8 & 5.6 & 19.4 \\
\hline F7-595 1282 & 2 & 21.8 & 7.0 & 28.8 \\
\hline F6-690 1284 & 2 & 25.8 & 6.8 & 32.6 \\
\hline F6-576_1186 & 1 & 9.2 & & 9.2 \\
\hline F6-370_1192 & 2 & 17.7 & 5.0 & 22.7 \\
\hline F6-345 1196 & 2 & 21.1 & 6.2 & 27.3 \\
\hline F6-181_1194 & 2 & 22.5 & 5.7 & 28.2 \\
\hline F6-068_1276 & 2 & 15.2 & 6.1 & 21.3 \\
\hline F5-493_1200 & 2 & 17.0 & 6.8 & 23.8 \\
\hline F5-457 1201 & 2 & 16.2 & 6.3 & 22.5 \\
\hline F5-402_1278 & 2 & 25.5 & 7.3 & 32.8 \\
\hline F5-332_1269 & 2 & 14.9 & 5.5 & 20.4 \\
\hline F5-282 1185 & 2 & 20.7 & 5.8 & 26.5 \\
\hline F5-194- 1199 & 3 & 17.5 & 12.4 & 29.9 \\
\hline F5-152_1267 & 2 & 25.9 & 5.3 & 31.2 \\
\hline F5-082_1265 & 2 & 23.2 & 5.9 & 29.1 \\
\hline \multicolumn{5}{|l|}{ MĀ̄ES } \\
\hline M7-721_1280 & 2 & 35.6 & 21.6 & 57.2 \\
\hline M7-709_1286 & 3 & 43.6 & 153.0 & 196.6 \\
\hline M7-643-1188 & 3 & 27.9 & 143.0 & 170.9 \\
\hline M7-618 1273 & 1 & 6.9 & & 6.9 \\
\hline M6-618_1187 & 3 & 83.4 & 214.6 & 298.0 \\
\hline M6-481_1190 & 2 & 11.9 & 14.0 & 25.9 \\
\hline M6-330- 1198 & 1 & 13.9 & & 13.9 \\
\hline M6-278_1195 & 1 & 21.1 & & 21.1 \\
\hline M6-210_1191 & 2 & 12.9 & 15.2 & 28.1 \\
\hline M6-193_1189 & 1 & 10.3 & & 10.3 \\
\hline M6-043- 1204 & 2 & 113.3 & 105.5 & 219.4 \\
\hline M6-056 1268 & 1 & 16.2 & & 16.2 \\
\hline M5-745 1279 & 3 & 61.2 & 80.8 & 142.0 \\
\hline M5-394_1203 & 2 & 28.6 & 193.8 & 222.4 \\
\hline M5-306 1277 & 2 & 10.1 & 185.6 & 195.7 \\
\hline M5-258_1270 & 1 & 7.1 & & 7.1 \\
\hline M5-231_1183 & 2 & 17.3 & 193.6 & 210.9 \\
\hline M4-892 1271 & 1 & 8.4 & & 8.4 \\
\hline M4-588 1281 & 1 & 9.0 & & 9.0 \\
\hline
\end{tabular}



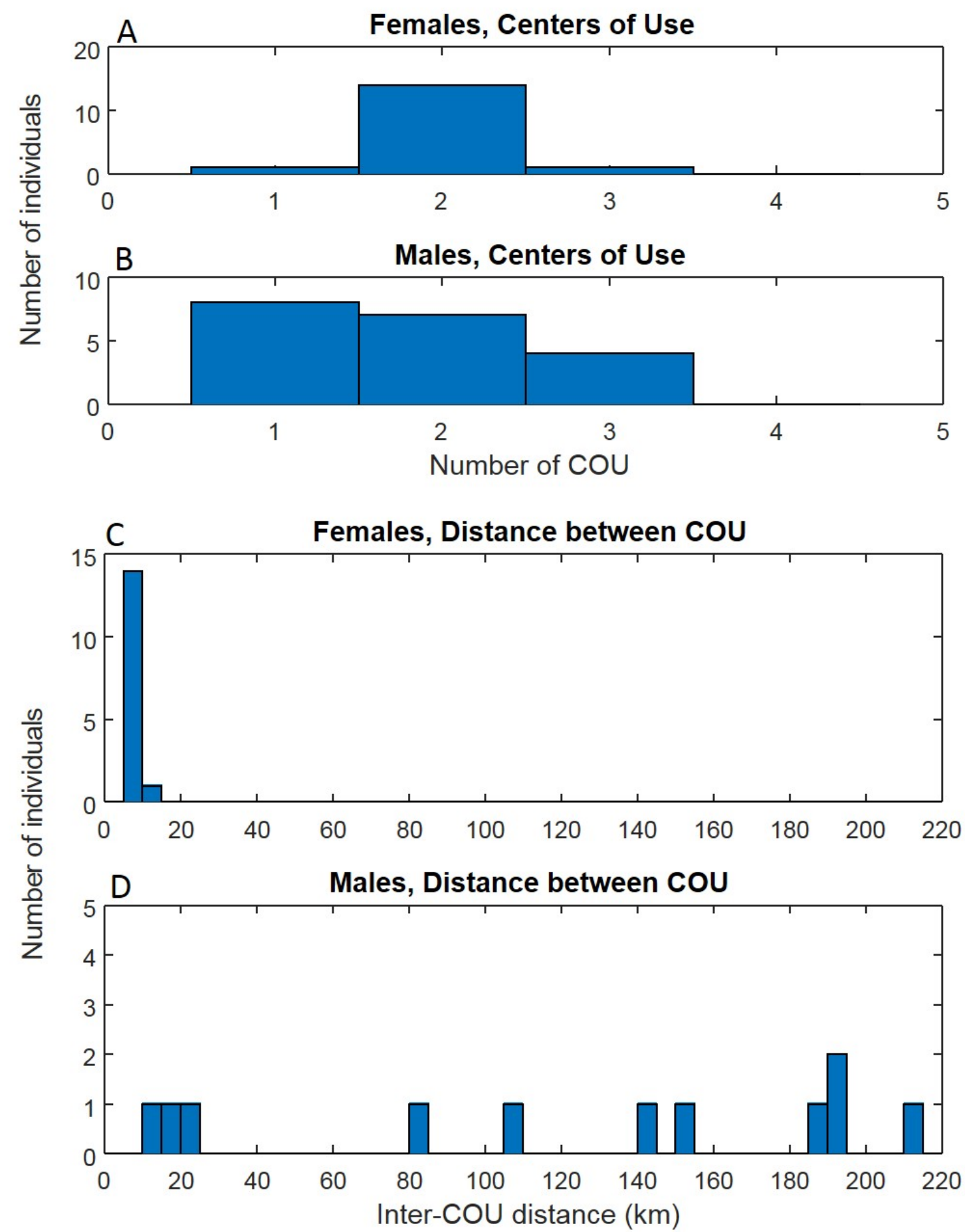

Figure 13. Histograms showing number of distinct centers of use (COU) for females (A) and males (B). Eightyeight percent of females had two "centers of use" while males exhibited much more variability. Histograms showing average distance between "centers of use" for females (C) and males (D). 


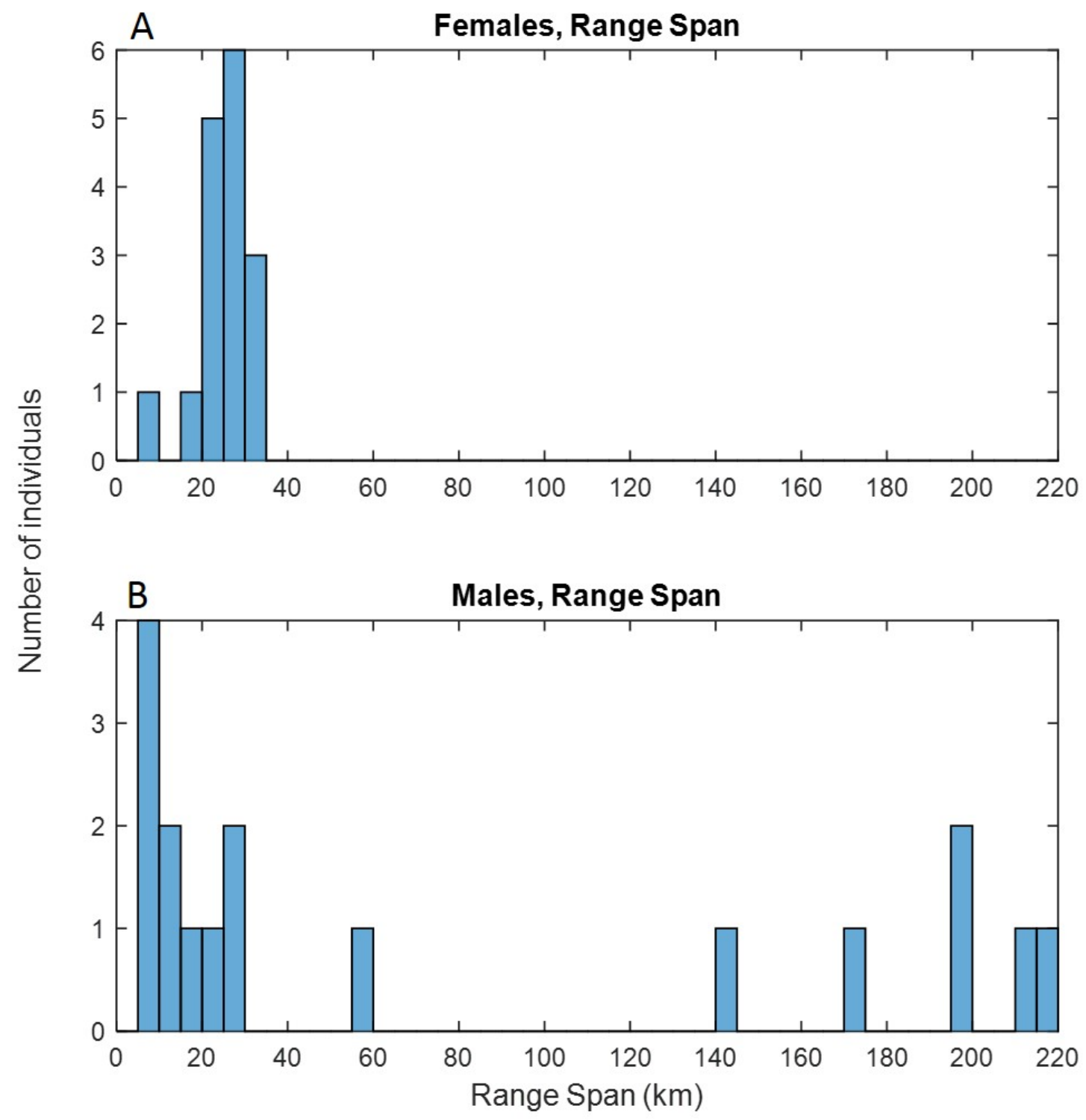

Figure 14. Graphs showing range spans of female sea otter (A) and male sea otter (B) home ranges in the Santa Barbara Channel study area showing distinct bi-modality. 


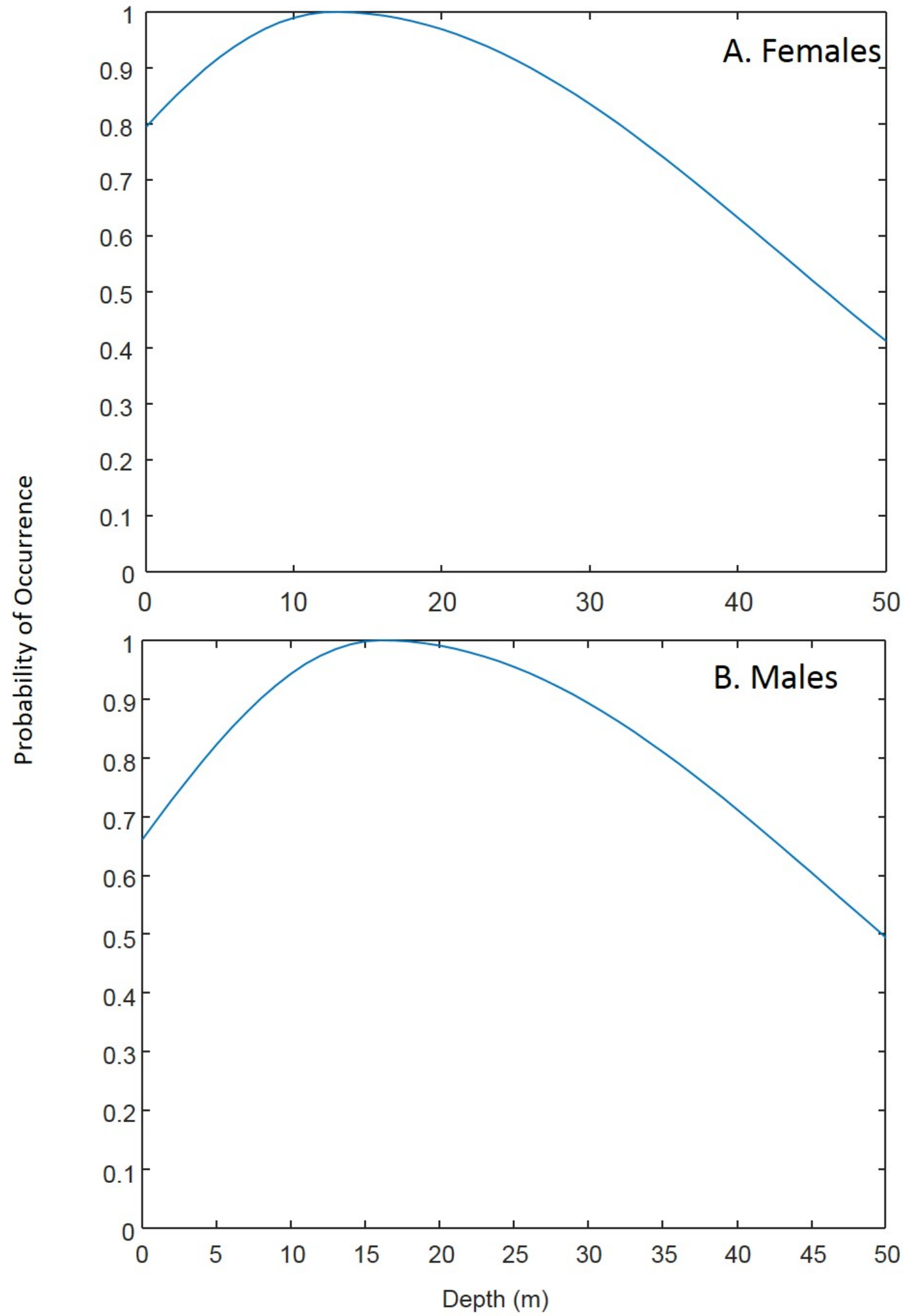

Figure 15. Graphs showing average probability of occurrence as a function of depth for females (A) and males (B) as predicted by the synoptic model. 
Effect of kelp canopy, Females

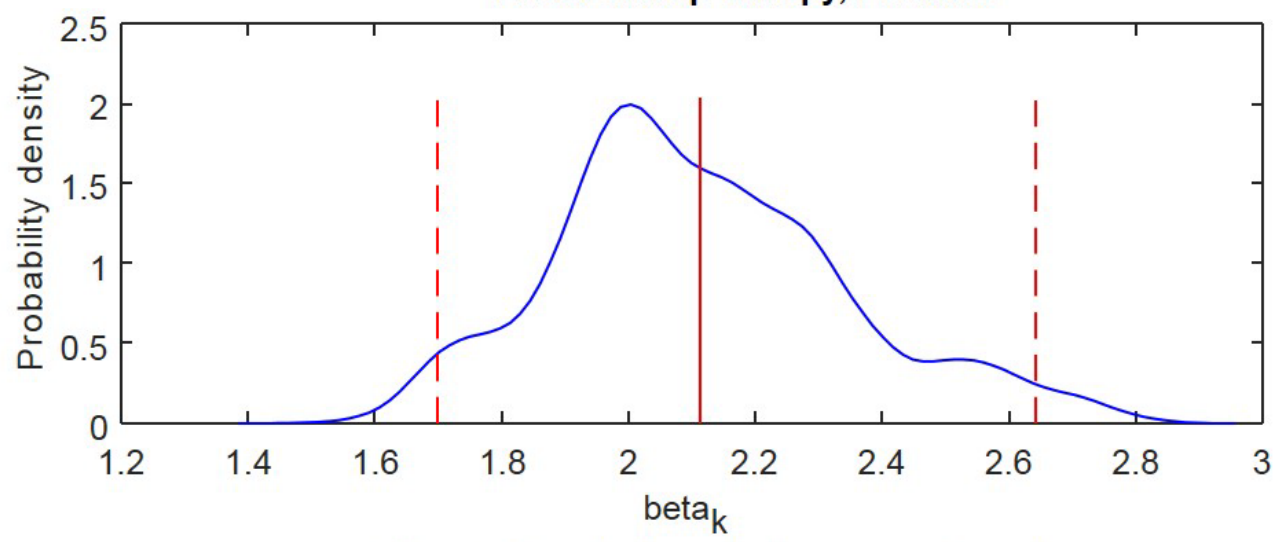

Effect of Proximity to kelp canopy, Females

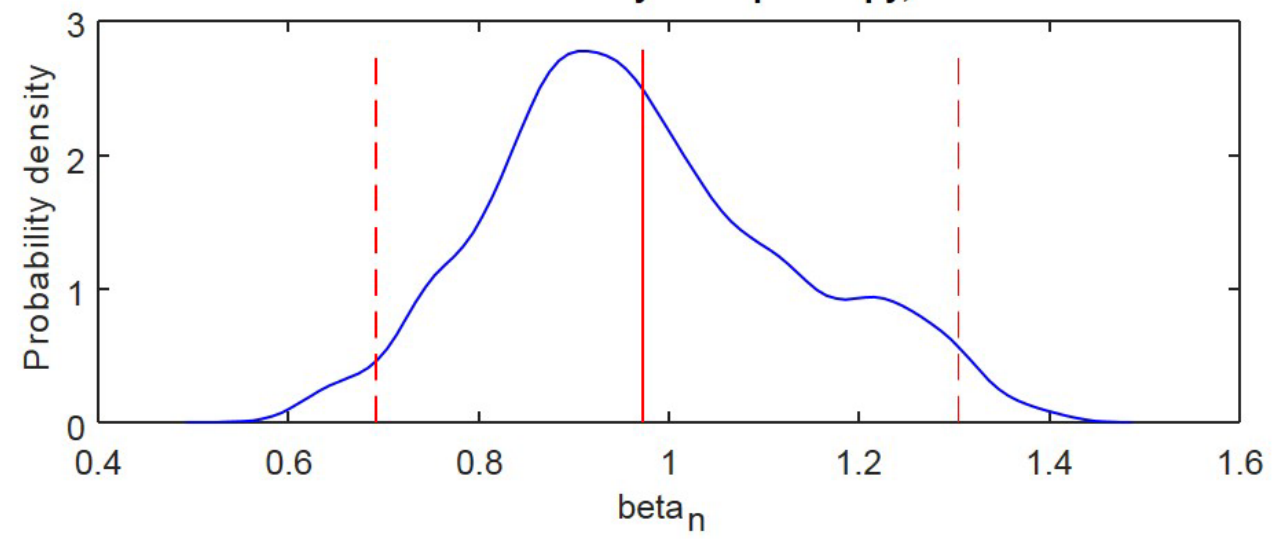

Effect of benthic substrate (soft vs hard), Females

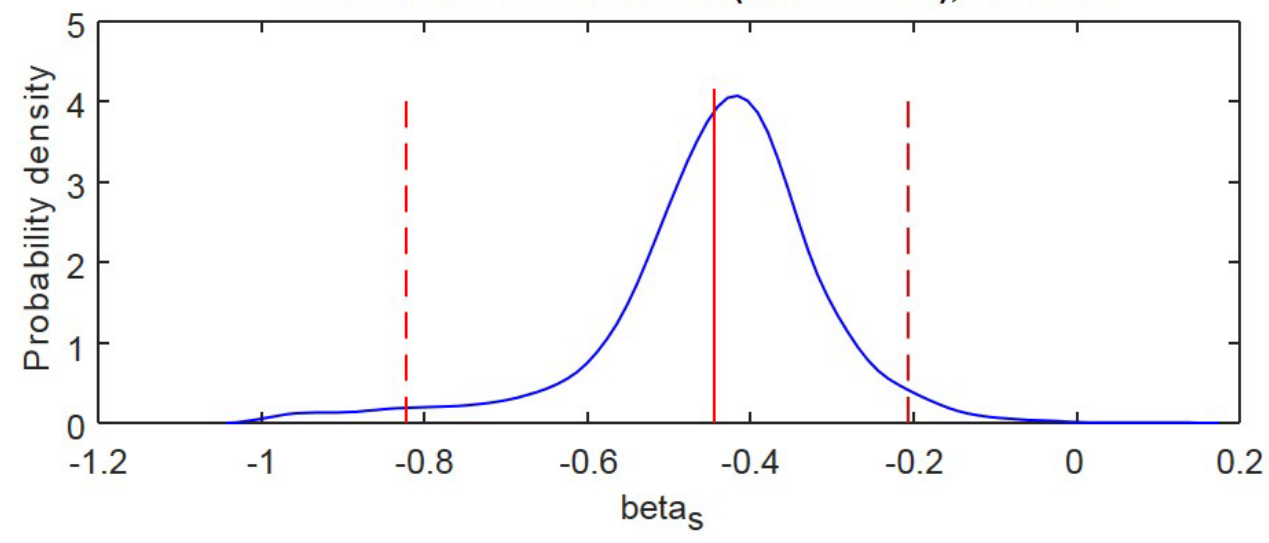

Figure 16. Posterior distributions of parameter estimates from Bayesian synoptic space-use model. Probability densities (solid curve), mean values (solid vertical line) and $95 \%$ credible intervals (dashed vertical lines) are shown for three fitted parameters $\left(\beta_{H}\right)$ associated with habitat variables that affect probability of use by sea otters: (A) presence of kelp canopy, (B) close proximity to kelp canopy and (C) benthic substrate type (soft vs. hard substrate). 


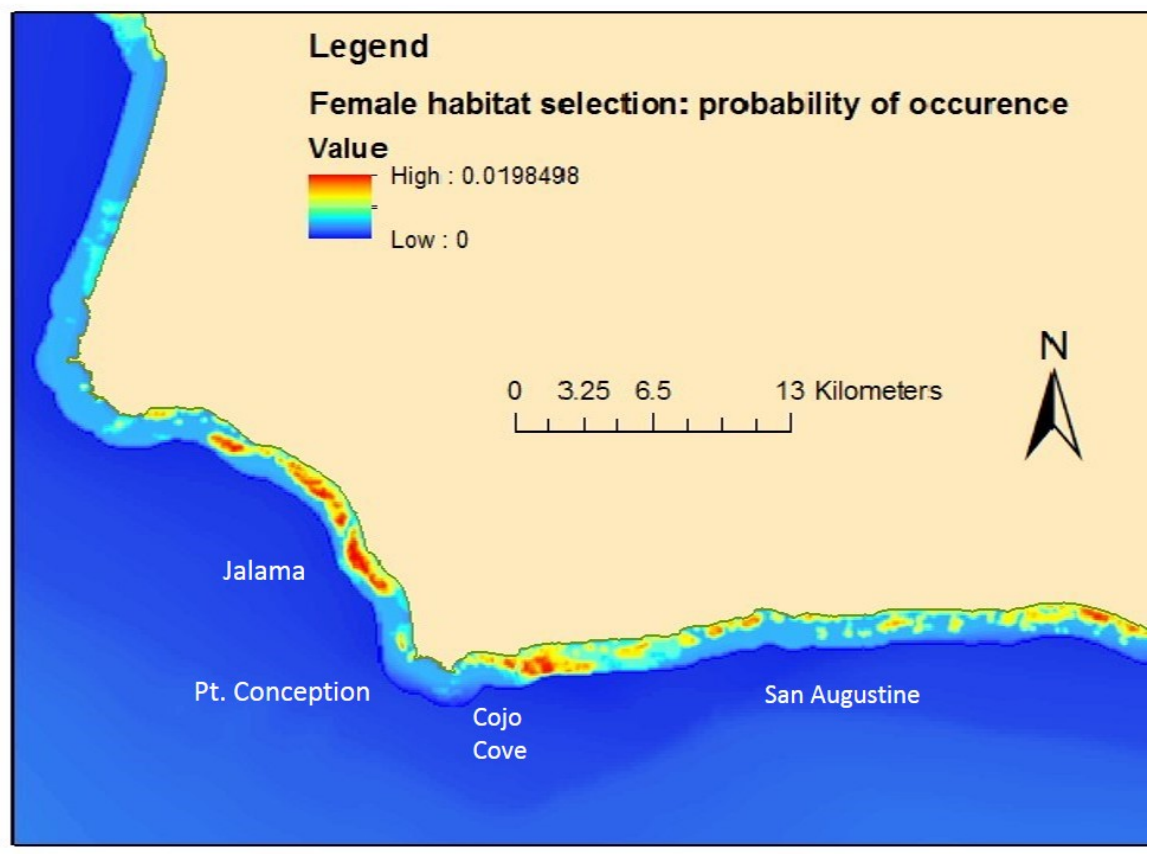

Figure 17. A habitat utilization map (excluding home range tendencies) predicting the probably of female sea otter occurrence in the Santa Barbara Channel study area.

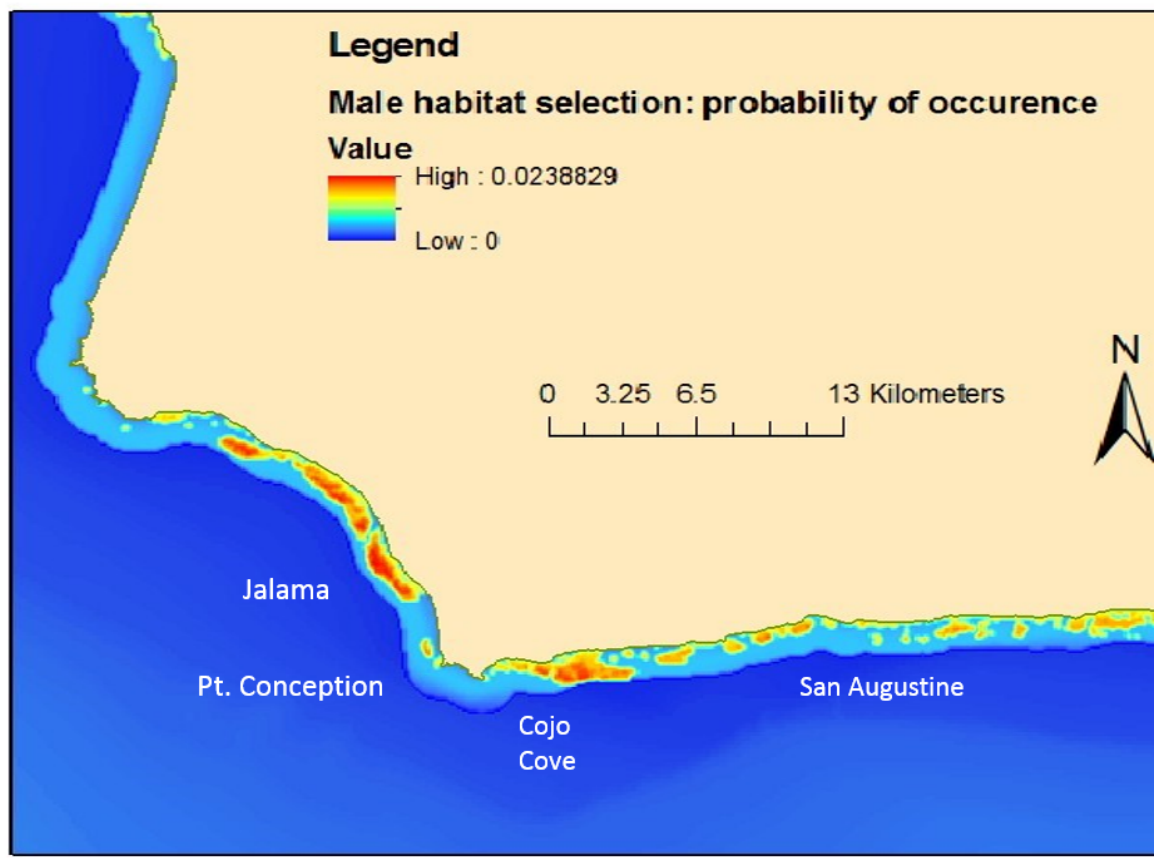

Figure 18. A habitat utilization map (excluding home range tendencies) predicting the probably of male sea otter occurrence in the Santa Barbara Channel study area. 
Based on the habitat selection behavior exhibited by sea otters in this study (as described by the synoptic model results), we estimated the relative likelihood that a sea otter would encounter any of the known seeps in Santa Barbara Channel. The Bayesian posteriors of population-level habitat selection parameters were used to estimate the relative probability of an otter encountering the seep at any point in time, scaled relative to the probability of encountering a seep at the "most preferred" depth and habitat types (the probability of which was assumed to be 1). Note that we implicitly assume that an encounter occurs if a sea otter swims within $100 \mathrm{~m}$ of the seep location (i.e., we ignore any possible avoidance behavior). Figure 19 shows the location and relative risk of encounter for 26 known seeps: the highest encounter probabilities were associated with seeps at or near Coal Oil Point. Note that the encounter risk values shown in figure 19 are per-capita values, but could easily be scaled to the current population density at each seep location: doing so would reduce the current risk of most seeps to near 0 , with the notable exception of the "Peter Paul Mounds" gas seep immediately offshore of the Cojo Cover kelp bed (fig. 19). The probability of encountering this seep for most animals was about $1 \%$ of their maximum probability of occurrence in their home range centers.

\section{Proximity to Man-Made Structures}

After 2.5 years of continuous monitoring, we found no evidence that any tagged otters utilized oil platforms or any other manmade structures. No study animals were detected near these structures by radio telemetry and no reports surfaced of tagged otters (or any otters) utilizing manmade structures over the course of the study. This lack of evidence strongly suggests that the sea otters in Santa Barbara Channel rarely if ever utilize these structures at the present time.

\section{Dive Behavior, Depth Use, and Time-Activity Budgets}

In general, sea otters at the SBC study area showed similar diving behavior and activity budgets to sea otters elsewhere in the range, but there were a number of key differences. As compared to sea otters at Monterey (MBA) and Big Sur (BSR), sea otters at SBC tended to have shorter feeding bouts with fewer dives per bout, and make shallower dives (table 3), particularly in the case of females. These differences are indicative of more readily available prey resources at shallower depths. Females at SBC also had longer post dive intervals (PDI), as is generally expected when larger and more calorie-rich prey are captured that require longer handling times. Females and males at SBC had similar dive durations, however males tended to have greater mean dive depths, as well as greater maximum depths (fig. 20).

In terms of Time-Activity budgets, sea otters at SBC spent significantly less time foraging than did sea otters at BSR and MBA $(\mathrm{F}=7.97, p=0.0002$; fig. 21$)$, and only slightly more time feeding than otters at San Nicolas Island (SBC: $p>0.05$ ). As with other areas, females at SBC spent slightly less time feeding than did males $(\mathrm{F}=6.57, p=0.014$; fig. 21$)$.

Because TDRs record diving behavior for an average of 1-2 years, it is often possible to record females giving birth to one or more pups (and raising until weaning) during the period of TDR data logging. These data usually allow us to analyze the effects of reproductive status on diving behavior and activity budgets. Unfortunately, due in part to the relatively small number of TDRs retrieved from female otters (3) and bad luck (low survival of both moms and pups for the TDRs that were successfully retrieved, due to shark bite), we were unable to record any complete records of pup birth to weaning on any of our TDRs. In the case of one female for which a partial pup dependency was recorded, more time was spent feeding when the pup was large, as has been seen in other populations. 


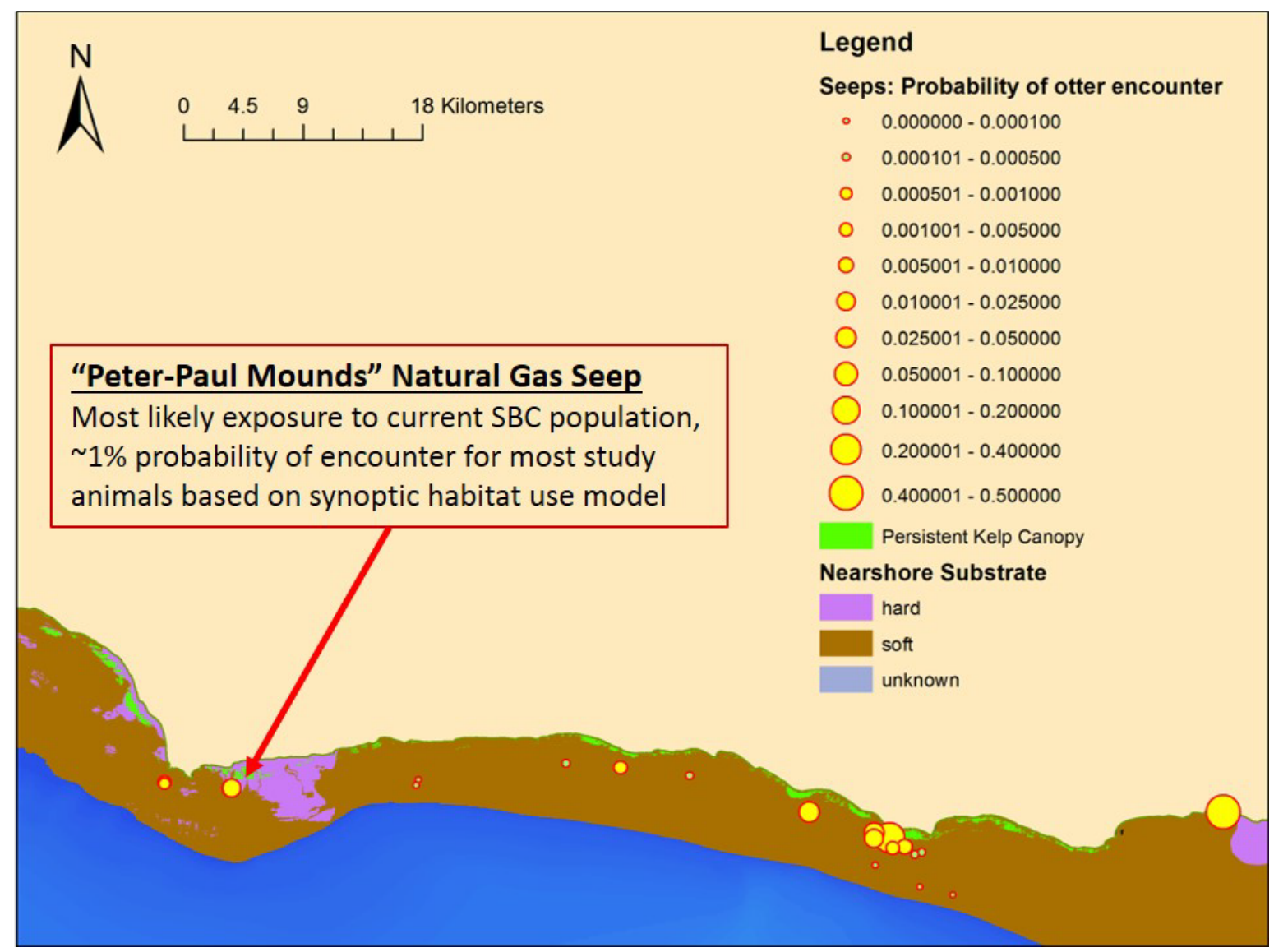

Figure 19. Map of Santa Barbara Channel between Pt. Conception and Santa Barbara showing locations and probability of encounter by sea otters of 26 known oil or natural gas seeps. Habitat variables represented on map that determine the likelihood of sea otter occurrence include water depth, the presence of kelp canopy and benthic substrate type. The "Peter Paul Mounds" seep is pointed out, as this seep is currently the most likely point of encounter given the distribution of sea otters in 2014. 

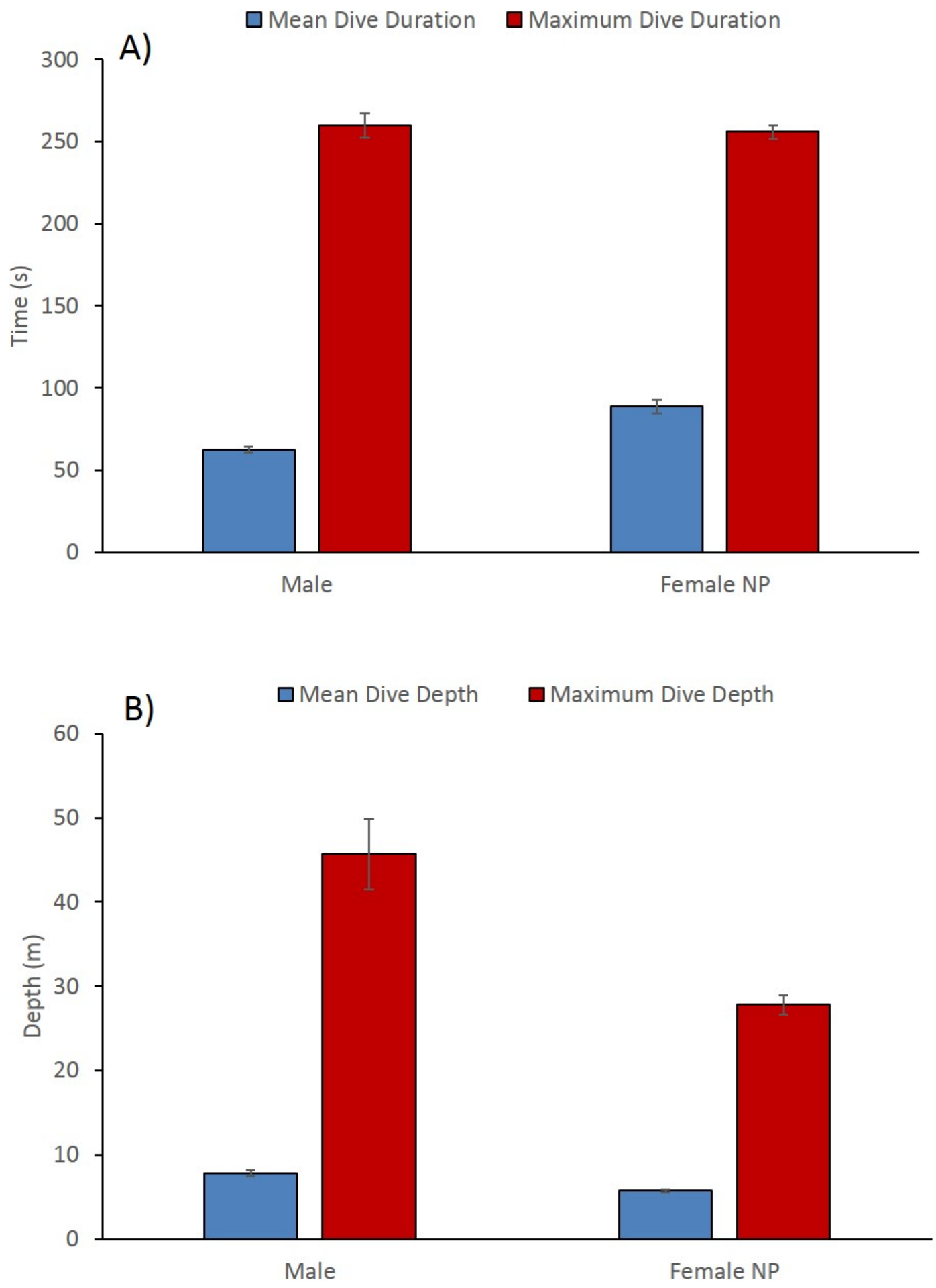

Figure 20. Mean and maximum dive durations for males and females with no pup showing an overall similarity (A) and mean and maximum dive depths for males and females with no pup showing depths were deeper for males than for females (B). Error bars represent $95 \%$ confidence intervals around the mean. 


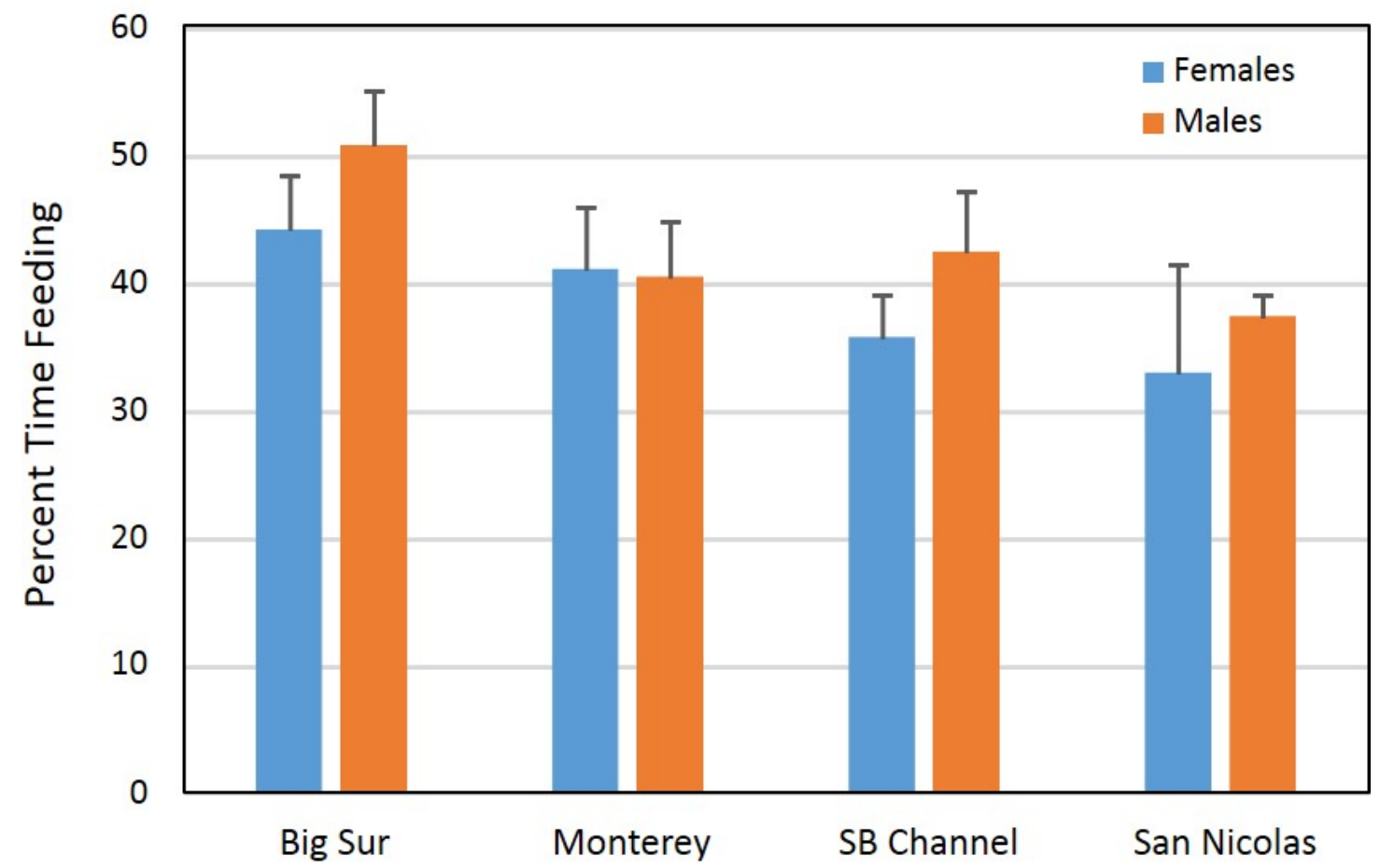

Figure 21. Percent time spent feeding for female and male sea otters compared across four different locations in California (error bars represent $95 \%$ confidence intervals around the mean). The percentage of time feeding by otters in the Santa Barbara (SB) Channel study area was most similar to San Nicolas Island.

\section{Foraging Ecology}

Despite limited and sporadic access to the coastal bluffs to the north and south of Pt. Conception, which limited the potential for conducting extensive foraging observations of our study animals, we were nonetheless able to record data for 824 feeding dives comprising 61 feeding bouts. This sample size was insufficient to base a meaningful estimate of the rate of energy gain (for which a minimum sample size of 2,000 dives is typically required), however, it provided sufficient data with which to make the first estimate of sea otter diet composition in Santa Barbara Channel.

The diet of sea otters at SBC appears to be dominated by a few prey types, specifically purple and red urchins (Strongylocentrotus sp.), kelp crabs (Pugettia producta), crabs of the genus Cancer, and red octopus (Octopus rubescens). This low diet diversity $\left(\mathrm{H}^{\prime}=1.38\right)$ was very similar to that recorded from sea otters at San Nicolas Island from 2003 to $2005\left(\mathrm{H}^{\prime}=1.07\right.$; fig. 22). Such a low diversity diet at the population level is typical of recently occupied habitats where preferred prey are still relatively abundant, and stands in contrast to the more diverse diets seen towards the center of the range in long occupied sites such as Big Sur or Monterey peninsula $\left(\mathrm{H}^{\prime}=2.16\right.$ and 2.31, respectively; fig. 21). 

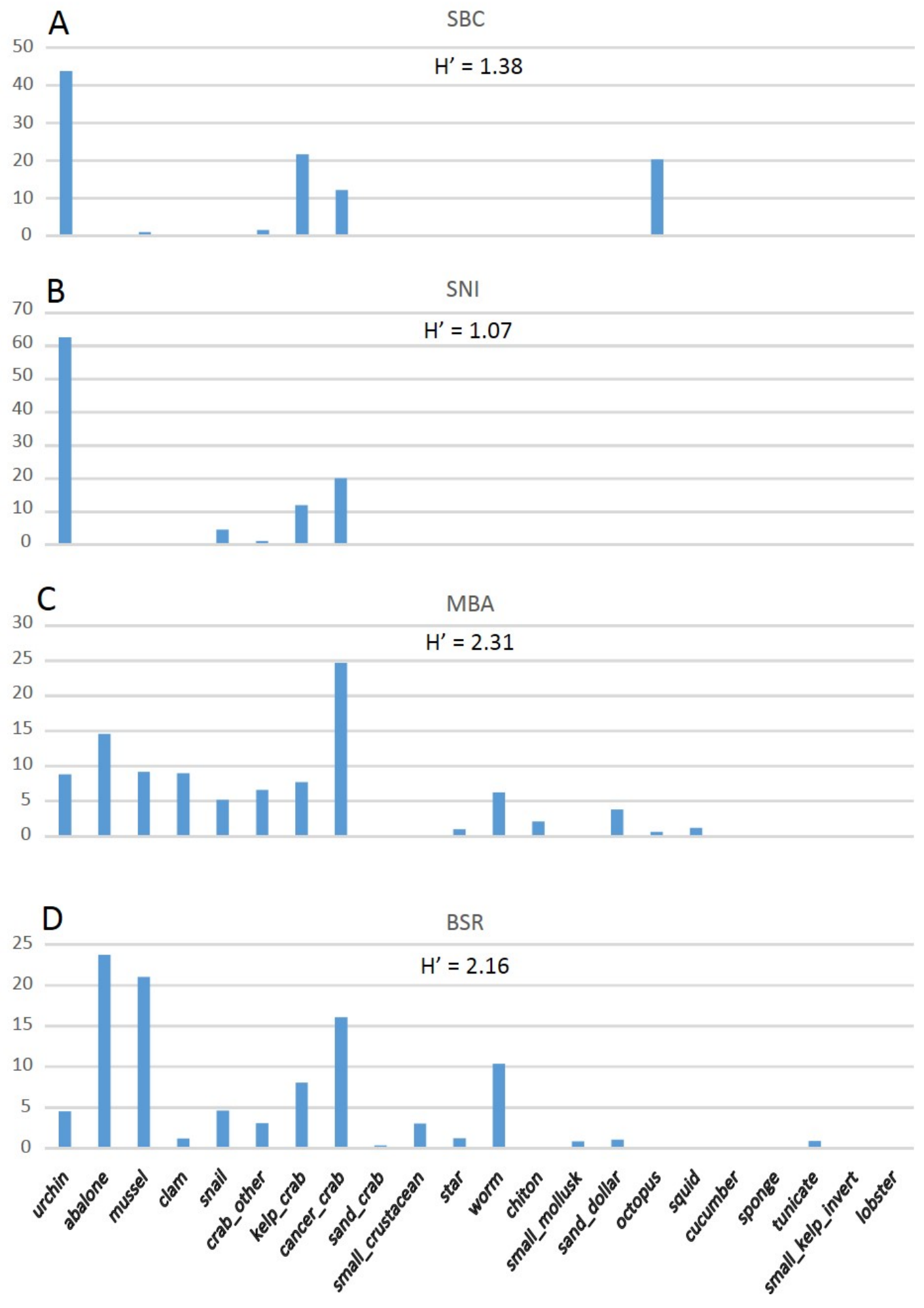

Figure 22. Overall diet of sea otters in the Santa Barbara Channel (SBC) (A) compared to San Nicolas Island (SNI) (B), Monterey (MBA) (C), and Big Sur (BSR) (D). H' represents diet diversity at the population level, which was highest in Monterey and lowest at San Nicolas Island. 


\section{Body Condition}

Growth curves fit to length vs. age and mass vs. age data for females and males (fig. 23) indicated considerable individual variation in body condition at all study sites. However, there were consistent and significant differences among sites in terms of both structural size and body condition (relative body mass at age). Females at the three sites near the range peripheries (SBC, SNI, and ELS) had greater structural size (fig. 24A) and body mass at age (fig. 25A) than did females at sites nearer the range center (BSR, MBA, SLO, and CAM). In terms of structural size, SBC females were significantly longer at age than were females at BSR and SLO $(\mathrm{F}=18.68, p<0.0001)$. In terms of mass at age, females at SBC were significantly larger than females at BSR, SLO, and CAM (F $=9.11, p<0.0001$; fig. 26A) and marginally larger at age than MBA females $(p<0.1)$. Overall, the Body Condition Indices for SBC females clearly grouped them with SNI and ELS females (fig. 26B).

The among-site patterns for male sea otters were less clear. Males at SBC were significantly shorter than males at the other range periphery sites (SNI and ELS; F $=6.97, p<0.0001$ ) but did not differ significantly from males at any other sites (fig. 24B). In terms of relative mass at age, males at SBC were significantly smaller than their counterparts at SNI and significantly larger than males at BSR $(\mathrm{F}=6.42, p<0.0001)$ but otherwise were similar to males at all other sites (fig. 25B).

The fact that males were generally more similar among sites than were females is consistent with the greater mobility of males reported above (and observed in previous studies), as greater mobility means that male condition will often be less reflective of local conditions than that of females that typically exhibit greater site-fidelity.

\section{Survival and Reproduction}

All model runs converged within 10,000 iterations, with well-conditioned posterior sample traces and $\hat{\mathrm{r}}$ values less than 1.1. Evaluation of DIC values indicated a lack of support for inclusion of the continuous time-varying effect $\left(\rho_{\mathrm{r}}\right)$, but all other parameters were included in the best-supported model. There was variation in hazards associated with age and sex differences (CAR parameters $\delta_{\mathrm{i}, \mathrm{j}}$ ), which resulted in "inverted-U" type survival curves for males and females that are typical for sea otters and other large mammals (fig. 27). The other covariates included in the model, body condition (relative mass-at-age) and reproductive status (for females) both had significant impacts on hazard rates (fig. 28). The lower the mean body condition index, the greater the hazard rate, such that a reduction in body condition from "average" to "very poor" (e.g., CAM females) was associated with a 1.8X increase in hazard rate $\left(\mathrm{CI}_{95}\right.$ 1.1-3.1), while an increase in body condition from average to very good (e.g., SNI females) was associated with a $2 / 3$ reduction in hazard rate $\left(\mathrm{CI}_{95} 0.14-0.79\right)$. This effect was evident as a positive relationship between body condition and survival rates across all study sites for both females and males (fig. 29). For all study sites except SNI and SBC there was also a 3.6X increase in hazard rate ( $\mathrm{CI}_{95}$ 1.9-6.3) for females when they were in "end-lactation" status.

After accounting for all fixed-effect covariates (age, sex, body condition and reproductive status), there was no statistically significant variation in hazard rates (based on overlap of $95 \%$ credible intervals) associated with random effects among study sites, although MBA and SBC tended towards slightly lower hazard rates while CAM and BSR tended towards slightly higher hazard rates (fig. 30). When the full model was evaluated at each site there were significant differences in survival between sites, but these were primarily driven by the differences in mean body condition and the proportion of end-lactation status females at each study site: for example, female survival at SNI and SBC was significantly greater than at CAM (fig. 31). 

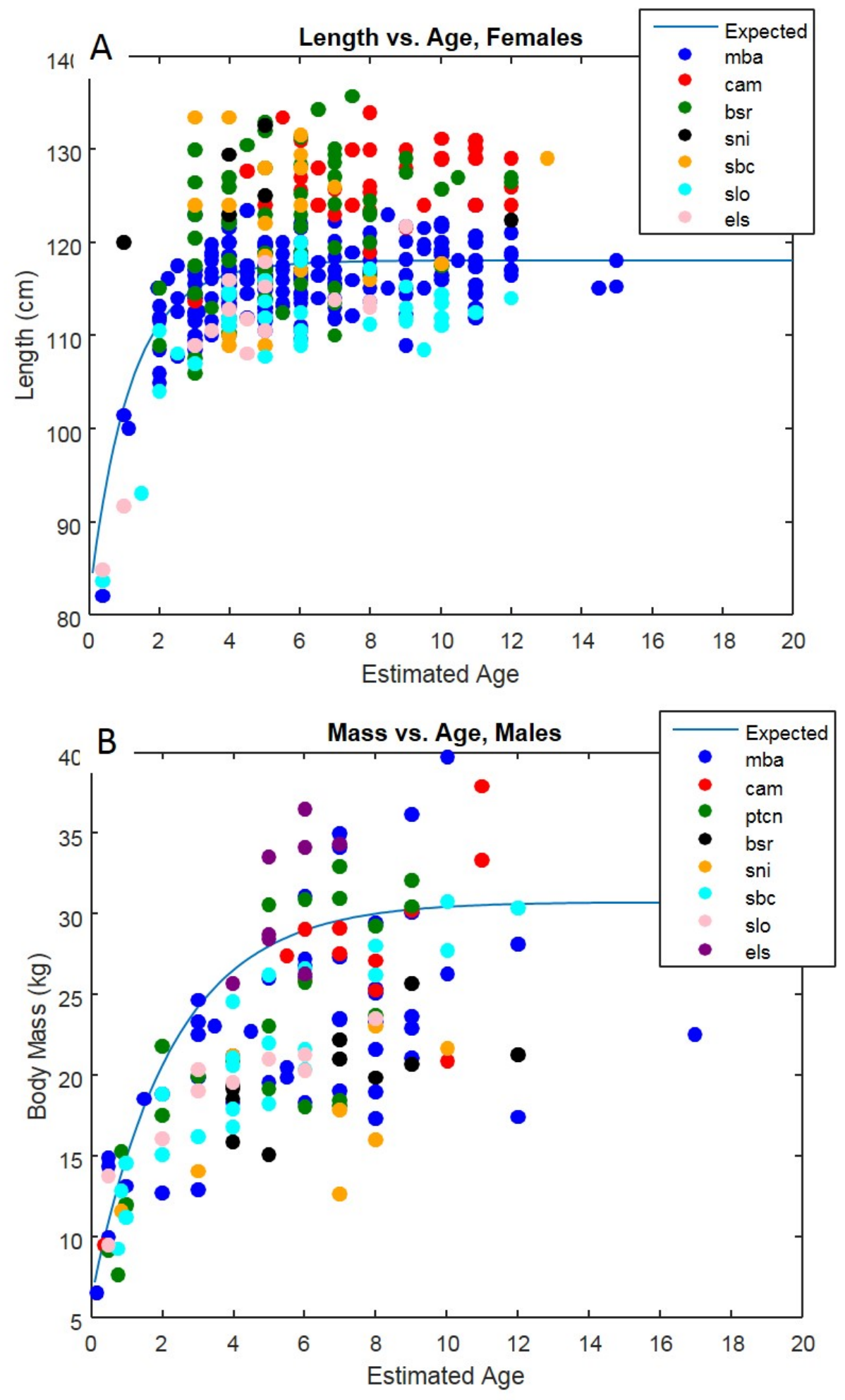

Figure 23. Growth curve fit to length vs age for females (A) and growth curve fit to body mass vs. age for males (B). Data from seven (for females) or eight (for males) study sites were used to fit growth curves. The solid blue line represents the expected growth curve, with residuals from this function indicating relative length or mass at age. bsr, Big Sur; cam, Cambria/San Simeon; els, Elkhorn Slough; mba, Monterey Bay area; ptcn, Pt. Conception; sbc, Santa Barbara Channel; slo, San Luis Obispo; sni, San Nicholas Island. 

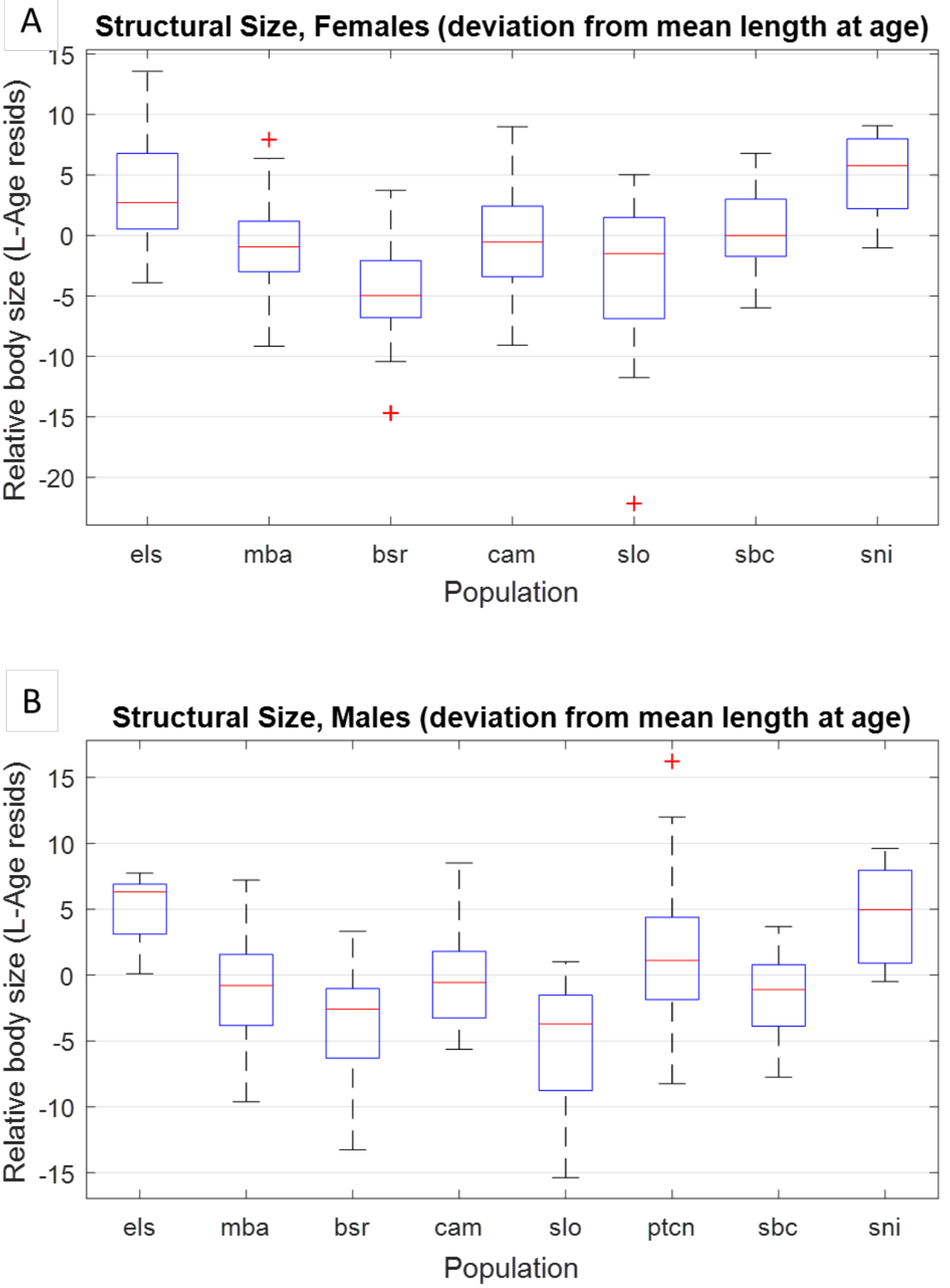

Figure 24. Boxplot comparison of sea otter structural size of females (A) and males (B) at seven and eight different locations in California (arranged north to south). The boxes represent the interquartile range (IQR) or the middle $50 \%$ of the values for each site. Horizontal lines within the boxes represent the median value. Dashed lines extending above and below the boxes represent maximum and minimum values, respectively. Plus symbols (+) denote outliers. bsr, Big Sur; cam, Cambria/San Simeon; els, Elkhorn Slough; mba, Monterey Bay area; Pt. Conception; sbc, Santa Barbara Channel; slo, San Luis Obispo; sni, San Nicholas Island. 

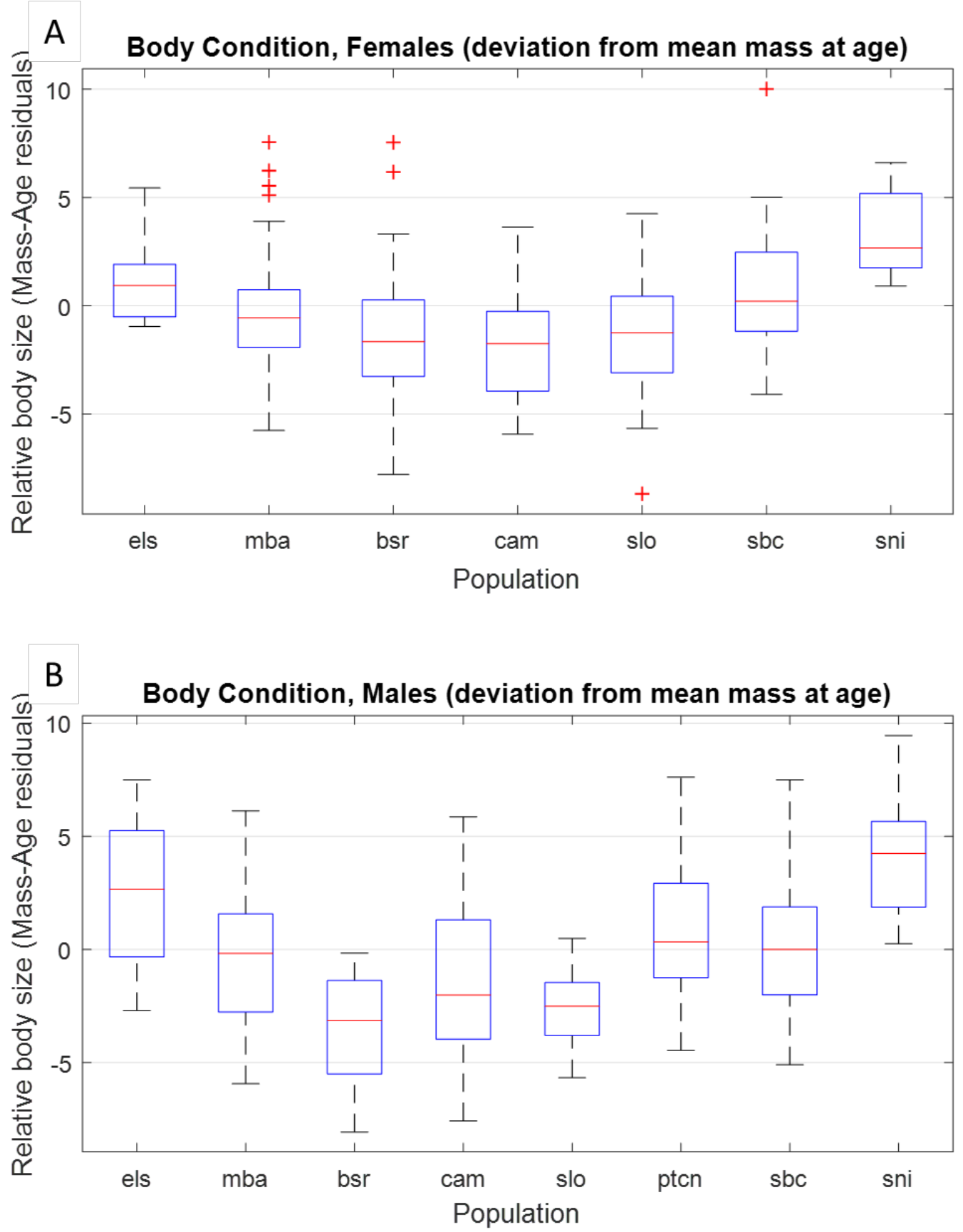

Figure 25. Boxplot comparison of sea otter body condition of females (A) and males (B) at seven and eight different locations in California (arranged from north to south). The boxes represent the interquartile range (IQR) or the middle $50 \%$ of the values for each site. Horizontal lines within the boxes represent the median value. Dashed lines extending above and below the boxes represent maximum and minimum values, respectively. Plus symbols (+) denote outliers. bsr, Big Sur; cam, Cambria/San Simeon; els, Elkhorn Slough; mba, Monterey Bay area; ptcn, Pt. Conception; sbc, Santa Barbara Channel; slo, San Luis Obispo; sni, San Nicholas Island. 
A

Females, Multiple Comparison: Mass/Age Residuals by Study Site
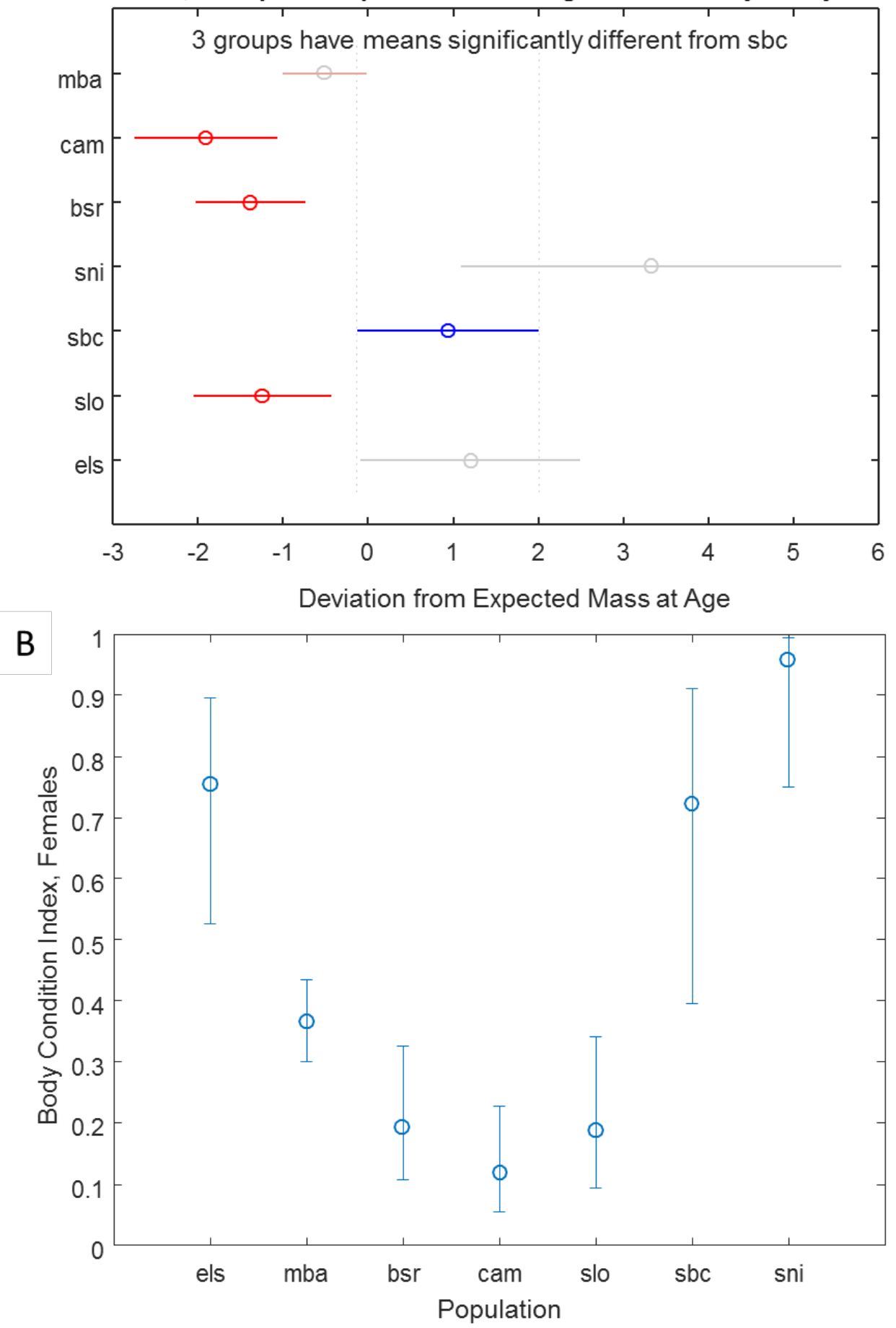

Figure 26. Plot showing deviation of expected mass at a given age for females at seven locations $(A)$ and plot of female body condition indices compared across seven locations showing that SBC females clearly cluster with females from San Nicolas Island and Elkhorn Slough (B). Error bars represent 95\% confidence intervals. bsr, Big Sur; cam, Cambria/San Simeon; els, Elkhorn Slough; mba, Monterey Bay area; sbc, Santa Barbara Channel; slo, San Luis Obispo; sni, San Nicholas Island. 

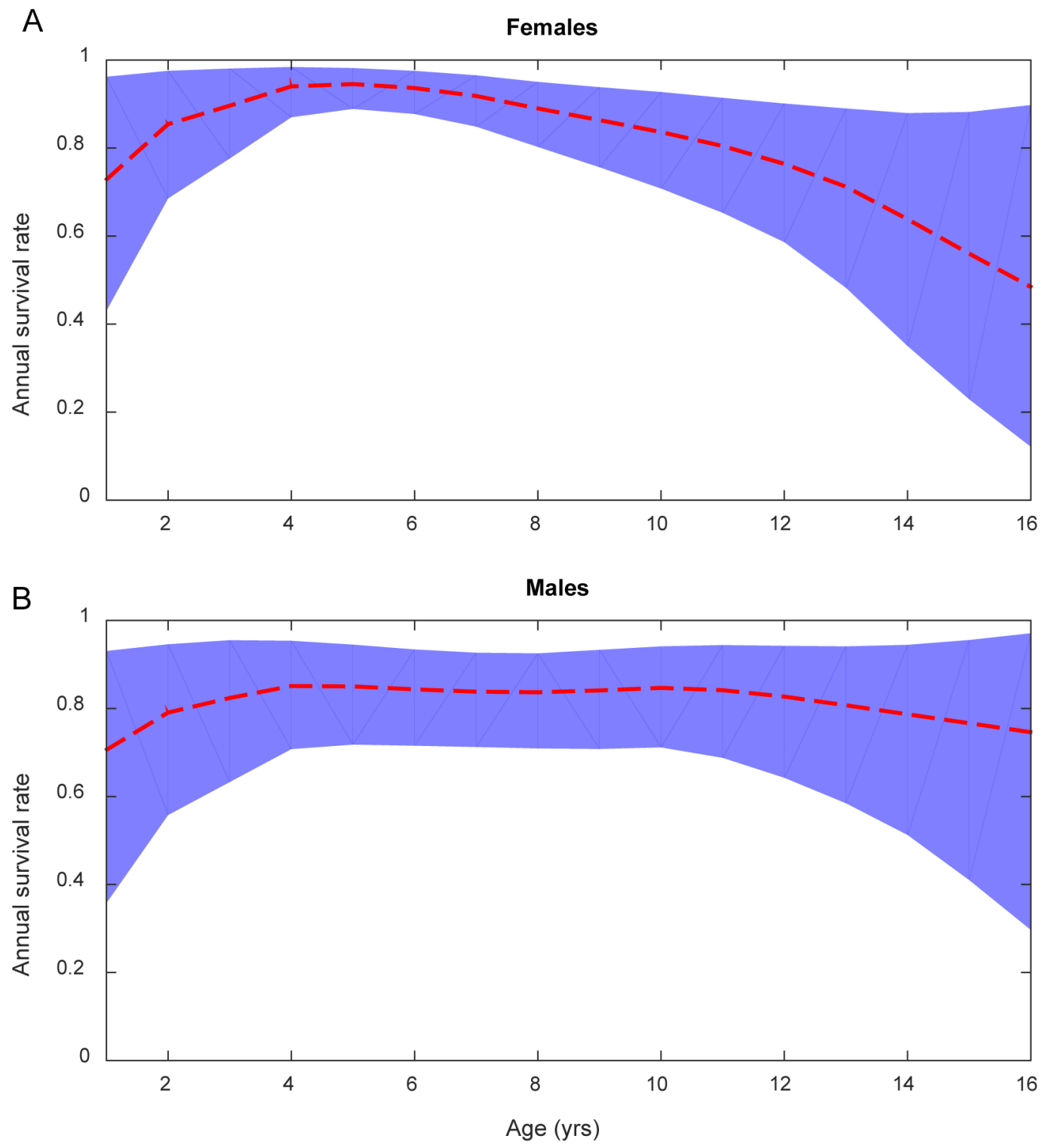

Figure 27. Results of a proportional hazards survival analysis estimating the annual survival rate at a given age for females $(A)$ and males $(B)$. The dashed line indicates the mean annual survival rate, and shaded area indicates $95 \%$ credible interval. 
A

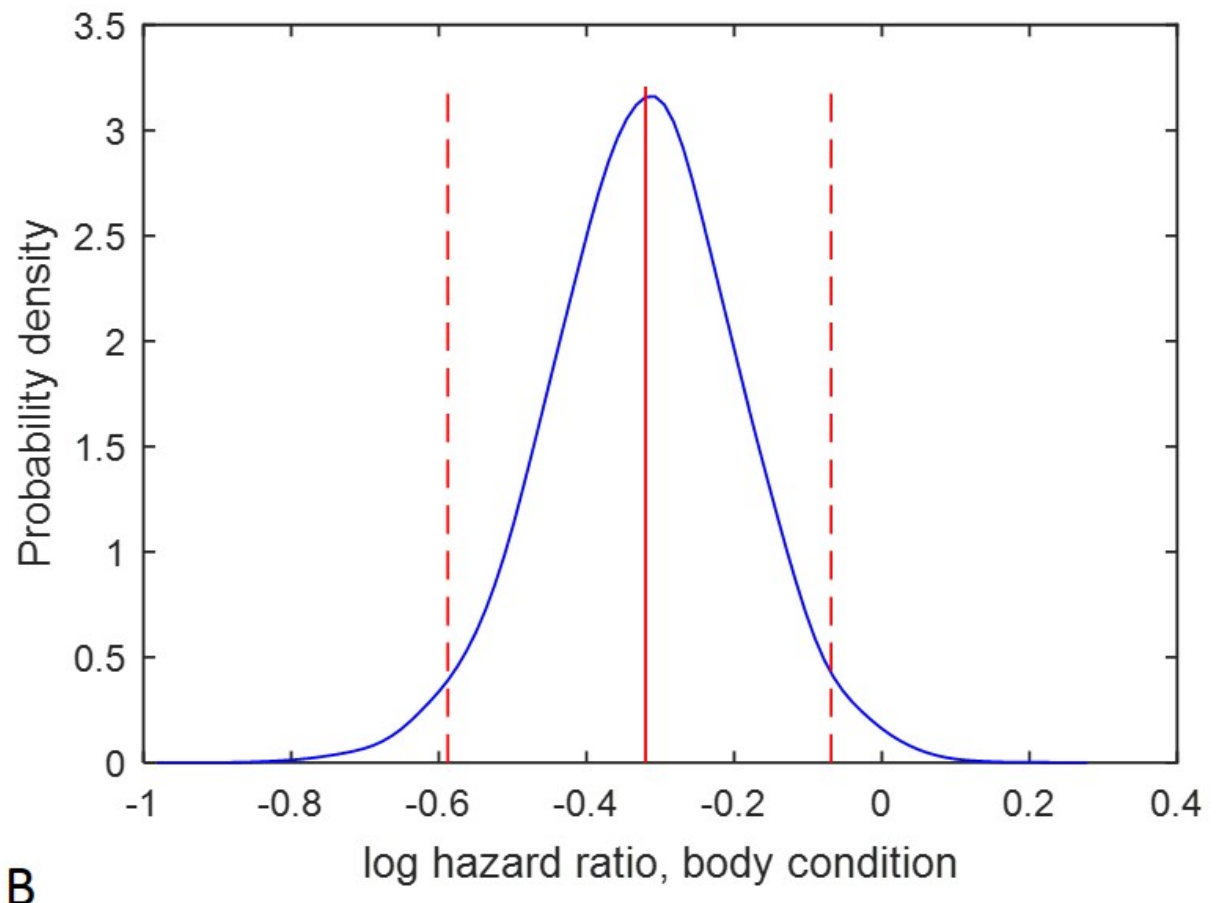

B

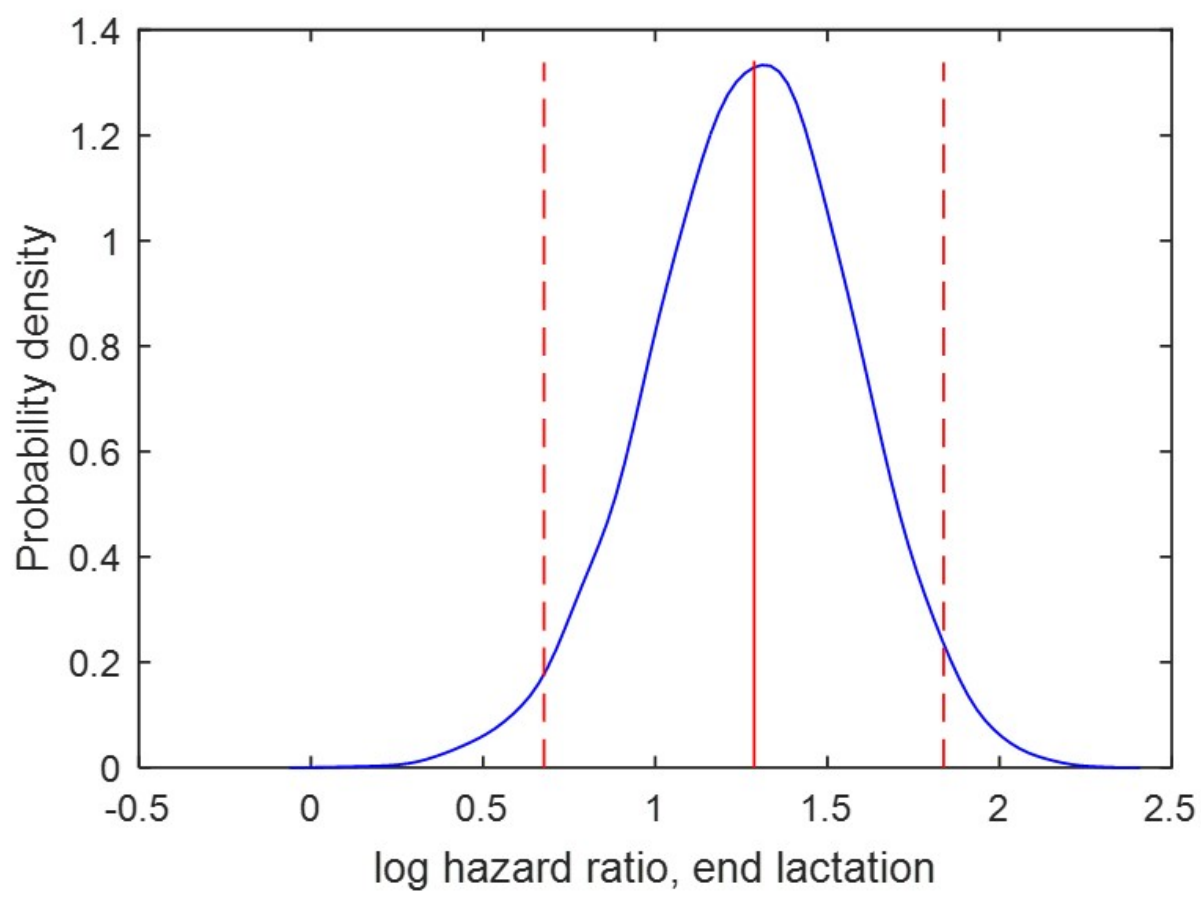

Figure 28. Posterior distributions of parameter estimates from the Bayesian survival model. Probability densities (curved solid line), mean values (vertical solid line) and $95 \%$ credible intervals (vertical dashed lines) are shown for two fitted parameters, (A) the effect of body condition on $\log$ (hazard rate) and (B) the effect of a female entering the end-lactation period on log(hazard rate). 


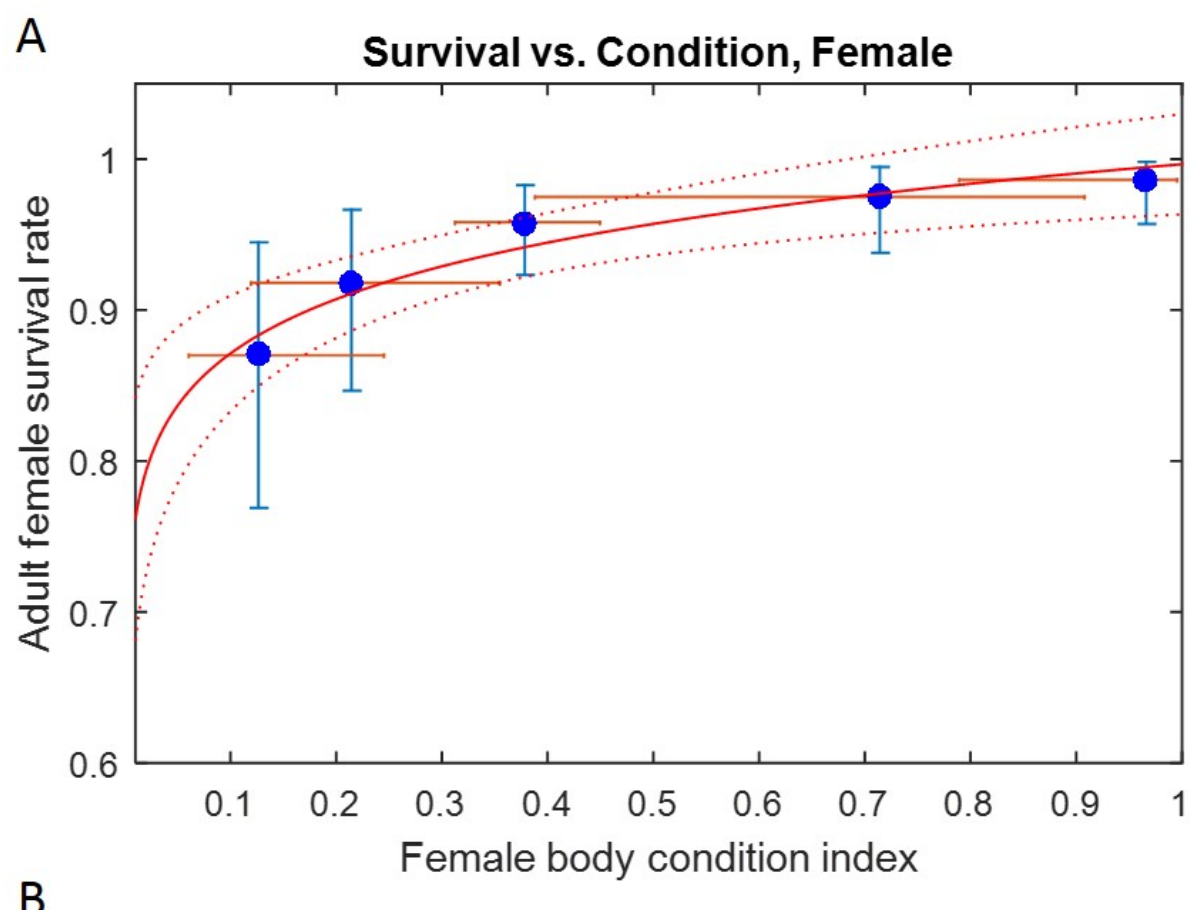

B

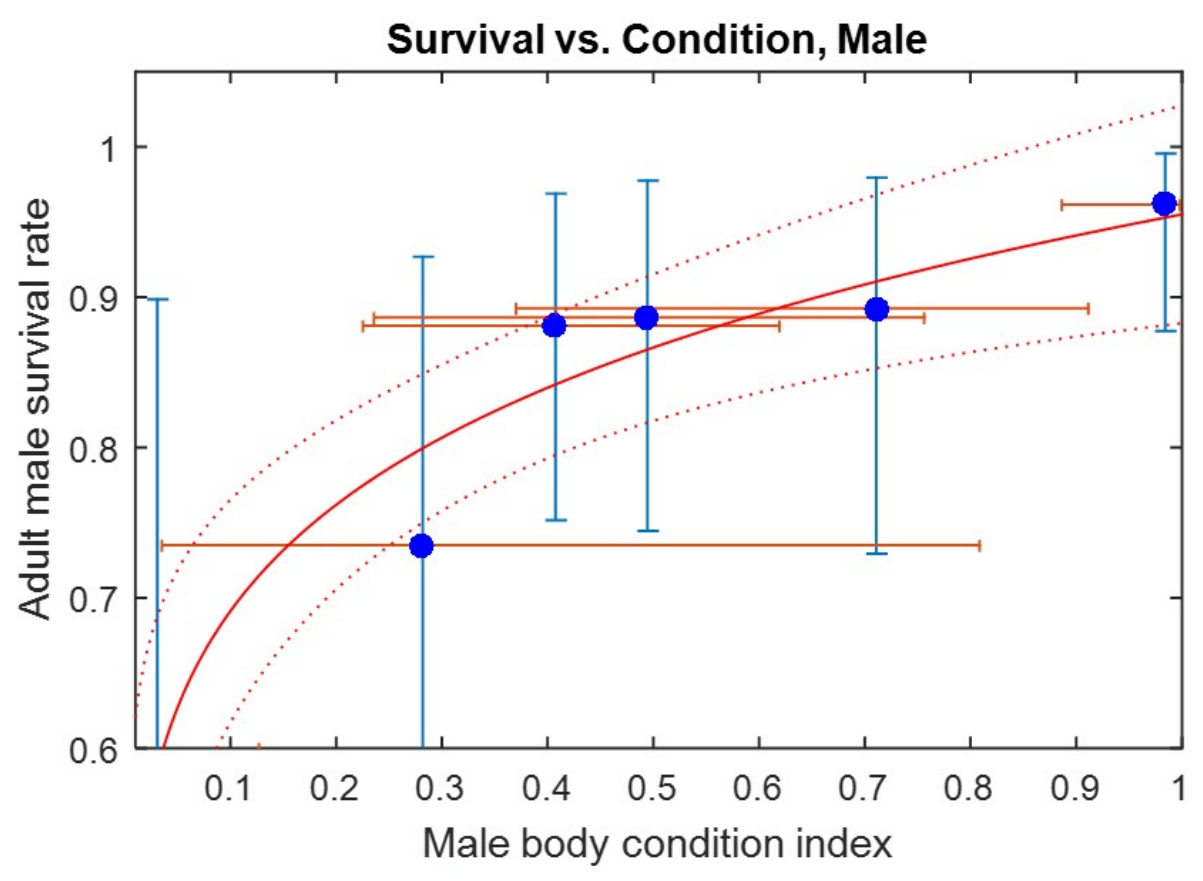

Figure 29. Plots of annual survival rate vs. body condition index for females (A) and males (B) at six different sites. A significant positive relationship exists for both sexes, as indicated by fitted power function (red solid line) and 95\% prediction interval (red dashed lines). Error bars represent $95 \%$ confidence interval around each point estimate. 


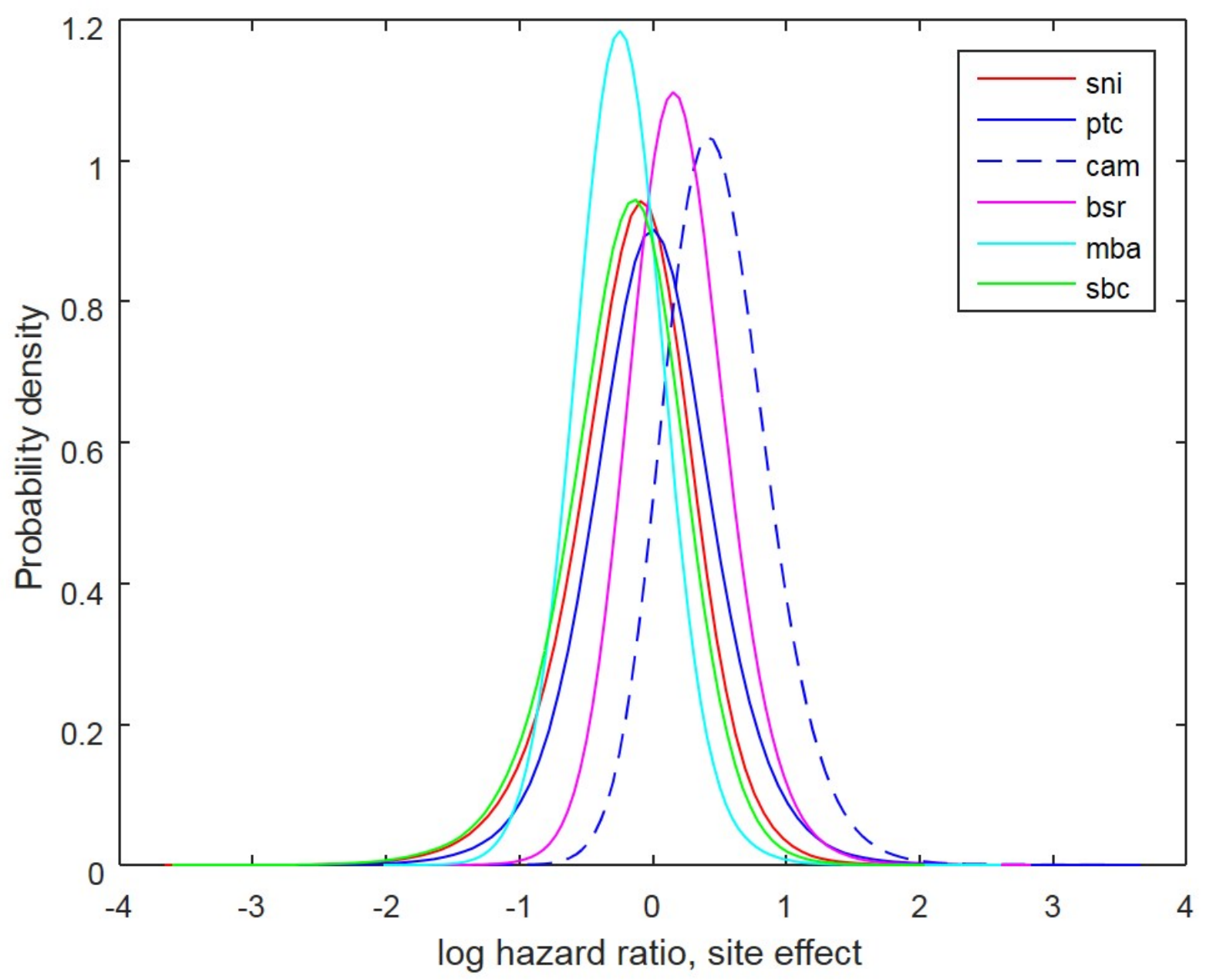

Figure 30. Posterior distributions of the random effect differences in hazard rates across six different study areas in California. Higher values indicate greater hazards and lower values indicate lower hazards, after accounting for all fixed-effect covariates (age, sex, body condition, and reproductive status). bsr, Big Sur; ptcn, cam, Cambria/San Simeon; Pt. Conception; mba, Monterey Bay area; sbc, Santa Barbara Channel; sni, San Nicholas Island. 
A

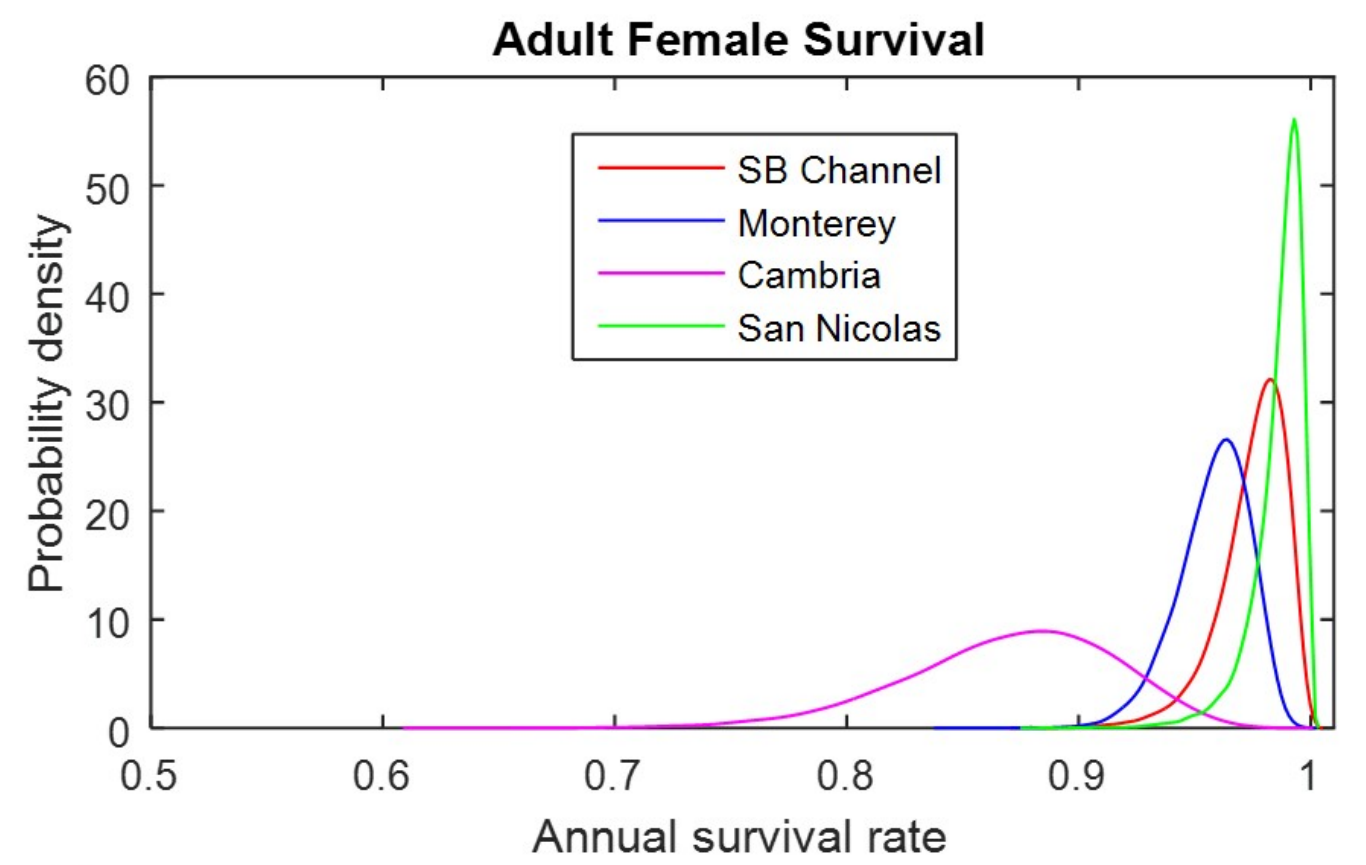

B

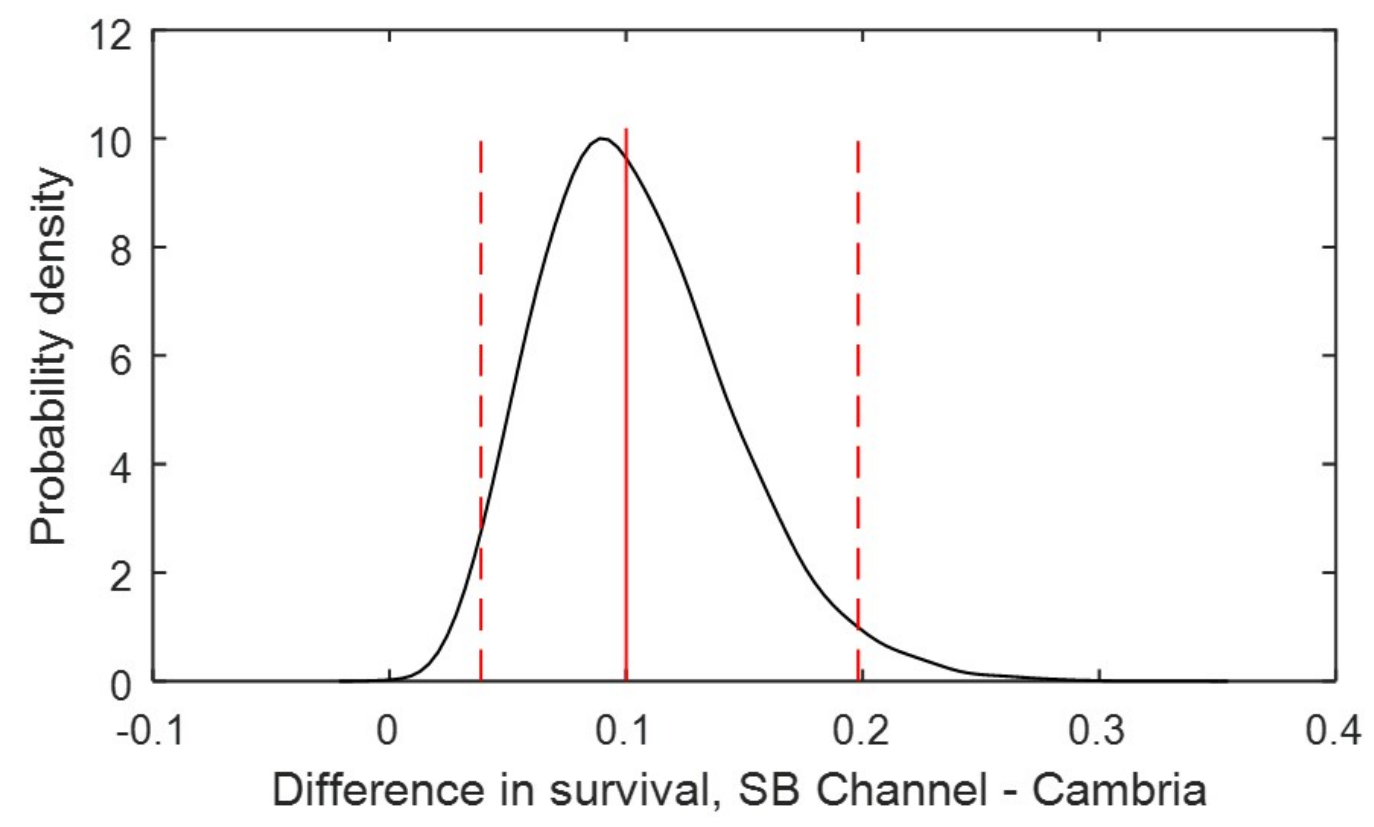

Figure 31. (A) Posterior distributions for adult female survival rates at four locations in California (as estimated from a full model including both fixed and random effects), and (B) Posterior distribution for a comparison of the difference in survival between females at Santa Barbara Channel and females at Cambria, showing significantly higher survival at SBC. 
The estimated age-specific survival rates at SBC differed depending upon whether shark-bite mortalities were "censored" from the dataset or not. Including shark-bite mortalities in the dataset resulted in a $4.5 \%$ reduction in the annual rate of survival, averaged across all age classes (fig. 32). By incorporating these alternative survivorship schedules into an age-structured projection matrix (Tinker, Doak, and others, 2006) we determined that reduced survival due to shark bite mortality corresponded to a $5.1 \%$ reduction in the projected annual rate of population growth, decreasing from $\lambda=1.13$ without shark mortality to $\lambda=1.08$ with shark mortality.

Based on the 30 pups born to tagged females at SBC, the estimated mean annual birth rate was 0.98, which is almost identical to the birth rate of 0.97 estimated from all previous telemetry studies in California (Tinker and others, 2013). Our analysis of pup mortality patterns was based on the observed survival outcomes for 539 pups born to study animals between 2001 and 2014 at seven study sites. The probability of pup mortality varied as a function of pup age, as has been previously reported (Riedman and others, 1994; Monson and others, 2000; Tinker, Doak, and others, 2006), although the CAR model we used allowed for a more detailed examination of the nature of this variation (fig. 33). The instantaneous hazard rate was highest immediately after birth (when many new-born pups are abandoned), dropped sharply over the next week but then increased slightly between 3 and 6 weeks of age, and then decreased to low values for the period between 6 and 14 weeks of age, after which the hazard rate again began to climb continuously up until the time of weaning (which generally occurs between 20 and 25 weeks of age).

The degree of mortality risk experienced by pups was affected by two factors, (1) the age of the pup's mother and (2) the relative body condition of the pup's mother. Average weaning success rates increased from 0.65 for 3 -year-old mothers to 0.75 for 8 -year-old mothers (fig. 34A), then declined for females over 10 years of age. Likewise weaning success increased from 0.65 for mothers in poor condition $(\mathrm{BCI}=-5)$ to 0.85 for mothers in good condition $(\mathrm{BCI}=5$; fig. $34 \mathrm{~B})$. The weaning success rate for females at SBC followed this typical pattern, increasing from 0.57 for young females to 0.71 for 10-11 year old females (fig. 32).

\section{Preliminary Findings from Necropsy of Tagged Sea Otters}

Over the course of the study there were five confirmed mortalities, for which carcasses were retrieved in four cases. In the case of the 5th animal with no carcass (adult female BRD 1193), the radio transmitter and TDR were recovered from the beach at Vandenberg Air Force Base on December 10, 2012 , with no sign of an associated carcass. This female had been seen a week previously looking healthy and behaving normally, so it is reasonable to conclude that the cause of death was trauma of some sort (as this would be the only explanation for the instruments to have exited the body cavity by 1 week later), with shark bite mortality being the most likely source of trauma in this area.

In the case of the remaining four deaths, full necropsies were performed by Dr. Miller, the veterinary pathologist at MWVCRC, California Department of Fish and Wildlife: preliminary necropsy reports are attached (following pages). In 3 of these 4 cases (one adult female and two adult males) the primary cause of death was shark bite mortality. The 4th animal was an aged male (estimated age 12 years) for which the primary cause of death was dilated cardiomyopathy. Thus with the exception of the one aged-male with heart disease, the only confirmed cause of death for sea otters in this study was shark bite mortality. All shark-bite cases were recovered north of Pt. Conception. 


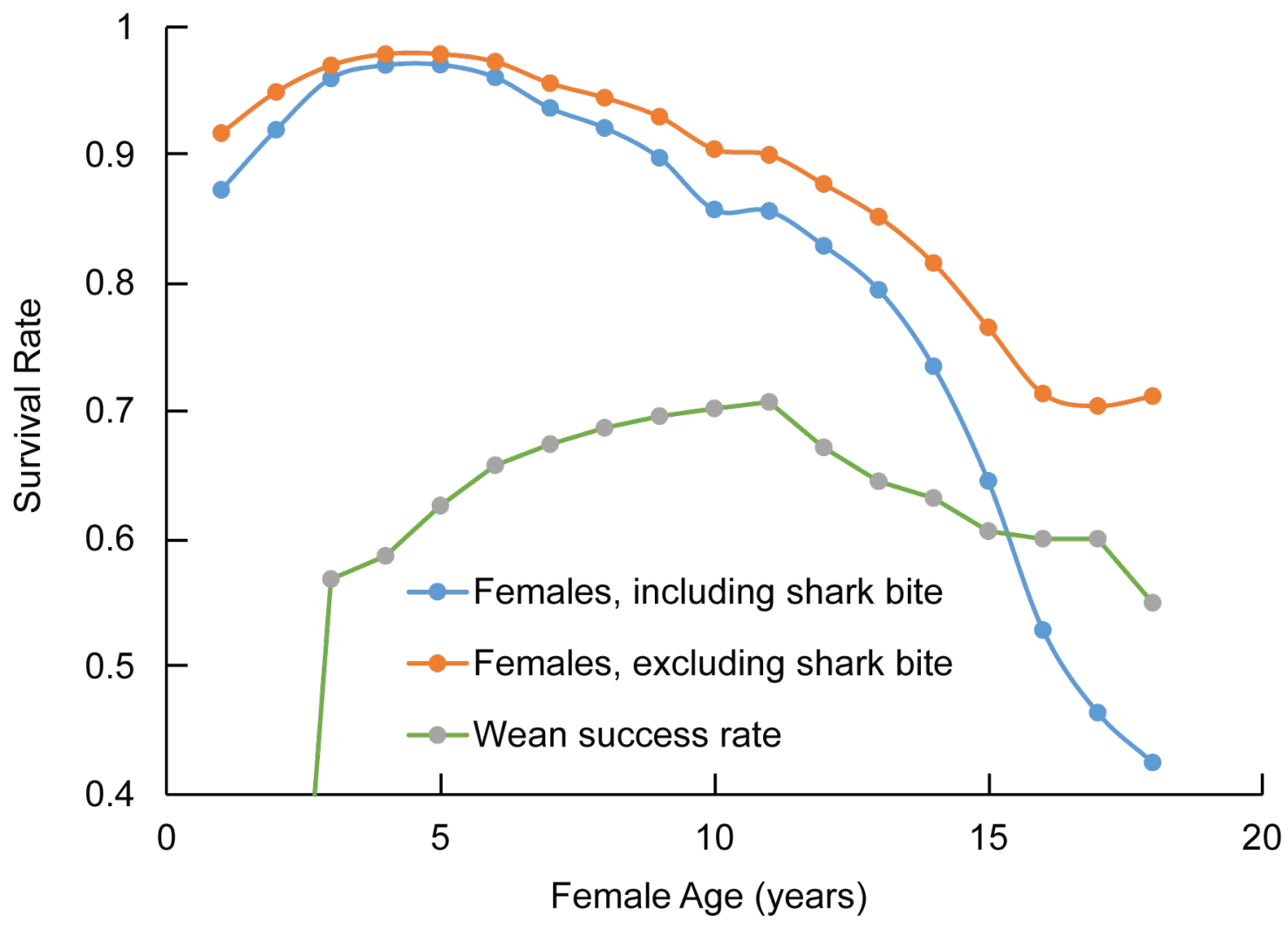

Figure 32. A plot of female survival as a function of age when shark bites were taken into account and when shark bites were excluded from the analysis. Weaning success is also plotted as a function of age. 


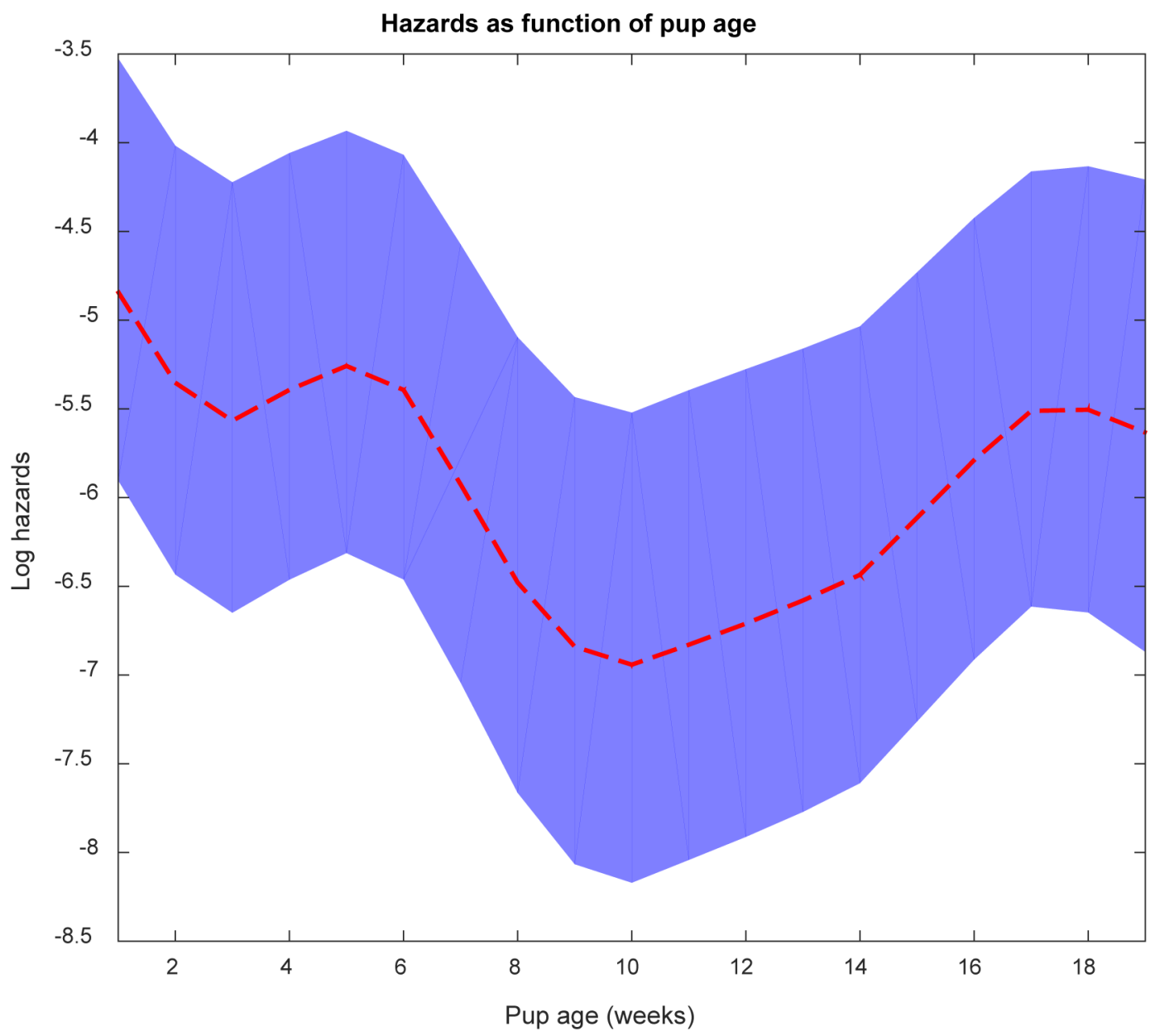

Figure 33. A hazards analysis for pup survival as a function of pup age in weeks. Note that lower log hazards values correspond to higher pup survival. The dashed line indicates best fit value and the shaded area indicates $95 \%$ credible interval. 

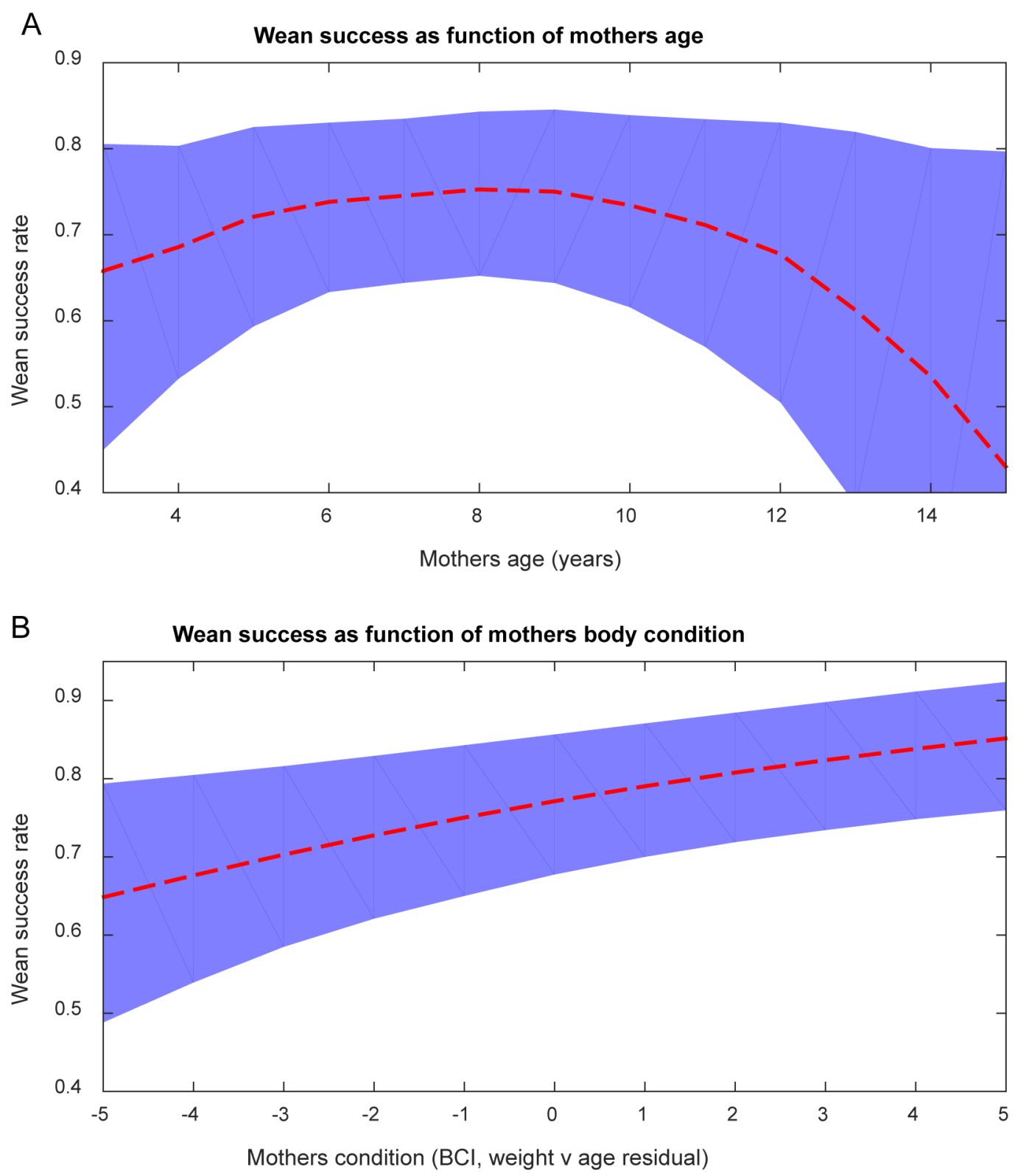

Figure 34. Pup survival rate (weaning success) plotted as a function of the mother's age (A) and as a function of the mother's body condition (B). The dashed line indicates mean expected values, and shaded areas indicate $95 \%$ credible intervals. 


\section{Discussion}

This report summarizes the results of a 3-year study of sea otters in Santa Barbara Channel, which represents the southern periphery of the sea otters mainland range in California. The results of this study provide new insights into space use and habitat selection of sea otters in this area, which will be useful for resource managers in anticipating potential conflicts or interactions between sea otters and natural oil seeps or (in future) man-made structures and human activities that may affect population health and persistence. Moreover, by combining data from the current study with similar data collected from sea otter populations at other sites throughout their range, we were able to use a comparative approach to infer population status, examine possible threats, and better understand the ecology of sea otters in the Santa Barbara Channel.

\section{Primary Objectives: Space Use Patterns and Exposure to Oil and Gas Seeps}

Resighting records for individual animals provided the necessary information to address primary objective 1: describing the extent of movements and spatial use patterns by sea otters in southern California. We found the spatial ecology of sea otters at the southern range periphery to be complex, as has been reported by previous investigations (Jameson, 1989; Tinker, Estes, and others, 2006; Tinker, Doak, and others, 2008; Lafferty and Tinker, 2014). At the time of a previous telemetry study of sea otters in this area (2001-2003), Santa Barbara Channel (SBC) was exclusively used by male sea otters, most of which were non-resident animals that only used this area seasonally (Tinker, Estes, and others, 2006). In the current study, our sample included almost equal numbers of male and female animals, and after 3 years of study it became clear that all females were full-time residents of the Pt. Conception area, most having home ranges split between Cojo Cove and Jalama Beach (just to the north of Pt.

Conception; figs. 8 and 10). In the case of males, approximately $60 \%$ were also resident animals, with home range distributions and range spans similar to those of their female counterparts, while the remaining 40\% were transient males, who spent part of the year in SBC and the rest of the year in other areas ranging from San Luis Obispo to Monterey (figs. 10 and 14). Some of the resident males exhibited behavior typical of territorial males, guarding small defined areas and monopolizing access to females in these areas (e.g., fig. 10C). Other resident males were part of a shifting male group that included transients and was often situated around the San Augustine kelp bed. The Synoptic model resulted in one of the most successful examinations of individual sea otter home ranges, showing hot-spots of use, accommodating multiple home range centers and avoiding overlap with "prohibited" features such as land (e.g., fig. 10A). This approach shows great promise for future sea otter home range analyses.

In addition to illustrating individual home range use, the synoptic model provided insights into habitat selection behavior by male and female sea otters. Important findings included the deeper modal depth preferred by males vs. females (fig. 15), a finding corroborated by analysis of Time-Depth Recorded data (table 3). Both males and females showed strong preferences for areas with persistent kelp canopy (fig. 16A), and even when not resting within the kelp they showed a preference for habitat in close proximity $(<200 \mathrm{~m})$ to kelp canopy (fig. 16B). Interestingly, while females showed a significant preference for rocky substrate vs. soft substrate habitat, males did not show any such preference, a finding consistent with their greater utilization of soft sediment habitats in other parts of the range (Wendell and others, 1986; Jameson, 1989; Tinker, Estes, and others, 2006). These differences resulted in subtle sex-based differences in expected habitat use patterns in Santa Barbara Channel (see fig. 17 vs. fig. 18). 
With respect to Objective 2, describing patterns of use of manmade structures: the sea otters in this study did not appear to make use of habitat associated with manmade structures, including offshore oil rigs. This does not, however, preclude the possibility that these manmade structures may be utilized in the future, especially as these structures are known to provide habitat for invertebrate prey that could attract sea otters (Bram and others, 2005; Guerin and others, 2007; Friedlander and others, 2014). As the population of southern sea otters continues to grow and expand in the Santa Barbara Channel, and their food resources along the coastline become limited, it is possible that manmade structures may become an important component of sea otter foraging or resting grounds.

To address primary objectives 3 and 4 , we used the results of the synoptic space-use model to evaluate the potential for sea otter encounters with natural seeps in Santa Barbara Channel (and/or other point-threats). This approach was more powerful and meaningful than simply plotting raw resighting data: in fact, none of the recorded resightings were close to known seep locations, but this fact does not provide evidence that sea otters do not use habitat adjacent to seeps given that we only observed the tagged animals for a fraction of their lives. Instead, the synoptic model provided us with a probability distribution for each individual animal's likelihood of occurrence in space (informed by the raw data), as well as a population-level density distribution for each sex. By calculating the value of these probability density distributions at the known locations of natural seeps, we were able to address objective 3 by identifying those seeps with higher potential for sea otter encounters (fig. 19).

The seeps with greatest associated risk were those in shallower waters and in close proximity to kelp beds: at present, it appears that "Peter-Paul Mounds" seep has the highest likelihood of impacting the current population, although as the population expands to the east the seeps near Coal Oil Point represent a greater risk. The relative probability of occurrence at locations near to some seeps was sufficiently high (about $1 \%$ likelihood of occurrence for some of our study animals) that one would anticipate occasional encounters. Such a prediction was supported by two independent observations, (1) the fact that 3 of the 46 study animals had some tar/oil contamination of their fur at time of initial capture (though not extensive enough to represent a health threat in the opinion of the veterinary staff); and (2) the fact that gene expression analysis indicated that $38 \%$ of otters in the 2012 SBC sample had AHR values above their normal range (Bowen and others, 2012b), suggesting periodic low level exposure to hydrocarbons. However, none of these independent metrics suggests that seep exposure is extremely common, or for that matter that it represents a significant health threat, only that it occasionally occurs. In fact, given the relatively high survival and reproductive rates and good body condition of most of the animals in our study, it appears that exposure to oil and gas seeps does not represent a significant population-level threat at this time. However, seeps with greater potential for sea otter encounter do occur to the southeast of the current range (fig. 19) and so oil exposure may become a more significant factor for sea otter health in the future.

\section{Secondary Objectives: Population Status and Threats to Recovery}

Our study has also provided insights into the current status (with respect to prey resources) of sea otters in Santa Barbara Channel, as well as current threats to recovery. Most of the indices evaluated suggest that sea otters at SBC are not resource-limited, as appears to be the case for sea otters in the center of the mainland range (Tinker and others, 2013; Thometz and others, 2014, 2016). Santa Barbara Channel animals spent less time feeding (fig. 21), had less diverse diets (fig. 22), had shorter feeding bouts and shallower dives (table 3), were in better body condition (fig. 26) and had higher survival rates (figs. 29 and 31) than did sea otters from sites in the range center. Moreover, in all these metrics the SBC study animals were most similar to sea otters from San Nicolas Island (SNI) as measured during a 2003-2005 study, and the SNI population appears to represent the high end of the spectrum in terms of resource abundance (Tinker, Doak, and others, 2008). One exception to this pattern was evident from 
the gene expression results: specifically, some of the 2013 study animals from Santa Barbara Channel clustered with the SLO study group, exhibiting a reduced level of gene activity that can sometimes correspond to nutritional stress (Bowen and others, 2014). In the case of males this is not entirely surprising, as most of these animals turned out to be transients that actually returned to the SLO study area. However, even some females from SBC showed this down-regulated pattern (fig. 12). It is unclear what this means: overall, females at SLO had higher-than average body condition (figs. 25 and 26), which is not consistent with nutritional stress, although a few animals were in poor condition. As with any sea otter population, year-to-year differences in environmental conditions, kelp cover and prey recruitment all contribute to variation in individual health and nutritional status over time, and likely explain the gene expression results.

Overall our findings support previous studies in suggesting that sea otters in Santa Barbara Channel are not resource limited (Lafferty and Tinker, 2014), and thus we would expect to see continued strong population growth in this area. It is therefore perplexing that population growth in this area appears to have slowed in recent years; however, some other unexpected findings from our study and related data sets may help explain this apparent enigma. Data from stranded sea otters indicates that there has been a dramatic increase in the frequency of shark bites on sea otters over the past 10 years (Tinker and others, 2015). Spatial trends in strandings suggest that this increasing trend is strongest at the southern end of the range (from Morro Bay to Vandenberg Air Force Base), and the results of our telemetry study are consistent with such a pattern. Excluding shark bite deaths, the survival rates of the SBC study group were extremely high, exactly as would be expected for a recently established and nonfood-limited population (fig. 31). However, 4 of the 5 confirmed mortalities in our study were the result of shark bite attacks, and when we factor those deaths into the survival analysis (fig. 32) we project a $>5 \%$ reduction in population growth. At present it therefore seems that increased shark bite mortality is the single biggest threat to continued population growth in the Santa Barbara Channel. The one potential bright spot in this picture is that the attacks all seemed to occur to the north of Pt. Conception, and not to the southeast (based on our existing sample). Further work will be needed to ascertain whether the risk of shark bite mortality drops as one moves southeast into Santa Barbara Channel. The low rate of carcass recovery from this area makes it difficult to estimate trends in mortality for this area.

This study provides a valuable baseline data set on sea otter ecology in Santa Barbara Channel, at a time when the population is in the early stages of re-colonization. Future studies will benefit from these data as they will allow for examination of how sea otters and communities change over time. The analysis of space use and habitat selection by sea otters presented here will be critical for anticipating habitat needs and identifying potential exposure risks to spatially defined threats such as natural seeps or manmade structures. As it is very likely that sea otters will continued to expand their range into southern California, such information will be important both for population conservation and for avoiding resource conflicts. The availability of more refined data sets on marine habitat variables (e.g., data on wave exposure and orbital velocity, and multi-beam sonar data on topographic complexity and composition of benthic habitats) will create future opportunities to build on the analyses we present here. More detailed habitat-use models would not only improve sea otter conservation, they would allow more powerful and specific predictions of the ecological effects of sea otter recolonization on sub-tidal invertebrate communities and associated fisheries. 


\section{Acknowledgments}

We would like to thank the Bureau of Ocean Energy Management, particularly Greg Sanders, and the U.S. Fish and Wildlife Service (especially Lilian Carswell) for their support of this research. We thank our collaborators from the California Department of Fish and Wildlife, especially Mike Harris, Colleen Young, Laird Henkel, Dr. Melissa Miller, Francesca Batac, Erin Dodd, Jessica Kunz, Frank Wilhelm, Witold Piekarski, RC Mitchell, Dave Jessup (Ret.) and Jack Ames (Ret.) for their support during capture events, tracking, and for conducting necropsies of dead study animals. We are grateful for the support of the U.S. Geological Survey's Western Ecological Research Center and Alaska Science Center, specifically Tom Kimball, Brian Hatfield, Ben Weitzman, Anne Meckstroth, Dan Esler, Dan Monson, and George Esslinger. The Monterey Bay Aquarium was a key collaborator on this work and we thank Marissa Young, Andy Johnson and Jessica Fujii for their tireless work during captures and continual support. We acknowledge the University of California Santa Cruz, especially Mike Kenner, Sarah Espinosa, Sarah McKay Strobel, Max Tarjan, Carolina DaCosta, and Nicole Thometz, who were also key players in a variety of support roles. We also thank the University of California Davis and the Oiled Wildlife Care Network, especially Tristin Burgess, for their assistance. We are grateful to the United States Coast Guard, who allowed us access to the Point Conception Light Station property and permitted us to set up a data logger at this location. We also thank the United States Air Force's Vandenberg Air Force Base for periodic access to their property for tracking purposes. We thank the Seattle Aquarium, especially Lesanna Lahner, for her excellent work as a veterinarian on this project. We also would like to thank Claire Simeone of Seaworld and Jeanette Tonnies of the Los Angeles Zoo for veterinary assistance.

We gratefully acknowledge the logistical support of California State Parks, specifically Gaviota State Park and Dion von der Lieth, for allowing us to use the park as a base of operations during captures, and for allowing us to use the Gaviota pier and hoist for launching our vessels. The Santa Barbara Zoo, especially Rich Block, Estelle Sandhaus, Ria Boner, Devon Pryor, and Summer Gentry, was extremely helpful in providing logistical and personnel support to our capture and tracking efforts. We also would like to thank the Marine Mammal Center, especially Heather Harris. We are grateful to 2 private ranches, the Cojo-Jalama Ranch and the Surfin' Cowboy Ranch, and Josh Farberow, for providing our research personnel with periodic access to their properties to track our sea otters. Without access to these ranches, our movement data would be much less complete and our foraging data would be almost non-existent. We would like to extend our sincere gratitude to the Channel Islands Marine \& Wildlife Institute, especially founders Sam and Ruth Dover, for their great hospitality and support of our research. They graciously allowed us to set up a field station on the CIMWI property for our research personnel and they assisted in our capture operations. Finally, we would like to thank the many biologists, especially Gena Bentall, Sarah Chinn, and Sue Benich, as well as the dozens of interns and volunteers that helped out during otter captures and with our daily tracking and data collection efforts. Without their hard work none of this would be possible. 


\section{References Cited}

Ames, J.A., Hardy, R.A., and Wendell, F.E., 1983, Tagging materials and methods for sea otters, Enhydra lutris: California Fish and Game, v. 69, p. 243-252.

Banerjee, S., Wall, M.M., and Carlin, B.P., 2003, Frailty modeling for spatially correlated survival data, with application to infant mortality in Minnesota: Biostatistics, v. 4, p. 123-142.

Beineke, A., Siebert, U., Muller, G., and Baumgartner, W., 2007, Increased blood interleukin-10 mRNA levels in diseased free-ranging harbor porpoises (Phocoena phocoena): Veterinary Immunology and Immunopathology, v. 115 , p. $100-106$.

Bodkin, J.L., Esslinger, G.G., and Monson, D.H., 2004, Foraging depths of sea otters and implications to coastal marine communities: Marine Mammal Science, v. 20, p. 305-321.

Bodkin, J.L., Monson, D.H., and Esslinger, G.G., 2007, Activity budgets derived from time-depth recorders in a diving mammal: Journal of Wildlife Management, v. 71, p. 2,034-2,044.

Bommer, U.A., and Thiele, B.J., 2004, The translationally controlled tumour protein (TCTP): International Journal of Biochemistry and Cell Biology, v. 36, p. 379-385.

Bowen, L., Aldridge, B., Miles, A.K., and Stott, J.L., 2006, Expressed MHC class II genes in sea otters (Enhydra lutris) from geographically disparate populations: Tissue Antigens, v. 67, p. 402-408.

Bowen, L., Miles, A.K., Kolden, C.A., Saarinen, J.A., Bodkin, J.L., Murray, M.J., and Tinker, M.T., 2014, Effects of wildfire on sea otter (Enhydra lutris) gene transcript profiles: Marine Mammal Science, v. 31, p. 191-210, 10.1111/mms.12151.

Bowen, L., Miles, A., Murray, M., Haulena, M., Tuttle, J., Van Bonn, W., Adams, L., Bodkin, J., Ballachey, B., Estes, J., Tinker, T., Keister, R., and Stott, J., 2012, Gene transcription in sea otters (Enhydra lutris) Development of a diagnostic tool for sea otter and ecosystem health: Molecular Ecology Resources, v. 12, p. 67-74.

Bowen, L., Riva, F., Mohr, C., Aldridge, B., Schwartz, J., Miles, A.K., and Stott, L.J., 2007, Differential gene expression induced by exposure of captive mink to fuel oil-A model for the sea otter: EcoHealth, v. 4, p. 298309.

Bram, J.B., Page, H.M., and Dugan, J.E., 2005, Spatial and temporal variability in early successional patterns of an invertebrate assemblage at an offshore oil platform: Journal of Experimental Marine Biology and Ecology, v. 317, p. 223-237, doi:10.1016/j.jembe.2004.12.003

Brooks, S., Gelman, A., Jones, G., and Meng, X.-L., 2011, Handbook of Markov Chain Monte Carlo: Taylor and Francis, United States.

Chen, Z., Wang, H., Matsumura, K., and Qian, P., 2012, Expression of calmodulin and myosin light chain kinase during larval settlement of the barnacle Balanus Amphitrite: PLoS ONE, v. 7, e31337.

De Maio, A., 1999, Heat shock proteins: facts, thoughts, and dreams: Shock, v. 11, p. 1-12.

Dong, L., Ma, Q., and Whitlock Jr., J.P., 1997, Down-regulation of major histocompatibility complex Q1b gene expression by 2, 3, 7, 8-tetrachlorodibenzo-p-dioxin: Journal of Biological Chemistry, v. 272, p. 29614-29619.

Eberhardt, L.L., and Schneider, K.B., 1994, Estimating sea otter reproductive rates: Marine Mammal Science, v. 10, p. 31-37.

Friedlander, A.M., Ballesteros, E., Fay, M., and Sala, E., 2014, Marine communities on oil platforms in Gabon, West Africa-High biodiversity oases in a low biodiversity environment: PLoS ONE, v. 9, no. 8, p. e103709, doi: 10.1371/journal.pone.0103709.

Goldsby, R.A., Kindt, T.J., Osborne, B.A., and Kuby, J., 2003, Immunology, 5th ed.: WH Freeman and Company, New York, NY.

Guerin, A.J., Jensen, A.C., and Jones, D., 2007, Artificial reef properties of North Sea oil and gas production platforms, in OCEANS 2007-Europe conference proceedings, Aberdeen, United Kingdom, p. 1-6, doi: 10.1109/OCEANSE.2007.4302338.

Gurish, M.F., Humbles, A., and Tao, H., 2002, CCR3 is required for tissue eosinophilia and larval cytotoxicity after infection with Trichinella spiralis: The Journal of Immunology, v. 168, p. 5,730-5,736.

Halstead, B.J., Wylie, G.D., Coates, P.S., Valcarcel, P., and Casazza, M.L., 2012, Bayesian shared frailty models for regional inference about wildlife survival: Animal Conservation, v. 15, p. 117-124. 
Harris, S.G., Padilla, J., Koumas, L., Ray, D., and Phipps, R.P., 2002, Prostaglandins as modulators of immunity: Trends in Immunology, v. 23, p. 144-150.

Heisey, D.M., Shaffer, T.L., and White, G.C., 2007, The abcs of nest survival-Theory and application from a biostatistical perspective: Studies in Avian Biology, v. 34, p. 13-33.

Horne, J.S., Garton, E.O., and Rachlow, J.L., 2008, A synoptic model of animal space use-Simultaneous estimation of home range, habitat selection, and inter/intra-specific relationships: Ecological Modelling, v. 214, p. 338-348.

Iwama, G.K., Mathilakath, M.V., Forsyth, R.B., and Ackerman, P.A., 1999, Heat shock proteins and physiological stress in fish: American Zoologist, v. 39, p. 901-909.

Jameson, R.J., 1989, Movements, home range, and territories of male sea otters off central California: Marine Mammal Science, v. 5, p. 159-172.

Jenne, D.E., and Tschopp, J., 1989, Molecular structure and functional characterization of a human complement cytolysis inhibitor found in blood and seminal plasma: Identity to sulfated glycoprotein 2, a constituent of rat testis fluid: Proceedings of the National Academy of Science, v. 86, p. 7,123-7,127.

Jennings, K.A., Loder, M.K., and Sheward, W.J., 2006, Increased expression of the 5-HT transporter confers a low-anxiety phenotype linked to decreased 5-HT transmission: Journal of Neuroscience, v. 30, p. 8,955-8,964.

Jessup, D.A., Johnson, C.K., Estes, J., Carlson-Bremer, D., Jarman, W.M., Reese, S., Dodd, E., Tinker, M.T., and Ziccardi, M.H., 2010, Persistent organic pollutants, in The blood of free-ranging sea otters (Enhydra lutris ssp.) in Alaska and California: Journal of Wildlife Diseases, v. 46, p. 1,214-1,233.

Kibenge, M.J.T., Munir, K., and Kibenge, F.S.B., 2005, Constitutive expression of Atlantic salmon Mx1 protein in CHSE-214 cells confers resistance to infectious salmon Anaemia virus: Virology Journal, v. 2, p. 75.

Kringel, H., Iburg, T., Dawson, H., Aasted, B., and Roepstorff, A., 2006, A time course study of immunological responses in Trichuris suis infected pigs demonstrates induction of a local type 2 response associated with worm burden: International Journal for Parasitology, v. 36, p. 915-924.

Krumm, B., Meng, X., Li, Y., Xiang, Y., and Deng, J., 2008, Structural basis for antagonism of human interleukin 18 by pox-virus interleukin 18-binding protein: Proceedings of the National Academy of Science, v. 105 , p. 20,711-20,715.

Lafferty, K.D., and Tinker, M.T., 2014, Sea otters are recolonizing southern California in fits and starts: Ecosphere, v. 5, no. 5, p. 1-11.

Laidre, K.L., Estes, J.A., Tinker, M.T., Bodkin, J.L., Monson, D.H., and Schneider, K.B., 2009, Patterns of growth and body condition in sea otters from the Aleutian archipelago before and after the recent population decline: Journal of Animal Ecology, v. 75, p. 978-989.

Laidre, K.L., Jameson, R.J., Gurarie, E., Jeffries, S.J., and Allen, H., 2009, Spatial habitat use patterns of sea otters in coastal Washington: Journal of Mammalogy, p. 906-917, http://dx.doi.org/10.1644/08-MAMM-A338.1.

Li, S., Xie, L., Zhang, C., Zhang, Y., and Gu, M., 2004, Cloning and expression of a pivotal calcium metabolism regulator: calmodulin involved in shell formation from pearl oyster (Pinctada fucata): Comparative Biochemistry and Physiology Part B: Biochemistry and Molecular Biology, v. 138, p. 235-243.

Lipscomb, T.P., Harris, R.K., Moeller, R.B., Pletcher, J.M., Haebler, R.J., and Ballachey, B.E., 1993, Histopathologic lesions in sea otters exposed to crude oil: Veterinary Pathology, v. 30, p. 1-11.

Ma, Q., Geng, Y., Xu, W., Wu, Y., He, F., Shu, W., Huang, M., Du, H., and Li, M., 2010, The role of translationally controlled tumor protein in tumor growth and metastasis of colon adenocarcinoma cells: Journal of Proteome Research, v. 9, p. 40-49.

McLoughlin, K., Turteltaub, K., Bankaitis-Davis, D., Gerren, R., Siconolfi, L., Storm, K., Cheronis, J., Trollinger, D., Macejak, D., Tryon, V., and Bevilacqua, M., 2006, Limited dynamic range of immune response gene expression observed in healthy blood donors using RT-PCR: Molecular Medicine, v. 12, p. 185-195.

Miles, A., Bowen, L., Ballachey, B., Bodkin, J., Murray, M., Estes, J., Keister, R., and Stott, J., 2012, Variations of transcript profiles between sea otters Enhydra lutris from Prince William Sound, Alaska, and clinically normal reference otters: Marine Ecology Progress Series, v. 451, p. 201-212. 
Monson, D.H., 2009, Sea otters (Enhydra lutris) and Steller sea lions (Eumetopias jubatus) in the North Pacific: Evaluating mortality patterns and assessing population status at multiple time scales: Santa Cruz, Department of Ecology and Evolutionary Biology, University of California, Ph.D dissertation, 223 p.

Monson, D.H., Estes, J.A., Bodkin, J.L., and Siniff, D.B., 2000, Life history plasticity and population regulation in sea otters: Oikos, v. 90, p. 457-468.

Monson, D.H., McCormick, C., and Ballachey, B.E., 2001, Chemical anesthesia of northern sea otters (Enhydra lutris) - Results of past field studies: Journal of Zoo and Wildlife Medicine, v. 32, p. 181-189.

Oesch-Bartlomowicz, B., and Oesch, F., 2005, Phosphorylation of cytochromes P450: first discovery of a posttranslational modification of a drug-metabolizing enzyme: Biochemical and Biophysical Research Communications, v. 338, p. 446-449.

Oftedal, O.T., Ralls, K., Tinker, M.T., and Green, A., 2007, Nutritional constraints on the southern sea otter in the Monterey Bay National Marine Sanctuary, and a comparison to sea otter populations at San Nicolas Island, California, and Glacier Bay, Alaska: Monterey Bay National Marine Sanctuary, Monterey, California.

Ponciano, J.M., Taper, M.L., Dennis, B., and Lele, S.R., 2009, Hierarchical models in ecology-Confidence intervals, hypothesis testing, and model selection using data cloning: Ecology, v. 90, p. 356-362.

Quintana, F.J., Basso, A.S., Iglesias, A.H., Korn, T., Farez, M.F., Bettelli, E., Caccamo, M., Oukka, M., and Weiner, H.L., 2008, Control of Treg and TH17 cell differentiation by the aryl hydrocarbon receptor: Nature, v. 453 , p. $65-71$.

Raisuddin, S., Kwok, K.W.H., Leung, K.M.Y., Schlenk, D., and Lee, J., 2007, The copepod Tigriopus: a promising marine model organism for ecotoxicology and environmental genomics: Aquatic Toxicology, v. 83, p. 161-173.

Ralls, K., Eagle, T.C., and Siniff, D.B., 1996, Movement and spatial use patterns of California sea otters: Canadian Journal of Zoology, v. 74, p. 1,841-1,849.

Ralls, K., Hatfield, B.B., and Siniff, D.B., 1995, Foraging patterns of California sea otters as indicated by telemetry: Canadian Journal of Zoology, v. 73, p. 523-531.

Ralls, K., and Siniff, D.B., 1990, Time budgets and activity patterns in California sea otters: Journal of Wildlife Management, v. 54, p. 251-259.

Ratkowsky, D.A., 1986, Statistical properties of alternative parameterizations of the von Bertalanffy growth curve: Canadian Journal of Fisheries and Aquatic Sciences, v. 43, p. 742-747.

Riedman, M.L., and Estes, J.A., 1990, The sea otter enhydra-lutris behavior ecology and natural history: U.S. Fish and Wildlife Service Biological Report 90, I-III, p. 1-126.

Riedman, M.L., Estes, J.A., Staedler, M.M., Giles, A.A., and Carlson, D.R., 1994, Breeding patterns and reproductive success of California sea otters: Journal of Wildlife Management, v. 58, p. 391-399.

Rigopoulou, E.I., Abbott, W.G., Haigh, P., and Naoumov, N.V., 2005, Blocking of interleukin-10 receptor-a novel approach to stimulate $\mathrm{T}$-helper cell type 1 responses to hepatitis $\mathrm{C}$ virus: Clinical Immunology, v. 117, p. 57-64.

Shimazaki, H., and Shinomoto, S., 2010, Kernel bandwidth optimization in spike rate estimation: Journal of Computational Neuroscience, v. 29, p. 171-182.

Sinha, D., and Dey, D.K., 1997, Semiparametric Bayesian analysis of survival data: Journal of the American Statistical Association, v. 92, p. 1,195-1,212.

Siniff, D.B., and Ralls, K., 1991, Reproduction, survival and tag loss in California sea otters: Marine Mammal Science, v. 7, p. 211-229.

Slaght, J.C., Horne, J.S., Surmach, S.G., and Gutiérrez, R.J., 2013, Home range and resource selection by animals constrained by linear habitat features-An example of Blakiston's fish owl: Journal of Applied Ecology, v. 50, p. $1,350-1,357$.

Spiegelhalter, D.J., Best, N.G., Carlin, B.P., and Van Der Linde, A., 2002, Bayesian measures of model complexity and fit: Journal of the Royal Statistical Society-Series B (Statistical Methodology), v. 64, p. 583639.

Squire, L., Berg, D., Bloom, F.E., du Lac, S., Ghosh, A., and Spitzer, N.C., 2008, Fundamental neuroscience: Elsevier Academic Press, Amsterdam. 
Tabuchi, M., Veldhoen, N., Dangerfield, N., Jeffries, S., Helbing, C.C., and Ross P.S., 2006, PCB-related alteration of thyroid hormones and thyroid hormone receptor gene expression in free-ranging harbor seals (Phoca vitulina): Environmental Health Perspectives, v. 114, p. 1,024-1,031.

Tanabe S., Iwat, H., and Tatsukawa, R., 1994, Global contamination by persistent organochlorines and their ecotoxicological impact on marine mammals: Science of the Total Environment, v. 154, p. 163-177.

Tarjan, L.M., and Tinker, M.T., 2016, Permissible Home Range Estimation (PHRE) in restricted habitats-A new algorithm and an evaluation for sea otters: PLoS One, v. 11, p. e0150547.

Thometz, N.M., Staedler, M.M., Tomoleoni, J.A., Bodkin, J.L., Bentall, G.B., and Tinker M.T., 2016, Trade-offs between energy maximization and parental care in a central place forager, the sea otter: Behavioral Ecology, $v$. 27 , no. 5 , p. $1,552-1,566$.

Thometz, N.M., Tinker, M.T., Staedler, M.M., Mayer, K.A., and Williams, T.M., 2014. Energetic demands of immature sea otters from birth to weaning-Implications for maternal costs, reproductive behavior and population-level trends: Journal of Experimental Biology, v. 217, p. 2,053-2,061.

Tinker, M., Guimaraes, P., Novak, M., Marquitti, F., Bodkin, J., Staedler, M., Bentall, G., and Estes, J., 2012, Structure and mechanism of diet specialisation-Testing models of individual variation in resource use with sea otters: Ecology Letters, v. 15, p. 475-483.

Tinker, M.T., Bentall, G., and Estes, J.A., 2008, Food limitation leads to behavioral diversification and dietary specialization in sea otters: Proceedings of the National Academy of Sciences, v. 105, 560-565.

Tinker, M.T., Doak, D.F., and Estes, J.A., 2008, Using demography and movement behavior to predict range expansion of the southern sea otter: Ecological Applications, v. 18, p. 1,781-1,794.

Tinker, M.T., Doak, D.F., Estes, J.A., Hatfield, B.B., Staedler, M.M., and Bodkin, J.L., 2006, Incorporating diverse data and realistic complexity into demographic estimation procedures for sea otters: Ecological Applications, v. 16, p. 2,293-2,312.

Tinker, M.T., Estes, J.A., Ralls, K., Williams, T.M., Jessup, D., and Costa, D.P., 2006, Population dynamics and biology of the California sea otter (Enhydra lutris nereis) at the southern end of its range: University of California at Santa Barbara, Coastal Research Center, Marine Science Institute, MMS OCS Study 2006-007, MMS Cooperative Agreement Number 14-35-0001-31063.

Tinker, M.T., Jessup, D.A., Staedler, M., Murray, M.M., Miller, M., Burgess, T., Bowen, L., Miles, A.K., Tomoleoni, J., Thometz, N.M., Tarjan, L.M., Golson, E.A., Batac, F., Dodd, E., Bentall, G., Nicholson, T., Newsome, S.D., MacCormick, H., Melli, A.C., Johnson, A.M., Henkel, L., Johnson, C.K., and Conrad, P.A., 2013, Sea otter population biology at Big Sur and Monterey California-Investigating the consequences of resource abundance and anthropogenic stressors for sea otter recovery: Draft Final Report to California Coastal Conservancy and U.S. Fish and Wildlife Service, 243 p.

Tinker, M.T., Hatfield, B.B., Harris, M.D., and Ames, J.A., 2015, Dramatic increase in sea otter mortality from white sharks in California: Marine Mammal Science, doi: 10.1111/mms.12261.

Tomoleoni, J.A., Weitzman, B.P., Young, C., Harris, M., Hatfield, B.E., and Kenner, M., 2012, Closed-circuit diving techniques for wild sea otter capture: Proceedings of the American Academy of Underwater Sciences 32nd Annual Scientific Diving Symposium. Monterey, California.

Tsai, M.J., and O'Malley, B.W., 1994, Molecular mechanisms of action of steroid/thyroid receptor superfamily members: Annual Review Biochemistry, v. 63, p. 451-486.

Tsan, M.F., and Gao, B., 2004, Cytokine function of heat shock proteins: American Journal of Physiology and Cell Physiology, v. 286, p. C739-C744.

Tumpey, T.M., Szretter, K.J., Van Hoeven, N., Katz, J.M., Kochs, G., Haller, O., García-Sastre, A., and Staeheli, P., 2007, The $M x 1$ gene protects mice against the pandemic 1918 and highly lethal human H5N1 influenza viruses: Journal of Virology, v. 81, p. 10,818-10,821.

Tuynder, M., Fiucci, G., Prieur, S., Lespagnol, A., Géant, A., Beaucourt, S., Duflaut, D., Besse, S., Susini, L., Cavarelli, J., Moras, D., Amson, R., and Telerman, A., 2004, Translationally controlled tumor protein is a target of tumor reversion: Proceedings of the National Academy of Sciences USA, v. 101, p. 15,364-15,369.

U.S. Fish and Wildlife Service, 1977, Determination that the southern sea otter is a threatened species: Federal Register, v. 42, no. 10, p. 2965-2968. 
Veldhoen, M., Hirota, K., Westendorf, A.M., Buer, J., Dumoutier, L., Renauld, J.C., and Stockinger, B., 2008, The aryl hydrocarbon receptor links TH17-cell-mediated autoimmunity to environmental toxins: Nature, $\mathrm{v}$. 453, p. 106-109.

Watt, J., Siniff, D.B., and Estes, J.A., 2000, Inter-decadal patterns of population and dietary change in sea otters at Amchitka Island, Alaska: Oecologia (Berlin), v. 124, p. 289-298.

Wegner, K.M., Kalbe, M., Rauch, G., Kurtz, J., Schaschl, H., and Reusch, T.B.H., 2006, Genetic variation in MHC class II expression and interactions with MHC sequence polymorphism in three-spined sticklebacks: Molecular Ecology, v. 15, p. 1,153-1,164.

Wendell, F.E., Hardy, R.A., Ames, J.A., and Burge, R.T., 1986, Temporal and spatial patterns in sea otter, enhydra-lutris - Range expansion and in the loss of Pismo clam fisheries: California Fish and Game, v. 72, p. 197-212.

Williams, T., and Siniff, D.B., 1983, Surgical implantation of radio telemetry devices in the sea otter: Journal of the American Veterinary Medical Association, v. 11, p. 1,290-1,291.

Zheng, S., Song, Y., Qiu, X., Sun, T., Ackland, M.L., and Zhang, W., 2008, Annetocin and TCTP expressions in the earthworm Eisenia fetida exposed to PAHs in artificial soil: Ecotoxicology and Environmental Safety: v. 71, p. $566-573$. 


\section{Appendix A. Analytical Methods for Dive Behavior and Time-Activity Budgets}

Raw TDR data were downloaded from the TDR instruments and pre-processed using the software "Instrument Helper" (version 3.0; Wildlife Computers, Redmond WA) to correct depth readings for drift from the zero mark, and compile the depth readings (at 2-second intervals) into distinct dives and contiguous surface intervals. For each identified dive, a series of 6 descriptive parameters were calculated (all depths in meters and all times in seconds): maximum dive depth $(D E P)$, duration of the sub-surface dive interval $(D T)$, duration of time at spent at the bottom of the dive $(B T,=$ $90 \%$ of maximum depth and thus not necessarily on the ocean floor), duration of the post-dive surface interval ( $P D I$, the number seconds elapsed until the next dive), descent rate ( $D R T$, vertical swim-speed from surface to bottom) and ascent rate ( $A R T$, vertical swim-speed from bottom to surface). These parameters were used to classify dives as feeding or non-feeding dives (i.e. dives conducted during grooming, travelling or social behavior), following previously published methods (Bodkin and others, 2004, 2007). Briefly, a logistic classification function was used to classify each recorded dive based on a combination of the above-described dive parameters:

$$
\log \left(\frac{P}{1-P}\right)=\beta_{1}+\beta_{2}(D T)+\beta_{3}(B T / D T)+\beta_{4}(A R T)+\beta_{5}(D T)(A R T)+\beta_{6}(B T / D T)(D R T) .
$$

where $\beta_{1}$ is a vector of parameters fit by maximum likelihood, and all dives with $p>0.5$ were classified as feeding dives. Equation A1 was initially fit to a sub-sample of 5,000 "confirmed" dives from animals at various locations (dives made by study animals which an observer was able to visually confirm as either $1=$ feeding or $2=$ non-feeding dive), and then validated by application to a second sub-sample of 1,000 confirmed dives, to ensure a classification accuracy of $>99 \%$. Best-fit values for $\beta_{1}$ were:

$$
[-5.115,0.258,0.487,-0.210,0.063,3.543]
$$

We applied equation A1 to each TDR record to classify all dives, and then sub-divided the entire TDR record into contiguous "bouts" of similar activity states (inactive/resting $=\mathrm{R}$, feeding $=\mathrm{F}$, and "active other" = AO) .

\section{Analytical Methods for Body Condition}

We compared sea otter body condition among sites by comparing relative body mass and total length after controlling for age effects (and thus the condition of each study animal was assessed relative to the "average" mass and length of all otters of that age). To accomplish this, we used maximum likelihood methods to fit sex-specific Von Bertalanffy growth models (Ratkowsky, 1986) to the massvs-age and length-vs-age data for all otters from all 7 study sites:

$$
\begin{gathered}
L_{x, s}=c_{s, 1}+a_{s, 1}\left(1-e^{-k_{s, 1}\left(x-b_{s, 1}\right)}\right) \\
M_{x, s}=c_{s, 2}+a_{s, 2}\left(1-e^{-k_{s, 2}\left(x-b_{s, 2}\right)}\right)
\end{gathered}
$$

Where $x$ is the estimated age of each animal, $M$ is total body mass, $L$ is total body length, $s$ is sex $(1=$ female, $2=$ male), and $c, a, k$ and $b$ are the Von Bertalanffy growth function parameters. Note that $L$ represents total length (nose to tail) rather than "length corrected for tail length" $\left(L^{c}\right)$, as has been recommended elsewhere (Monson, 2009), because we did not have tail length measurements for sea otters at 3 of the 7 study sites. To determine if variation in $L$ provided a reliable estimate of variation in 
$L^{c}$, we plotted a regression of $L$ vs. $L^{c}$ for otters from SBC, BSR, MBA and PTC, and determined that there was a strong linear relationship between these two measures $\left(R^{2}=0.95\right)$, with no indication of sitespecific differences in residual distributions. We thus concluded that total length $(L)$ provided a reliable index for assessing variation in structural size, as long as among-site comparisons were limited to California. We used boot-strap resampling to account for sample-size differences among sites: specifically, for both males and females we randomly drew 20 otters (with replacement) from each study site, fit equations A2 and A3, then repeated this 1,000 times and used the mean expected values to define the "average" length or mass at age for each sex.

We calculated two indices of relative condition for each animal as the residual values from the mean growth curves calculated from equations A2 and A3. Residuals from the length vs. age function represent an index of relative structural size after controlling for age: this structural size index (SSI) provides insights into long-term patterns of food abundance at a given site, as these long-term conditions determine the growth rates and asymptotic skeletal size of otters over the first 5-7 years of life. Residuals from the mass vs. age function provide a more comprehensive body condition index (BCI), reflecting both relative structural size as well as dynamic body stores (muscle and fat biomass) that can increase or decrease in response to short term variation in food abundance, animal health or reproductive status. These two indices are expected to be strongly correlated, because otters that have greater structural size at a given age clearly have the potential to reach larger body mass; however, short-term variation in conditions can lead to some variation in biomass for an otter of a given age and body length. Accordingly, we also computed the residuals from a linear regression of BCI vs. SSI, which represent a "dynamic condition index" (DCI), in order to assess short-term variation in conditions at each study site.

We graphically compared the SSI, BCI, and DCI among sites using boxplots, and used Analysis of Variance (ANOVA) to test for statistically significant differences in all three indices among sites. We conducted separate analyses for males and females because data on movements and habitat use patterns suggested that males and females may experience local resource depletion in different ways and thus exhibit distinct patterns of variation in relative body condition. Finally, we used an inverse logit transformation of $\mathrm{BCI}$ to create a rescaled body condition index (BCI') for each sex at each study site that varied between 0 and 1 :

$$
B C I^{\prime}=e^{B C I} /\left(1+e^{B C I}\right) .
$$

We used bootstrap resampling (as described above) to account for sampling error and sample size differences among sites in calculating $\mathrm{BCI}$.

\section{Analytical Methods for Survival and Reproduction}

\section{Survival}

Our model incorporated both fixed effects of age, sex, reproductive status and mean body condition, as well as random site effects, also referred to as shared frailties (Banerjee and others, 2003; Halstead and others, 2012). Because independent hazards are multiplicative in nature (as with many time-dependent biological processes), it is more convenient to formulate hazard models in terms of $\log$ (hazards), which are additive and thus lend themselves to the fitting of linear models using maximum likelihood or Bayesian methods. Specifically, over a short time interval ( $t=r$ to $t=r+1)$, the cumulative effects of all hazards for an individual of age $i$, sex $j$, at site $k$, having covariate values $X_{c}$, can be 
estimated by the "log unit cumulative hazard" $\left(\gamma_{r}\right)$, which represents the additive effects of various $\log$ (hazards) within that time interval:

$$
\gamma_{r, i, j, c, e, k}=\gamma_{0}+\rho_{r}+\delta_{i, j}+\beta_{1} X_{c}+\beta_{2} Y_{e}+Z_{k}
$$

where $\gamma_{0}$ represents the baseline $\log$ hazard rate, $\rho_{r}$ represents the effect of time-varying hazards (i.e. the hazard ratio associated with conditions specific to time interval $r$, relative to the baseline mean hazard rate), $\delta_{i, j}$ represents the effect of age-varying hazards (i.e. the hazard ratio associated with animals of age $i$ and sex $j$ relative to the baseline mean hazard rate), $\beta$ represents a vector of parameter values each corresponding to the fixed-effects of a particular covariate ( $X_{c}$ and $Y_{e}$, described below), and $Z_{k}$ represents any additional random effects (or shared frailties) associated with study site $k$ that were not accounted for by any of the fixed-effects included in the model. The time-varying and age-varying hazards ( $\rho$ and $\delta$ respectively) were both treated as continuously-varying effects, estimated using nonparametric conditional auto-regressive (CAR) methods (Sinha and Dey, 1997; Banerjee and others, 2003). Additional covariates evaluated in equation (A5) included body condition and reproductive status. To evaluate the effect of body condition $\left(X_{c}\right)$ on survival, each otter was assigned the appropriate mean sex- and site-specific body condition index (BCI). Note that a negative value of $\beta_{l}$ would correspond to increased hazards for animals with lower than average BCI values, and reduced hazards for animals with higher than average BCI values. To evaluate the effect of reproductive status $\left(Y_{e}\right)$ on survival, female otters were assigned a score of $0-1$ at each time interval: $0=$ female with no pup or a dependent pup of 1-5 months old, and 1 = "end-lactation period" status (females having dependent pups $>5$ months old or having weaned a pup within the last 30 days).

In addition to the full model shown in equation A5, we also evaluated simpler models with fewer effects, and used model DIC values to select the most parsimonious model (Spiegelhalter and others, 2002). Because equation (A5) is expressed in terms of the log of the cumulative hazards, it is worth noting that the baseline instantaneous hazard rate is estimated by $\exp \left(\gamma_{0}\right)$, while all other parameters represent the log of a hazard ratio, whereby a parameter value of 0 corresponds to a ratio of 1 (no significant effect), a value of $<0$ corresponds to a ratio of $<1$ or a reduction in hazard rates relative to baseline values, and a value of $>0$ corresponds to a ratio of $>1$ or an increase in hazard rates relative to baseline values.

While log hazards are convenient for statistical estimation, the metric we are really interested in is the conditional survival probability for a given otter over a specified time period. That is, given that an individual is alive at time $r$, what is the likelihood it will survive until time $s$ ? This probability can be calculated from instantaneous hazards as:

$$
S(s \mid r)=\exp \left[-\left\{\int_{r}^{r+1} h(u) d u+\int_{r+1}^{r+2} h(u) d u+\ldots+\int_{s-1}^{S_{N}} h(u) d u\right\}\right]
$$

where each of the integral terms on the right-hand side of equation (A6) represents the "unit cumulative hazard" over a short time interval, and can be approximated by a point-estimate of the instantaneous hazard rate:

$$
\int_{r}^{r+1} h(u) d u \cong h(r)=\exp \left(\gamma_{r}\right)
$$


Thus the conditional survival can be calculated from a summation of log unit cumulative hazard values $\left(\gamma_{r}\right.$, as calculated in equation (A5)) over the time period of interest:

$$
S(s \mid r)=\exp \left[-\sum_{t=r+1}^{s} \exp \left(\gamma_{t}\right)\right]
$$

Bayesian MCMC fitting algorithms (implemented using the MATLAB and JAGS "Just Another Gibbs Sampler" programming environments) were used to fit equations (A5) and (A8) to intervalcensored survival/mortality data from radio-tagged sea otters. Bayesian model fitting was conducted following standard procedures: all parameters were initiated with uninformative parameters, and 10,000 burn-in MCMC iterations were conducted to allow model convergence, before saving 10,000 iterations (thinned by a factor of 3 ) for evaluation of posterior distributions. We graphically evaluated the traces of 3 independently initiated MCMC chains and examined $\hat{\mathrm{r}}$ values to ensure model convergence and stability (Brooks and others, 2011).

The Kaplan-Meier analysis of individual survival histories consists of identifying the leftcensored and right-censored entry points for each monitoring record (the date first tagged and the date last observed), as well as the fate at the end of the monitoring period (died, still alive, or disappeared and thus unknown fate). Our model was evaluated at time-step intervals of 1 month. Survival outcomes for each otter, over each observed time interval, were represented as random Bernoulli trials with probabilities determined by equation (A8), and these comprise the binomial likelihoods maximized by the MCMC algorithm (Heisey and others, 2007). Over the course of the study, shark-bite mortality was identified as a significant concern. We were interested in estimating survival with and without the effects of shark bite (in order to determine the degree to which shark bite mortality reduces survival), so we evaluated two versions of the data, one with shark-bite victims "right-censored" (i.e. marked as missing on the day they were bit by sharks) and one with shark-bite victims recognized as mortalities. The difference in survival estimates for SBC derived from these alternative versions of the data provided insights into survival rates in the absence of shark bite, and the additive effect of shark bite mortality.

We present results of the model fitting in terms of posterior distributions of log hazard ratios and the derived annual survival probabilities. The inclusion of terms in the final model was determined by model comparisons using DIC values (Spiegelhalter and others, 2002), and we evaluated the significance of model parameters by determining whether the $95 \%$ credible intervals $\left(\mathrm{CI}_{95}\right.$, which correspond loosely to the $95 \%$ confidence intervals for statistics computed using non-Bayesian methods) excluded 0 , because a value of 0 corresponds to a hazard ratio of 1 (no significant effect). We tested for variation in survival among sites due to "random effects" (differences associated with environmental, ecological, or anthropogenic influences) by evaluating the degree of overlap in the $95 \%$ credible intervals of $Z_{i}$. Because there could still be realized net differences in survival between sites, even in the absence of differences due to random effects (e.g., differences caused by differing distributions of covariate values between sites), we also calculated the $95 \%$ credible intervals for pairwise contrasts of age- and sex-specific survival rates among sites. To evaluate the overall effect of density-dependent variation in body condition on survival rates, we plotted the estimated site-specific adult survival rates as a function of site-specific body condition index values (with separate plots for males and females), and fit a non-linear power function of the form $y=p l \cdot x^{p 2}$. A positive relationship between body condition and survival rate would be represented by positive values of parameters $p 1$ and p2 (with the 95\% CI for each parameter excluding 0 ). 


\section{Reproduction}

We used longitudinal records of observational data from radio-tagged individual females to estimate per-capita birth rates (number of pups born per year per female) and pup survival rates (also called weaning success rates). To estimate birth rates we used a previously described algorithm (Eberhardt and Schneider, 1994):

$$
\bar{b}=\frac{1}{K} \sum_{k=1}^{K} b_{k}\left(\frac{365}{N_{k}}\right)
$$

where $K$ is the total number of females monitored for at least 365 days, $b_{k}$ is the number of observed births observed for female $k$, and $N_{k}$ is the number of days female $k$ was monitored. We compared birth rates at SBC with those measured at other study sites in California (Tinker and others, 2013).

To estimate pup survival rates, we used Bayesian MCMC algorithms to fit an instantaneous proportional hazards model similar to the model used to analyze adult survival rates, but modified in order to estimate the instantaneous hazard rate over a 20-week pup dependency period (we assumed that pups that survived to 20 weeks were successfully weaned: Siniff and Ralls, 1991). This approach allowed us to measure variation in mortality risk over the course of the pup dependency period, and also to include risk covariates thought to affect pup survival probability (specifically, the mother's age, body condition, and site-specific random effects). In this model, pup age was substituted for time, and expressed in units of days since the pup's birth ( $t=0$ at the instant of birth). We estimated $\log$ (unit cumulative hazards) over the interval $t=d$ to $t=d+1$ as:

$$
\gamma_{d, a, c, k}=\theta_{d}+\varphi_{a}+\beta_{3} X_{c}+Z_{k}
$$

where $\theta_{d}$ represent baseline hazards assumed to vary with pup age, $\varphi_{a}$ represents the effect of the mother's age (i.e. the hazard ratio associated with having a mother of $a$ years of age, scaled relative to the baseline hazard rate for a 3-year old mother), $\beta_{3}$ is the parameter corresponding to the effect of the mother's body condition $\left(X_{c}\right)$, and $Z_{k}$ represents any additional random effects (or shared frailties) associated with study site $k$ that were not accounted for by the fixed-effects included in the model. The mother's body condition was assessed based on her relative mass-at-age (BCI), averaged across all capture events for that female. Note that a negative value of $\beta$ would correspond to increased hazards for mothers with lower than average BCI values, and reduced hazards for mothers with higher than average BCI values. The age-varying hazards $(\theta$ and $\varphi)$ were treated as continuously-varying effects, estimated using non-parametric conditional auto-regressive (CAR) methods (Sinha and Dey, 1997; Banerjee and others, 2003).

The pup survival model was evaluated at time-step intervals of 1 day, and survival outcomes for each pup, over each time step, were represented as random Bernoulli trials with conditional probabilities given by:

$$
S(s \mid d)=\exp \left[-\sum_{t=d+1}^{s} \exp \left(\gamma_{t}\right)\right]
$$

Methods of Bayesian model fitting, evaluation and statistical assessment of parameter significance were identical to the procedures described above for analysis of independent otter survival. We fit the model to data from the SBC, MBA, BSR, CAM and SNI study sites. We plotted the mean weaning success rate as a continuous function of mother's age and mother's body condition. 
Publishing support provided by the U.S. Geological Survey Science Publishing Network, Tacoma Publishing Service Center

For more information concerning the research in this report, contact the Director, Western Ecological Research Center U.S. Geological Survey 3020 State University Drive East Sacramento, California 95819 http://www.werc.usgs.gov/ 
